\title{
Vol. I. Theory of the Coronal Plasma in Laser-Fusion Targets
}

\author{
C. E. Max \\ Iawrence Livermore National I aboratory* \\ Livermore, California 94550 \\ and \\ F́cole Polytecbinque \\ 91128 Palaiseau, France
}

Manuscript date: December 1981

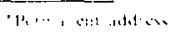

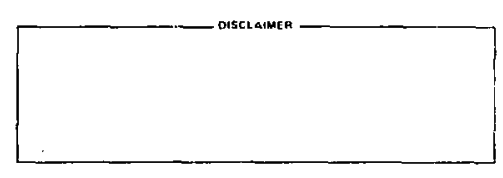




\section{PREFACE:}

This repore was wigmalls prepared as a

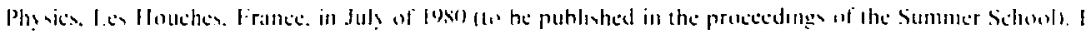

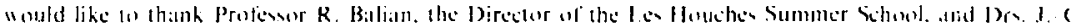

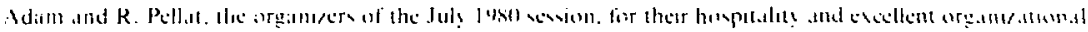
ahilities.

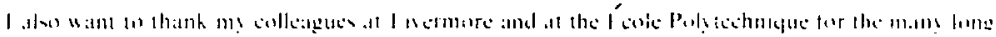

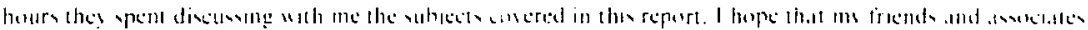

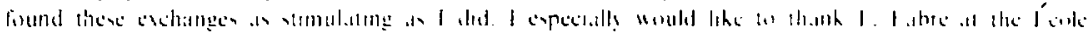

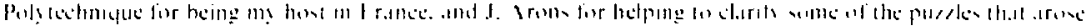

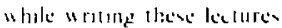

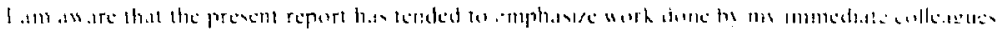

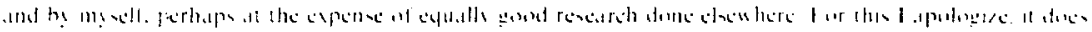

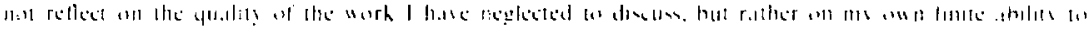

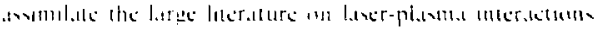




\section{CONTENTS}

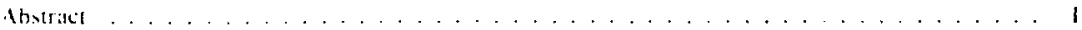

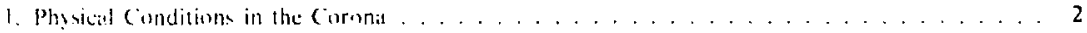

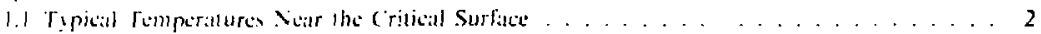

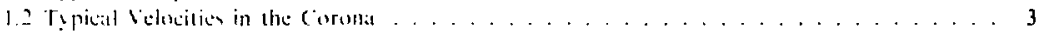

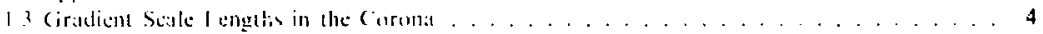

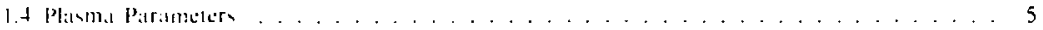

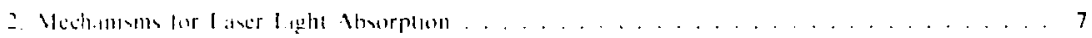

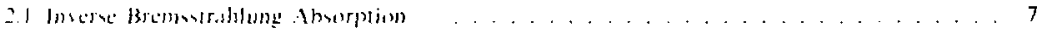

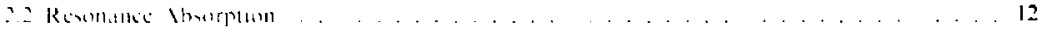

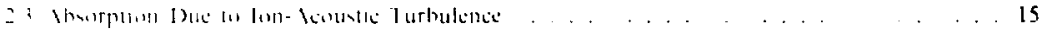

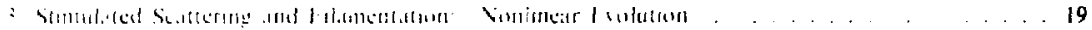

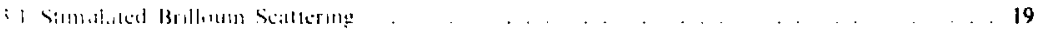

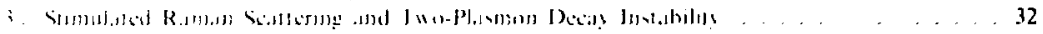

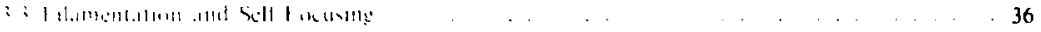

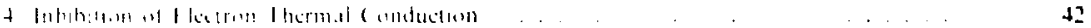

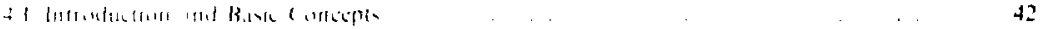

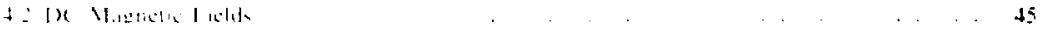

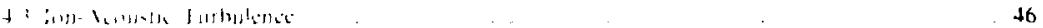

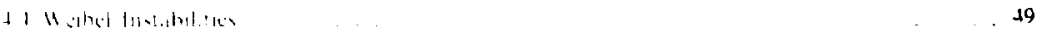

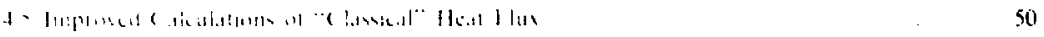

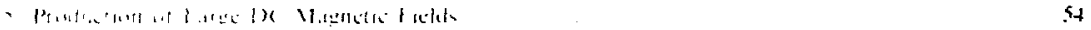

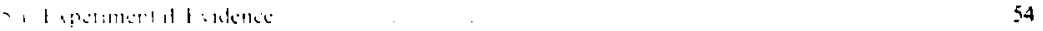

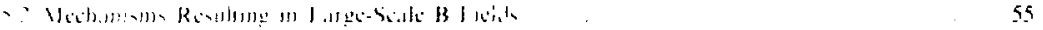

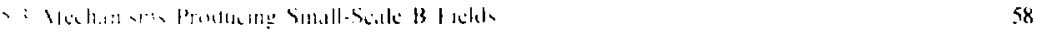

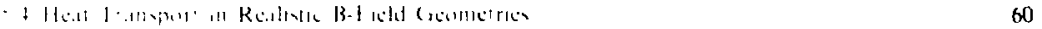

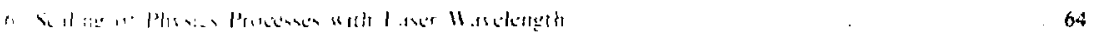

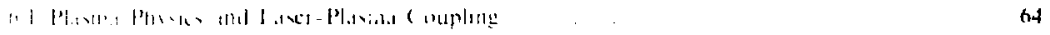

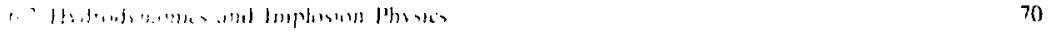

Rolithes . 78 


\title{
PHISICS OH I. ASHK II SION \\ Vol. I. Theory of the Coronal Plasma in Laser Fusion Targets
}

\begin{abstract}
ABSTRAC
This monograph deals with the physics ol the coronal region in laser fusion

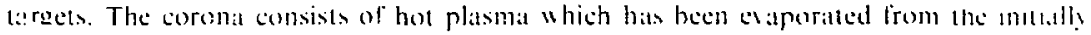
sold target during latser heating. It is in the corona that the laser lighe is aboorbed by the target. and the resulting thermal energy is conducted low ard cold high-dellsits regum. where ablatton oceurs. The topies to be discussed are theoretical mechanisms for laser light abserption and reflection. holetectron production. and the physics of heat condaction in

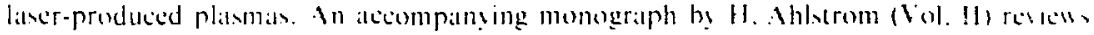
the facilitiss. diagnesties. and dalta from recem laser fusion experiments.
\end{abstract}




\section{PHYSICAL CONDITIONS IN THE CORONA}

When it laser beam shines on an initially solid target. at plasmat (ionied gas) is rapidly formed on tha front surlite of the target. Thereafter, the propagation of the latser light is modified by the frece clectrom in the plarmit. The disporsion relitlion for the laser light is

$$
k_{1}^{2} \omega^{2}=1-\frac{\omega_{11}^{2}}{\omega_{1}^{2}} .
$$

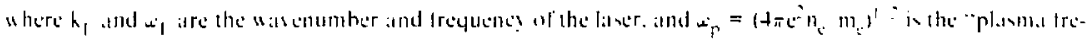

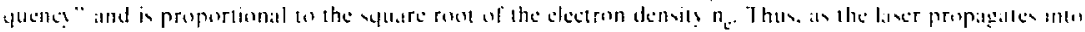

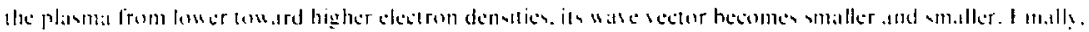

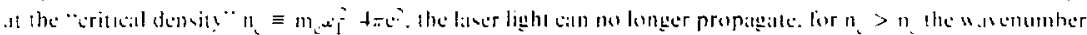

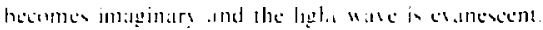

lhw !he

$$
n_{1}=1.1 \cdot 101^{2-1}\left(\begin{array}{c}
1 \mu \mathrm{m} \\
\lambda_{1}
\end{array}\right)^{2} \mathrm{~cm}: 1
$$

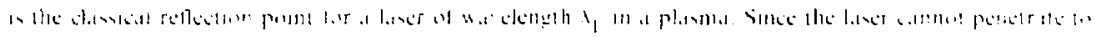

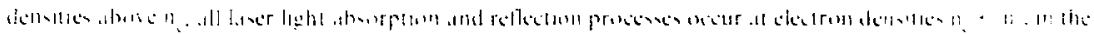

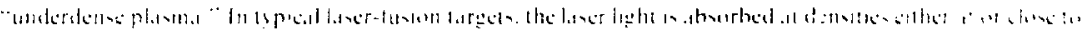

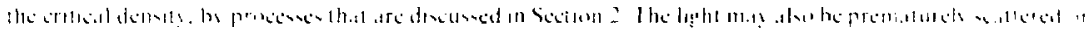

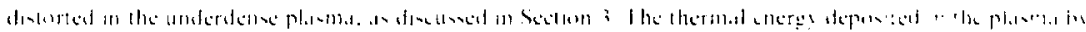

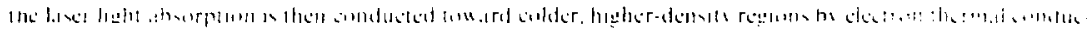

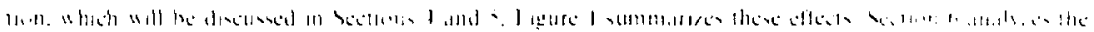

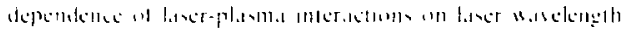

11 : hegh he

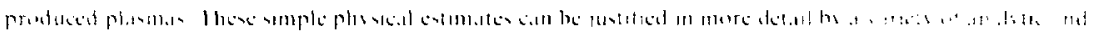

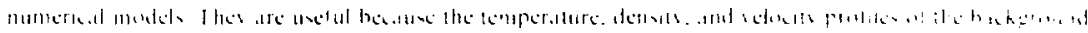

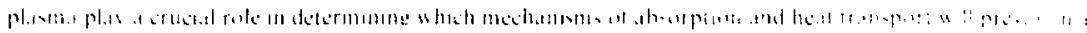

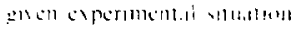

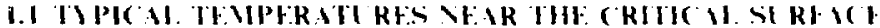

L I.

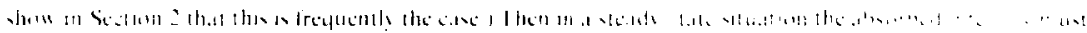

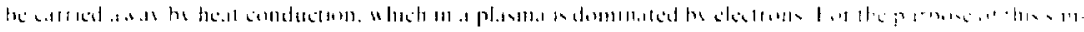

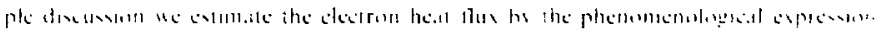

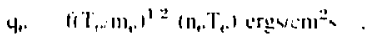

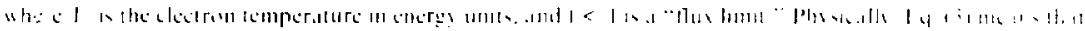

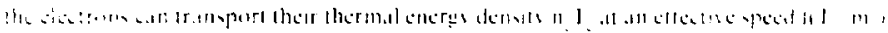

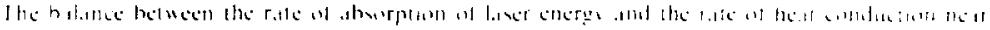
1.:. hewntic.

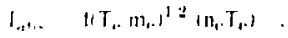




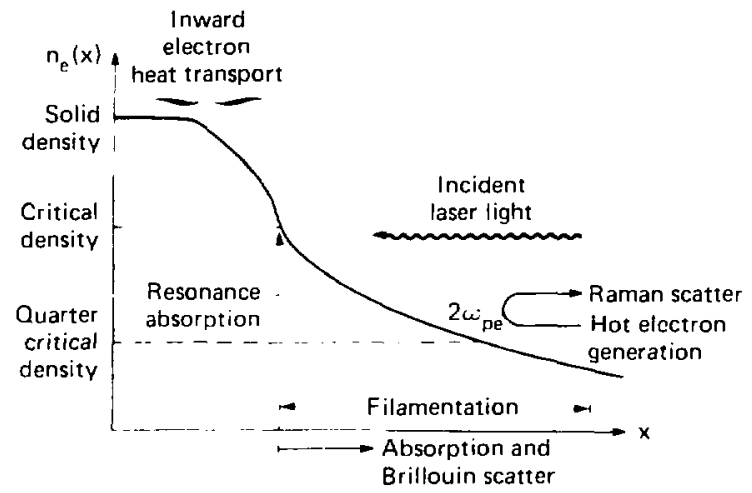

HIC. I. Schematic picture of electron denoits profile in a laser-produced plasma, shosing location of major plasma-physies coupling processes. The

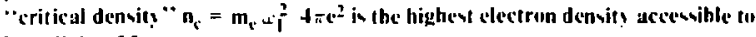
laser light of frequency 4 .

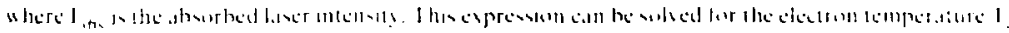

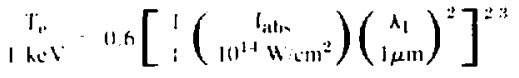

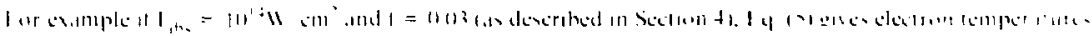

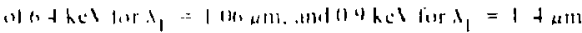

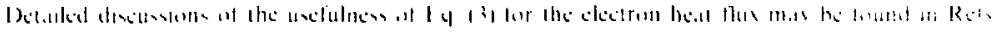

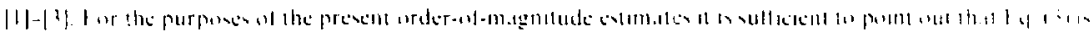

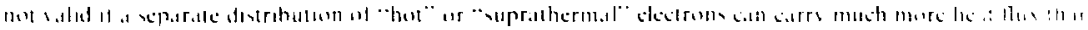

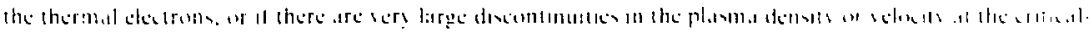

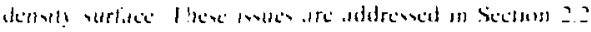

\section{I.2 TMPIC A. VFIOCOTIFS IN THF CORONA}

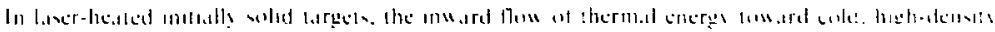

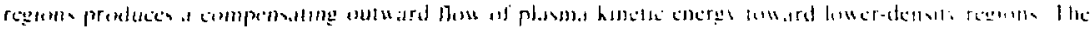

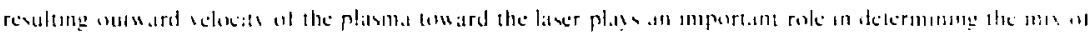

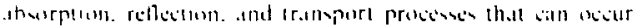

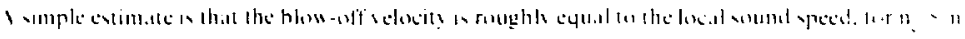

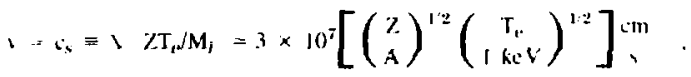

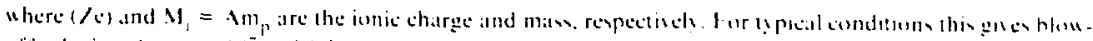

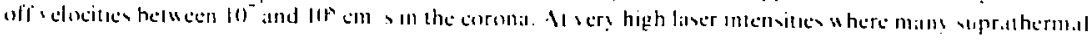


electrons are produced, the suprathermal electrons can at times determine the temperature to he used in F.q. (6). as descrihed in Ref. [4].

Several different 1ypes of analytic theories [1.5.6] indicate that the blow-off velocity should he at least sonic [F.y. (6)] at the critical density surface, and that it should then rise to supersonic values $>$ iv for densilies $n_{e}<n_{c .}$. While this hehavior is confirmed in computer-hydrodynamics calculations where the lather intensity is stcids over relatively long periods of time [1]. hydrodynamit simulations of shorttr-pulse caperements under some conditions shou regions of underdense plasma where the flow is slightly subsonic |7l. Thu, 1.4. (ii) should not he regarded as more thin a crude estimate.

\subsection{GRADIFNI SCAIE LENGTHS IN THE CORONA}

Becatuse the curonal electron temperature is ty pically a few keV or larger, thermal conduction in the

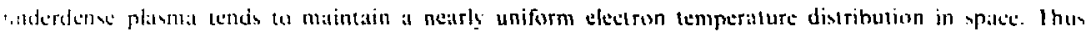

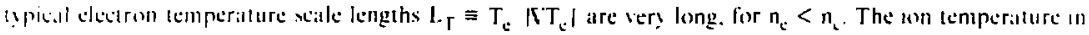

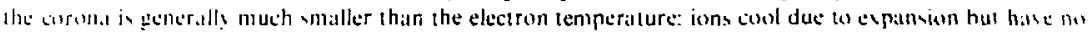

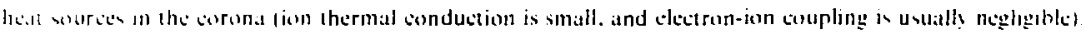
thas the ian lemperature and pressure are usualls small relative to the ctectrons. and gradient in ion tem. per.ture hase little phusical impatit.

B. contras. gratdient wale lengtho for densily and velocily are usually determaned hy the

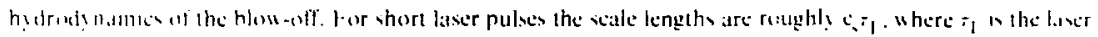

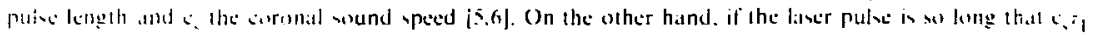

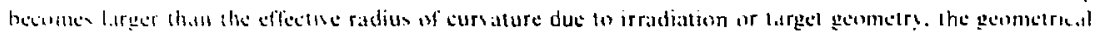

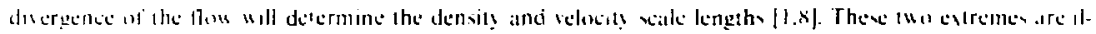

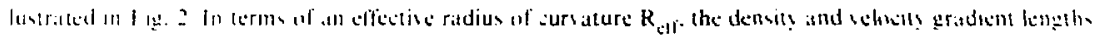
.110 rumphl!

l. - mun $\left.\{c, \pi\} . \mathbf{R}_{\mathbf{e}-\delta 1}\right\}$.

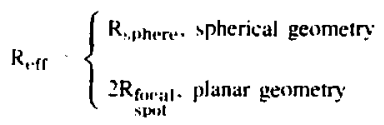

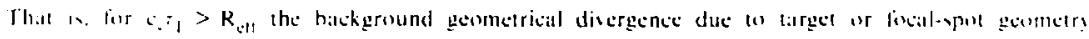

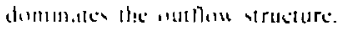

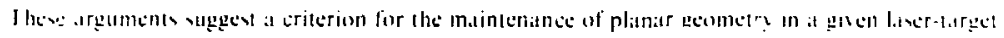

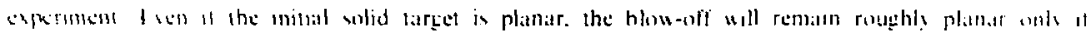

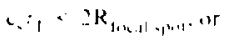

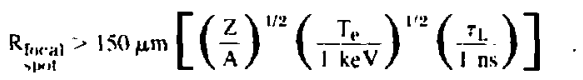

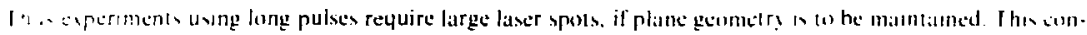

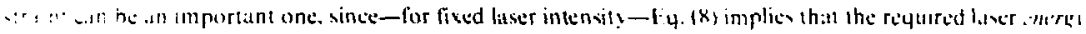

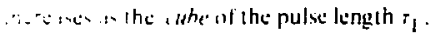

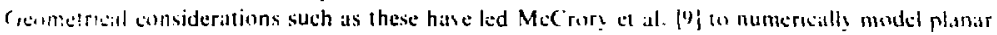

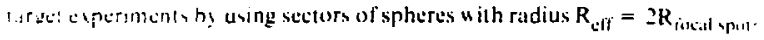




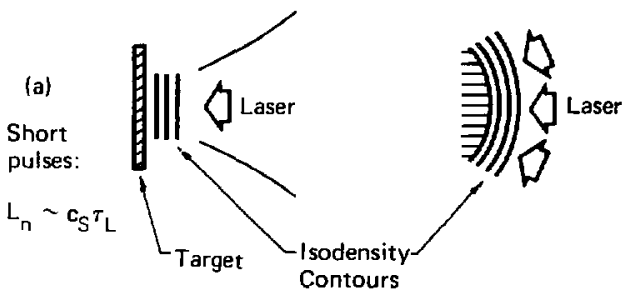

FIC;. 2a. Isodensity contours typical of short-pulse experiments. The density scale length $I_{n}$ is determined $b$ y the laser pulse length for both planar and spherical targets: $I_{n} \simeq c_{2} \tau_{1}$.

$$
\text { Planar }
$$

(b)

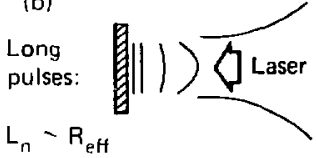

$$
R_{\text {etf }} \sim 2 R_{\text {spot }}
$$

Spherical

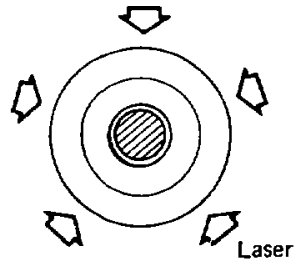

$R_{\text {eH }} \sim R_{\text {target }}$

FIC;. 2h. Isodensity contours typical of long-pulse experiments. The density scale length is limited by the geometrical divergence of the plasma flow. For planar targets the effective radius of curvature $R_{t \cdot f}$ is roughly Iwice the radius of the focal spot.

\subsection{PI.ASMA PARAMETERS}

In the corma of a laser fusion larget, the electron Debse length $\lambda_{b c} \equiv\left(T_{c} 4 \pi n_{0} s^{3}\right)^{3}$ is Is pically much vmaller thatl the laxer "abelength. Numerically.

$$
\lambda_{1 x^{+}}=7.4 \times 10^{-7} \mathrm{~cm}\left[\left(\frac{T_{\mathrm{e}}}{1 \mathrm{keV}}\right)\left(\frac{10^{21} \mathrm{~cm}^{-3}}{\pi_{\mathrm{e}}}\right)\right]^{1 / 2}
$$

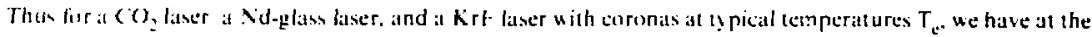
criticial demait?: 
TABLE 1. Typical values of the Debye length $\lambda_{\mathrm{De}}$ at three different laser wavelengths $\lambda_{\mathrm{I}}$.

\begin{tabular}{|c|c|c|}
\hline$x_{1}$ & $T_{*}$ & $x_{10}$ \\
\hline $111.6 \mu \mathrm{m}$ & 20 ket & $1 \% . .34 \mathrm{~m}$ \\
\hline $1.010 \mu \mathrm{m}$ & IH hor & $2.10+1$ \\
\hline 11. ? $\mathrm{n} \mathrm{m}$ & $1,5 \mathrm{kel}$ & 131 \\
\hline
\end{tabular}

From at theoretical point of view. much of standard plasma kinetic theors assumes that there are many particles in a Debye sphere. That is. $\lambda_{1} \gg 1$ where

$$
N_{12}={ }_{3}^{4 \pi} n_{1}, \lambda_{01}^{3}=1.7 \times 10^{3}\left[\left(\begin{array}{c}
T_{*} \\
1 \mathrm{keV}
\end{array}\right)^{22}\left(\begin{array}{c}
10^{21} \mathrm{~cm}^{-3} \\
n_{4}
\end{array}\right)^{12}\right]
$$

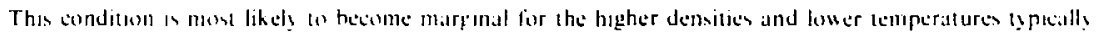

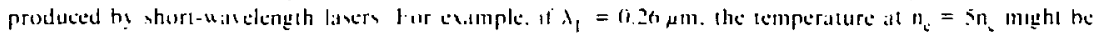
$<50$ \&. in which case $v_{1}<2$.

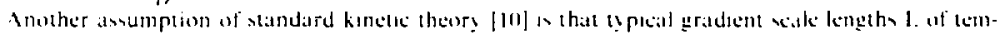

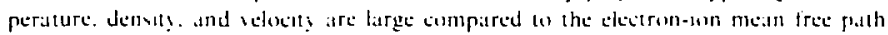

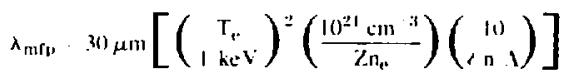

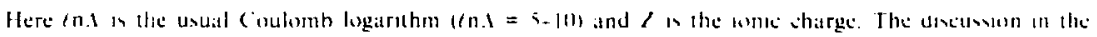

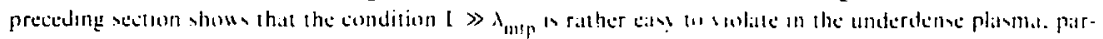

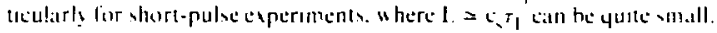

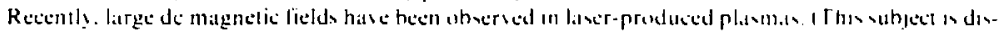

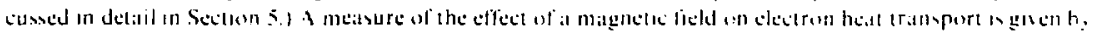

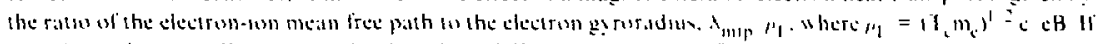

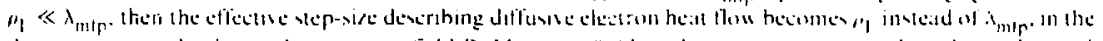

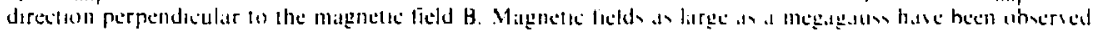

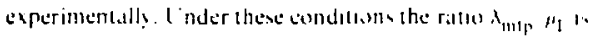

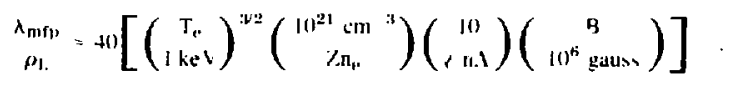

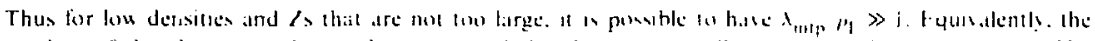

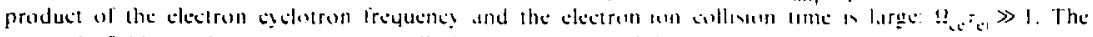

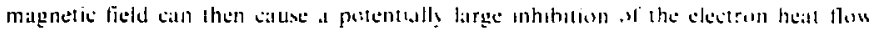




\section{MECHANISMS FOR LASER LIGHT ABSORPTION}

Fssential to almost all laser fusion schenes is the concept that inward momentum is imparted to the imploding larget by the ablation of a hot gals. rather than by the momentum of the laser photons themseties. The reatson is clear: for a given laser energy $E$. the ratio of available momentum to available energy is $\mathrm{c}^{-1}$ for the laser photons. By contrast. this ratio is $2 x^{-1}$ if the laser light is first a sorbed by a plasma that then ablates at a velocit? $x$. Thus for a hot gas $u$ ith a (nonrelativistic) ablation velocits $s$. the momentum per unit energy is ¿ \$1 tines thall available lor photon pressure alone.

As a conseyuence. efficient absorption ol laser light energy by the coronil plasma is crucial to laser fusion. In litel. the ultimale efficiency of a laser fusion power plant is directly proportional to the fration of incident lande energy absorbed by the target. In the present section we discuss the three absorption mechanism. presently thought w be most imporlant: I) inverse Bremsstrahlung (sometimes ealled "classical" "r "collisional" absorption). 2) resonance absorption. and 7) absorption due (o ion-atoustic turbulence.

\subsection{INFRSE BREMISSTRAHLI VG ABSORPTION}

Inserse Hremsirathlung absurpuon is due to electron-ion collisions in the plasma. If plasma clece-

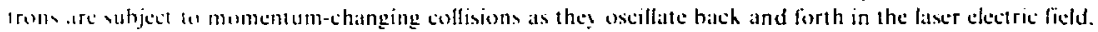

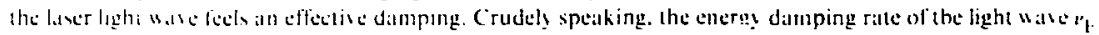

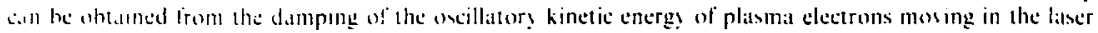
stevisiticld I,

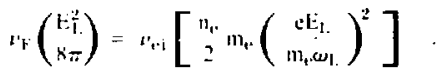

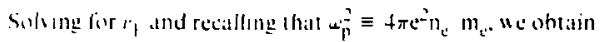

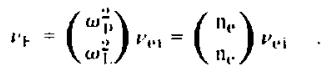

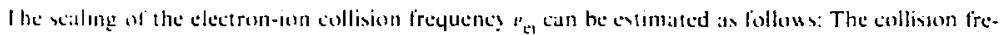

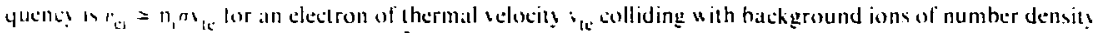

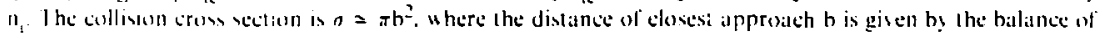
potental and kinclic energs:

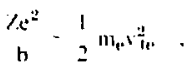

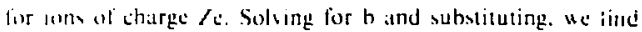

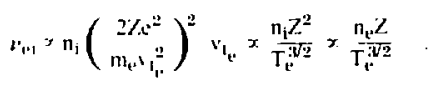

In laser fusion applications. it is generally most relesant to know tite spatial damping rate of an inci-

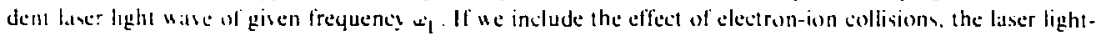
wase deppersiun relillom (1) becomes

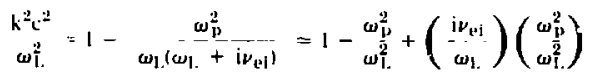

where at halte expanded assuming "ea $e_{1} \ll 1$. This can be solved lior $h$.

$$
\mathrm{k}= \pm \stackrel{\omega_{\mathrm{l}}}{i}\left(1-\frac{\omega_{\mathrm{l}}^{2}}{\omega_{\mathrm{l}}^{2}}\right)^{1 / 2}\left\{1+i\left(\frac{\nu_{\mathrm{el}}}{2 \omega_{\mathrm{l}}}\right)\left(\frac{\omega_{\mathrm{p}}^{2}}{\omega_{\mathrm{l}}^{2}}\right) i-\frac{1}{\omega_{\mathrm{p}}^{2} / \omega_{\mathrm{l}}^{2}}\right\} .
$$


The spatial damping rate of wave energy, $\kappa_{\mathrm{ib}}$, is then twice the imaginary part of $k$ :

$$
\begin{aligned}
& \kappa_{\mathrm{ib}}=\frac{\nu_{q \mathrm{i}}}{c} \frac{\omega_{\mathrm{p}}^{2}}{\omega_{\mathrm{L}}^{2}}-\frac{1}{\left(1-\omega_{p}^{2} / \omega_{\mathrm{L}}^{2}\right)^{1 / 2}} \\
& \kappa_{\mathrm{ib}} \propto \frac{\mathrm{Zn}_{\mathrm{e}}^{2}}{\mathrm{~T}_{\mathrm{e}}^{3 / 2}\left(1-n_{\mathrm{e}} / \mathrm{n}_{\mathrm{c}}\right)^{1 / 2}} .
\end{aligned}
$$

Inverse Bremsstrahlung is thus strongest for low temperatures. high densities, and high- $Z$ largei materials. A more rigorous calculation of the inverse Bremsstrahlung absorption coefficient can be made by using kinetic theory, to take into account the actual distribution function of the electrons and the actual positions of the ions. A clear review of this approach may be found in Ref. [11]. The net absorption is shown to depend on the correlation function of the background ions. Highly correlated ions treated. for example. by ion-acoustic turbulence can result in enhanced absorption. This mechanism is discussed in Section 2.3. On the other hand, a thermal distribution of jons and a Maxwellian distribution of electrons produce the follow: ing inverse Bremssta-ahlung absorption coefficient [12] for $\omega_{L} \geqslant \omega_{p}$ :

$$
\begin{aligned}
& \kappa_{\mathrm{ib}}=(2 \pi)^{1 / 2}\left(\frac{16 \pi}{3}\right)-\frac{\mathrm{Zn}_{\mathrm{e}}^{2} \mathrm{e}^{6}(\mathrm{n \Lambda}}{c\left(\mathrm{~m}_{\mathrm{e}} T_{\mathrm{e}}\right)^{3 / 2} \omega_{\mathrm{L}}^{2}\left(\mathrm{I}-\mathrm{n}_{\mathrm{e}} / \mathrm{n}_{\mathrm{e}}\right)^{1 / 2}} . \\
& \Lambda \equiv \frac{v_{\mathrm{te}}}{\omega_{\mathrm{g}} P_{\min }} \cdot P_{\min } \equiv \max \left[\frac{Z e^{2}}{T_{\mathrm{e}}} \cdot \frac{\hbar}{\left(m_{\mathrm{e}} T_{\mathrm{e}}\right)^{1 / 2}}\right]
\end{aligned}
$$

Thus a uniform plasma of length $L$ and density $n_{c}<n_{c}$ would product a onc-uay absorption fraction

$$
\alpha_{\mathrm{abs}}=1-\exp \left(-\kappa_{\mathrm{ib}} L\right)
$$

For weuk absorption, $\kappa_{i b} L \ll 1$ and $\alpha_{a b s} \simeq \kappa_{i b} L$. For strong absorption. $\alpha_{b} L \gg 1$ anui $a_{a b} \rightarrow i$. So the absorption fraction is linear in $\kappa_{i b} \mathrm{~L}$ for small absorplion, and then salurates $\mathrm{w}$ ben ${ }_{\mathrm{h}} \mathrm{L}$ is Jarge. In general leng plasma lengths $L$ enhante the absorption.

Results for inverse Bremsstrahlung absorpior, in an inhomogeneous plasma are more complicated. since in Eq. (17) $n_{e} . T_{e}$, and fni may all depend on position. In reality, hovever. $T_{t}$ varies muth more slow!s in space than $n_{e .}$ and the variation of $n .1$ is sufficiently slow that it ean be neglected. Thus the domirant spatial dependence in Eq. (16a) or (17) comes from $n_{\mathrm{e}}(x)$.

The classic reference on the subject of inverse Bremsistrahlung in a density gradient is Ginsburg |1.3|. Ginsburg shows by integrating Eq. (16a) from $n_{c}=0$ to $n_{c}=n_{c}$. and then back to $n_{c}=0$. that the: 1 wit)-wils absorption fraction for a linear density prolile with scale length $L$ is

$$
\alpha_{\mathrm{abs}}=1-\exp \left(-\frac{32}{15} \frac{\nu_{\mathrm{e} i}\left(\mathrm{n}_{\mathrm{c}}\right)}{\mathrm{c}} \mathrm{L}\right)
$$

Thus in integrated form, all the density-dependent factors in Eq. (16a) combint to vield the numerical coelficient $32 / 15$ for a linear profile, with the collision frequency "ui now evaluated at the critical density $n_{e .}$. The increased absorption for low $T_{e}$, high $n_{e}$, and long $L$ is retained in a density gradient.

Because of the dependence of $\kappa_{i b}$ on $\left(n_{\mathrm{e}} / \mathrm{n}_{\mathrm{c}}\right)^{2}\left(1-\mathrm{n}_{\mathrm{e}} / \mathrm{n}_{\mathrm{c}}\right)^{-1}{ }^{2}$ in Eqs. $(16 \mathrm{~d})$ and (17), a significunt frit:tion of the inverse Bremsstrahlung absorption comes from the region very near $1 \mathrm{~h}$ : critical density $n_{c}$. But as we discuss below. there are several important processes which can steepen the density profile near $n_{6 . .}$ and which may thus eliminate much of the region where inverse Bremsstrahlung vould be expected to be 


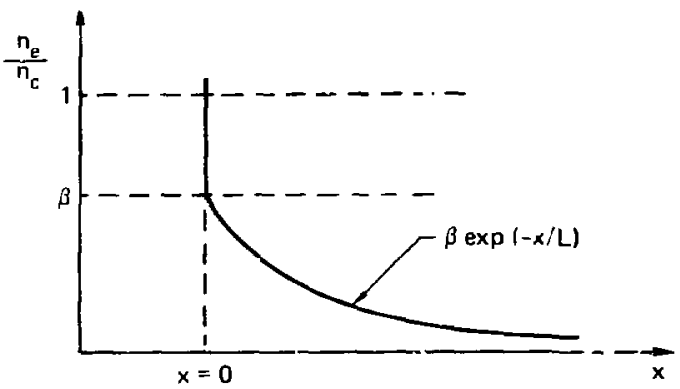

FIC;. 3. Model density profile for calculation of inserse Bremsitrahlung absorption in a steepened profile. The density is assumed $t$ rise infinitels steeply above a density ofn, $d<1$.

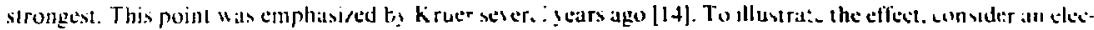

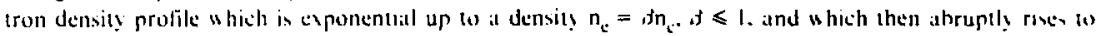

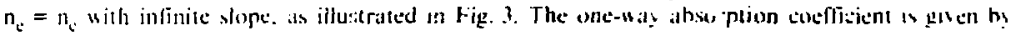

$$
\begin{aligned}
& \int \kappa_{i h} d s=\alpha \int_{n_{e}=0}^{n_{e}=\beta n_{c}} \frac{\left(\frac{n_{e}(x)}{n_{c}}\right)^{2}}{\left(1-\frac{n_{e}(x)}{n_{c}}\right)^{1 / 2}} d x . \\
& \alpha \equiv{ }^{\prime \prime e i\left(n_{c}\right)}=3 \times 10^{-21} n_{c} 7.1 \mathrm{n.1}\left(\frac{1 \mathrm{keV}}{T_{a}}\right)^{: / 2} \mathrm{~cm}^{-1} .
\end{aligned}
$$

with density protile $n_{e}(x)=$ sn

$$
\begin{aligned}
& \int_{n_{k}=0}^{n_{1}=\beta n_{c}} \kappa_{i n} d x=\left(\frac{4}{3} \alpha L\right) F(\beta) . \\
& F(\beta)=1-(1+\beta / 2)(1-\beta)^{1 / 2} .
\end{aligned}
$$

The function $F(\beta)$ in protled in Fig. 4. It is equal to 1 when $s=1$, hut it then falls quickly touard rero for

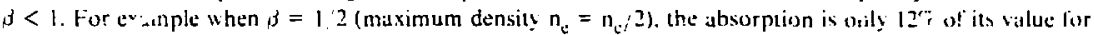
$\beta=1$. T'،e same physical effect is seen for lint:. [ [ 14$]$ or other tspes of density profiles: inverse Bremsotratlung

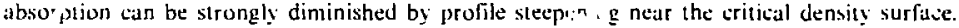

In addition to prolile modification there are $(w)$ wher nonlinear effects whicb can decreace the in. v.rse Bremsstrahiung absorption coefficient fer high liss, intensi:kes. In the first effect the electrot, distribuion function is assumed to remain Maxwellian as in : $\mathbf{y}$. (17), but the electoon-ion Couloar' collision frequency is modilied by the electrons coherent uscillatisy motion in the laser eletric field. Thus rather that having a typical mean-square velocity $v^{2}$. the electron velceit instead has an effectic dispersion

$$
\left(v^{2}\right)_{\text {eff }}=v_{t_{e}}^{2}+\left(\frac{e E_{L}}{m_{e} \omega_{l}}\right)^{2}
$$




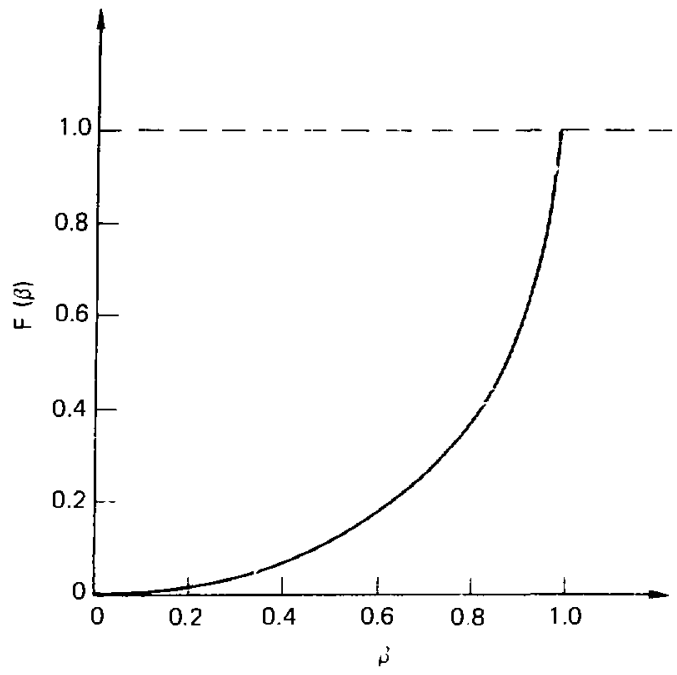

liti. 4. The factor Fi, i) from Fy. 1221, describing the reduction of inserse Bremsstrahlung optical depth in a steeptesed densits profile. The parameter $f$ is defined in Fig. 3 .

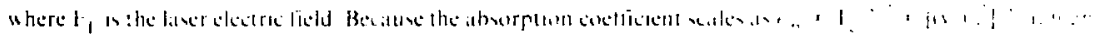

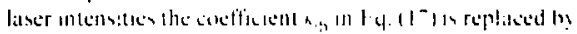

$$
\kappa_{i b} \rightarrow 1+\frac{3}{2}\left(\frac{\kappa_{i b}}{m t_{1}, \omega_{1} b_{1}}\right)^{2}
$$

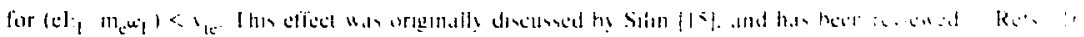
and $[1 ?]$.

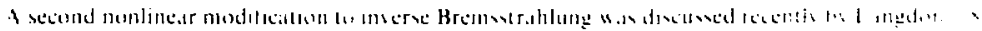

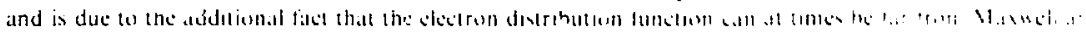

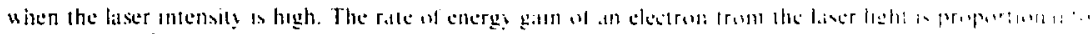

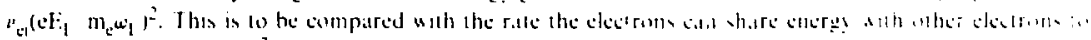

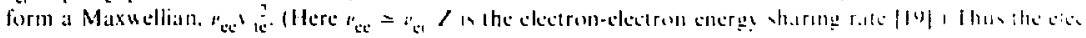

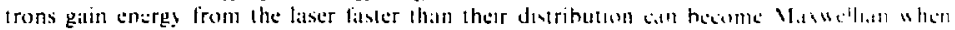

$$
z\left(\frac{\mathrm{eE}}{m_{\mathrm{k}} \omega_{\mathrm{i}}, \mathrm{v}_{\mathrm{e}}}\right)^{2}>1 .
$$

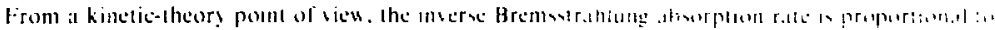

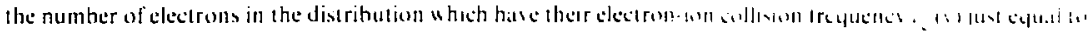

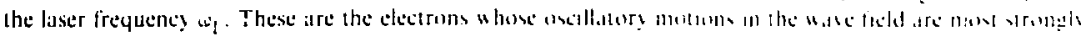




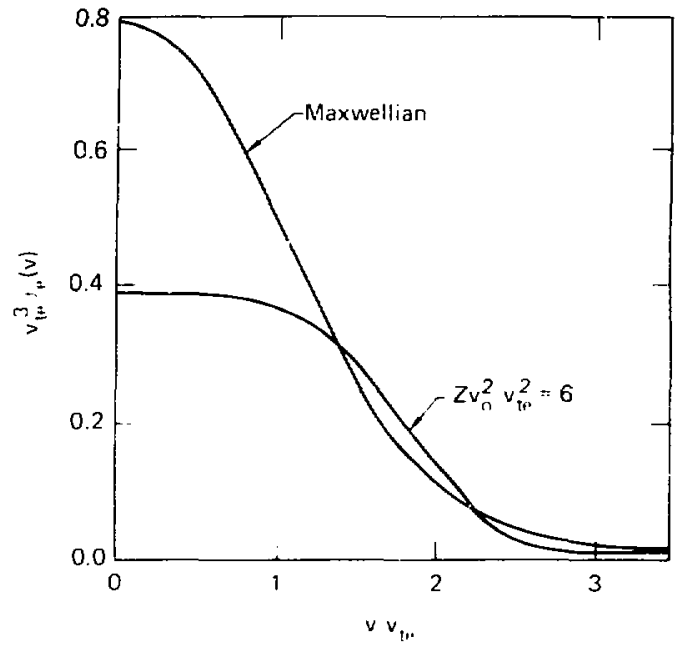

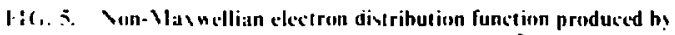

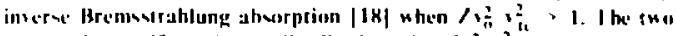

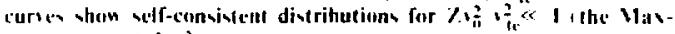

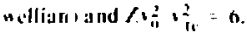

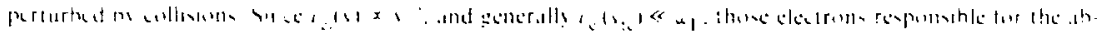

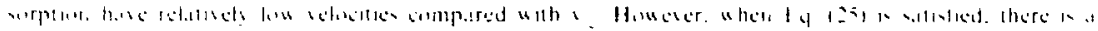

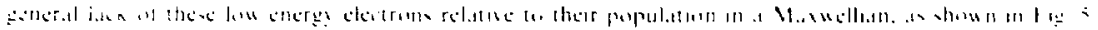

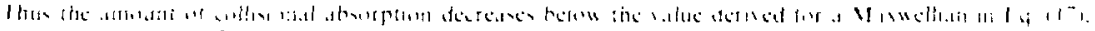
when $/ 1 \cdot 1,13+1,1 \cdot 1$

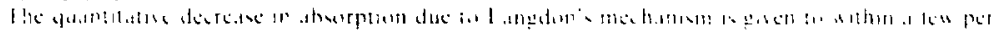
chin in

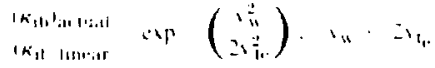

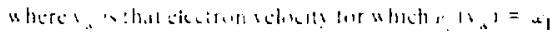

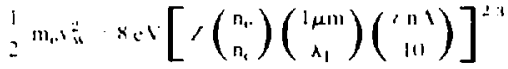

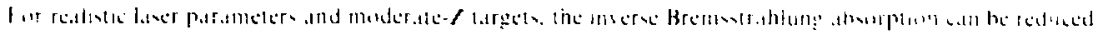

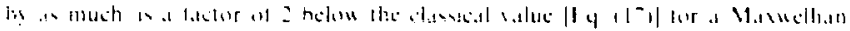

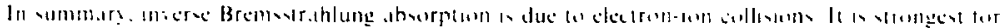

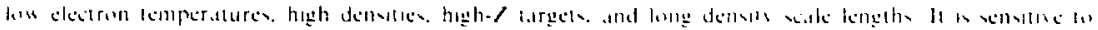

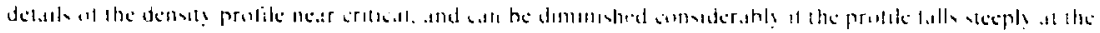

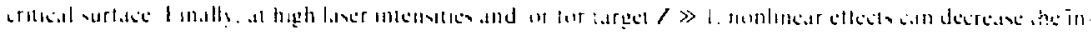

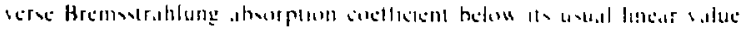




\subsection{RESONA.N(E ABSORPTION}

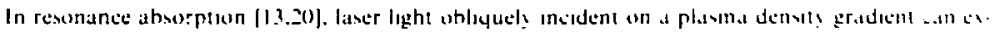

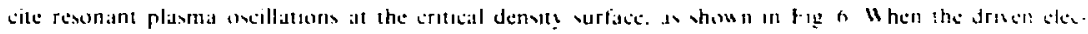

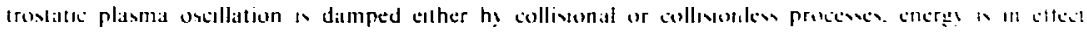

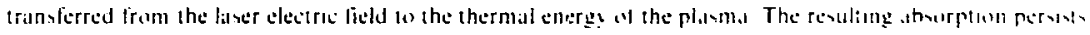

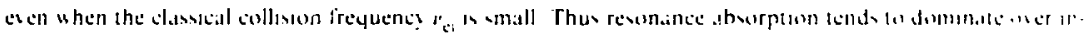

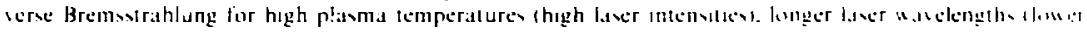

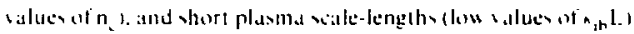

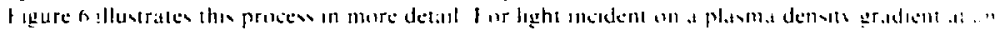

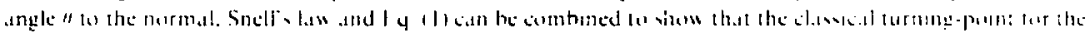

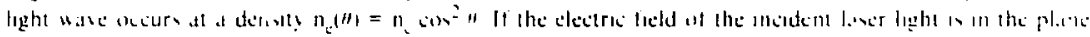

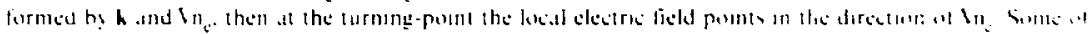

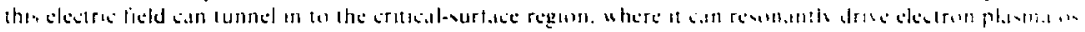
(alldtum, 11 angmuir water

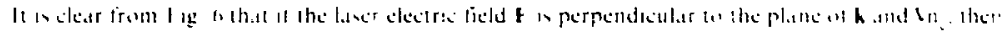

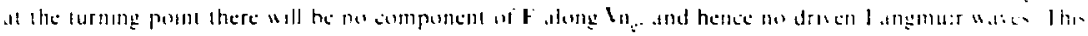

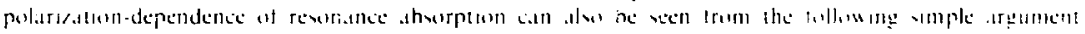

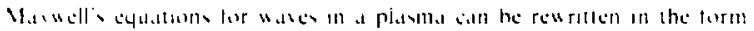

$$
\begin{aligned}
& \nabla \cdot|\epsilon \mathbf{E}|=0 . \\
& \epsilon^{2}-1, \frac{\omega_{1}^{2}}{\omega_{1}^{2}=1-}=1
\end{aligned}
$$

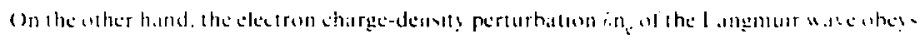

$$
-4 \pi \dot{L} n_{n_{1}}=\nabla \cdot \mathbf{E}=-\left(\begin{array}{c}
\mathbf{E} \cdot \nabla \epsilon \\
\epsilon
\end{array}\right) \times\left(\begin{array}{c}
E \cdot \nabla n_{\epsilon} \\
\epsilon
\end{array}\right)
$$

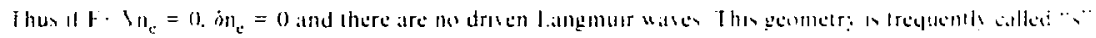

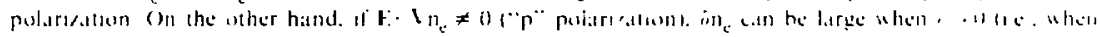

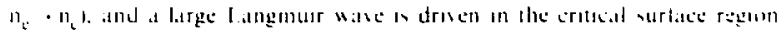

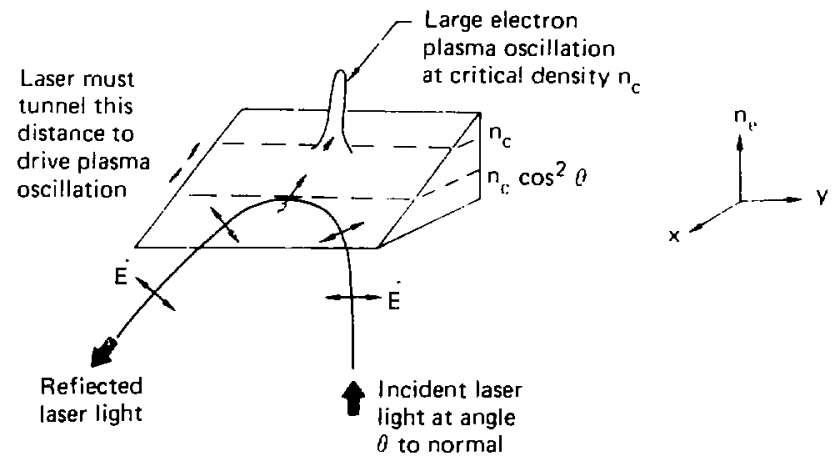

FIC; 6. Schematic configuration for resonance absorption of p-polarized light. where $F$ is in the plane of $k_{1}$, and $i_{e}$. 


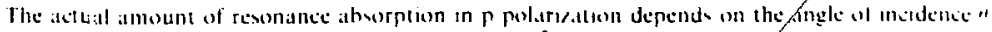

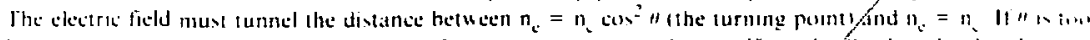

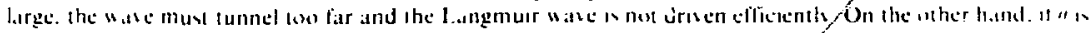

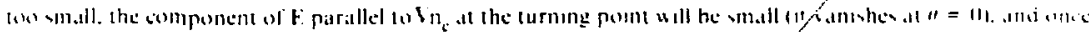

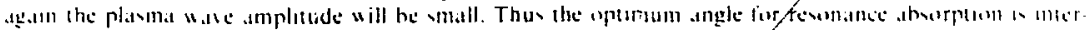

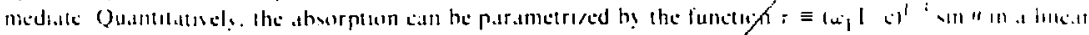

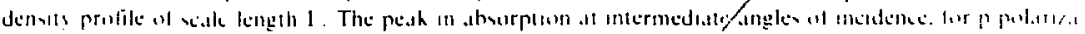

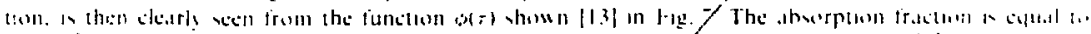

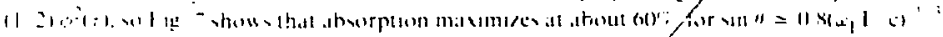

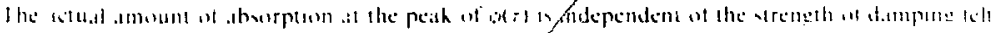

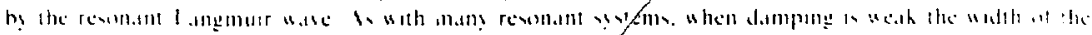

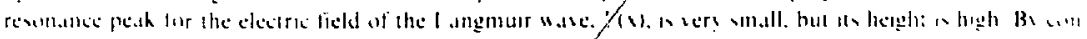

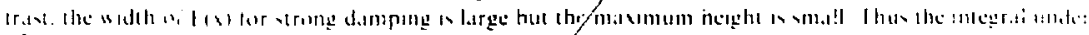

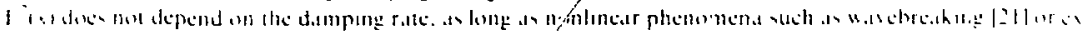

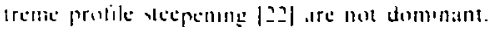

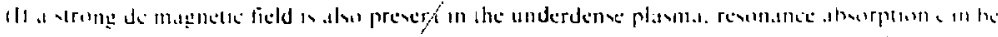

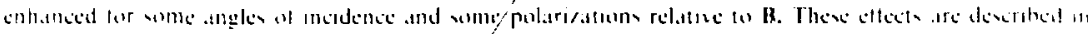
Rel, I:? $\mid 2,1]$

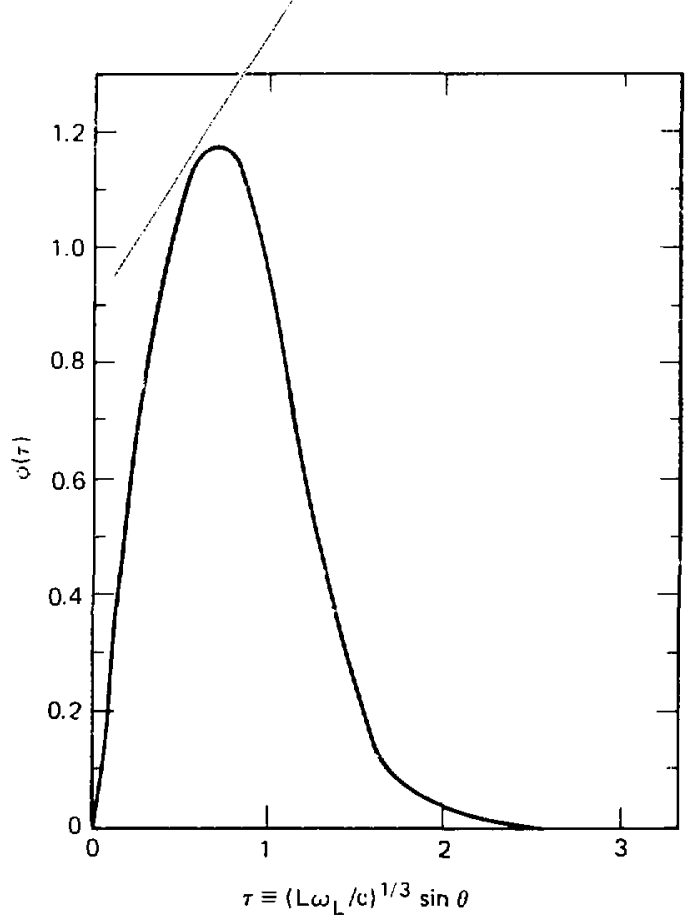

FIG. 7. The function $\phi(\tau)$ characterizing resonance absorption $|13|$. The total absorption at an angle of incidence $A$ is equal to $(1 / 2) \phi^{2}(\tau)$, where $\tau \equiv\left(L_{w} / / c\right)^{1 / 3} \sin f$. 
Parlicle-an-cell computer sumulations of resonanse .tosorption at high laster intenvilies $\mathrm{I}_{1} \lambda_{i}^{2}>\mathrm{a} \times 10^{1+} \mathrm{W}_{\mu} \mathrm{m}^{2} \mathrm{em}^{2}$ ) tend to show collisionless heating of electrons tras eling through the resunim plasma socillation from high densities toward low densities [22.27]. These electrons see a nearly stationars clectric licld. and can then be strongly accelerated down the gradient. The healed electron distribution is ilpprovimately Maxwellian. for reasons that hate been addressed only recentl! [28). The ateritge hot-electron encre! $\Gamma_{h}$, ol this hol Masusllian has been estimated as

$$
1 \mathrm{keV}=1.3\left(\frac{T_{\mathrm{L}}}{1 \mathrm{keV}}\right)^{1 / 4}\left[\left(\frac{\mathrm{l}_{\mathrm{l}}}{10^{1.5} \mathrm{~W} / \mathrm{cm}^{2}}\right)\left(-\frac{\lambda_{\mathrm{L}}}{1.06 \mu \mathrm{m}}\right)^{2}\right]^{0.39}
$$

III R.t. |27) and in

$$
1 \mathrm{kLV}=7\left(\begin{array}{c}
T_{\mathrm{r}} \\
1 \mathrm{keV}
\end{array}\right)^{1 / 3}\left[\left(\begin{array}{c}
\mathrm{l}_{\mathrm{L}} \\
10^{15} \mathrm{~W} / \mathrm{cm}^{2}
\end{array}\right)\left(1 \frac{\lambda_{\mathrm{L}}}{1.06 \mu \mathrm{m}}\right)^{2}\right]^{1 / 3}
$$

II Ret [2]]. Here I is the temperature of the cold batkground electrons. $1_{L}$ is the laser intensits. and $\lambda_{1}$ is the l.der wavelength. ( The reader is citutiened that I hase multiplied the value of $T_{h}$ given in Ret. [27] h! $3:$.

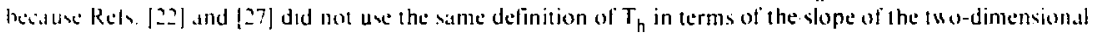
Jistrihuteits buncitisn.)

We deracd an $1 \cdot 4$. 15 a difierent expression for the temperature as a lunction of $I_{1}, t_{1}^{2}$. which applies

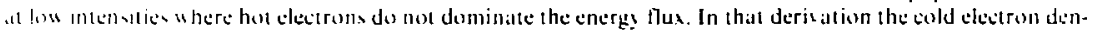

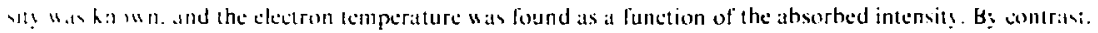

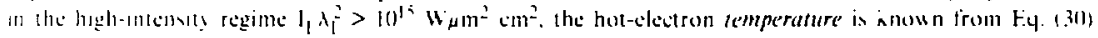

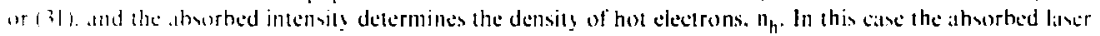

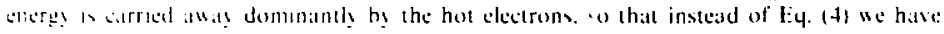

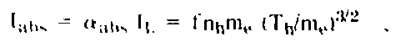

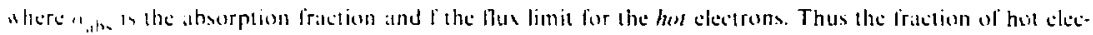
trons all the sritcict densily

$$
n_{h 1}=r_{i a l_{1}}\left(\begin{array}{c}
c v_{11}^{2} \\
n_{h} \\
v_{h}^{3}
\end{array}\right) \text {. }
$$

"here we tidse delined $\frac{2}{h} \equiv T_{h}$ w... and

$$
v_{11} \equiv \mathrm{LF}_{\mathrm{I}} / \mathrm{ml}_{\mathrm{l}} \mathrm{\omega}_{\mathrm{I}}
$$

1he wallatury colosit: of an electron in the laser field $\mathrm{E}_{1}$.

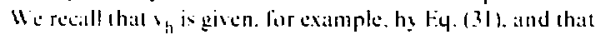

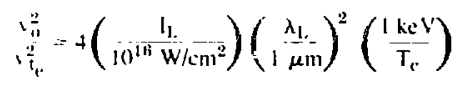

Ihen ! 4. 1.32)-135] ean be combined [2?] w ith some algebra we find the fraction of hot electrons at the criticul densil?

$$
n_{h}=\frac{0.4 \alpha_{a b s}}{f}\left(\frac{v_{0}}{v_{t_{0}}}\right)
$$

I ar eample fur an absorption liaction of $30 \%$ and an for suprathermal electrons eyual to ahout (0.6, we find

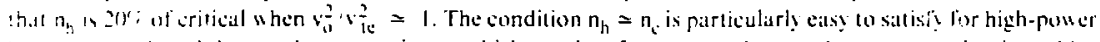
livers is wa ietength longer than one micron. which are therefore expected to produce coron. , dominaled b? hal clectruns. 
In addition to hat-electron generation. computer smulattems hase ahown the importance of profilc-

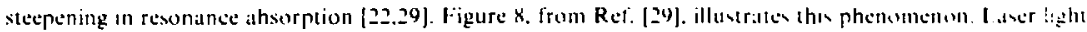

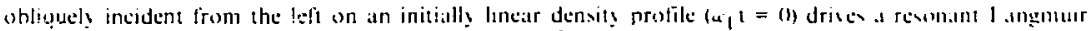

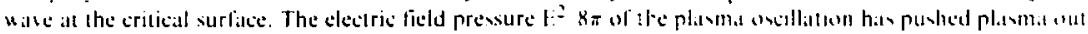

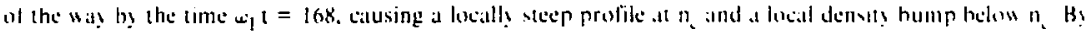

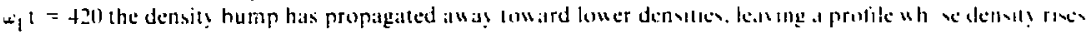

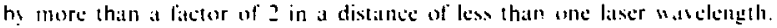

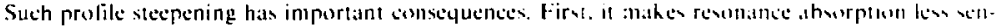

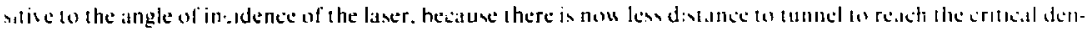

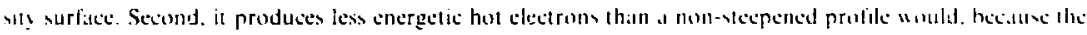

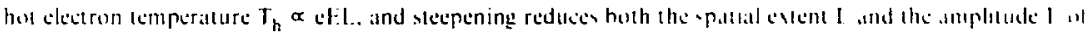

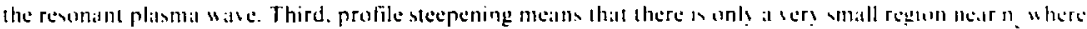

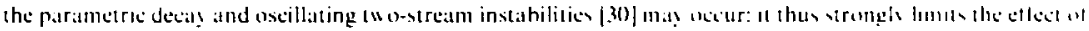
these twa processes on ahsorption and preheat when the laser mlemst: : high.

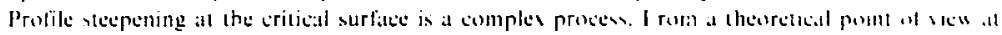

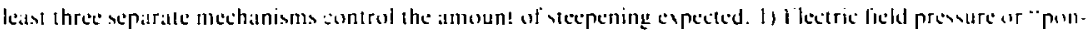

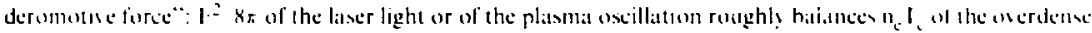

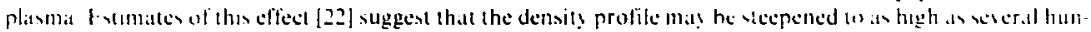

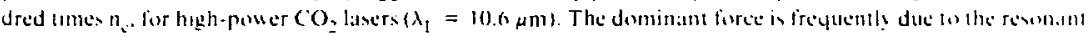

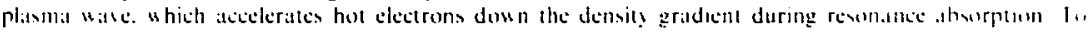

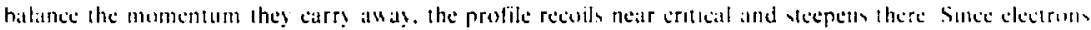

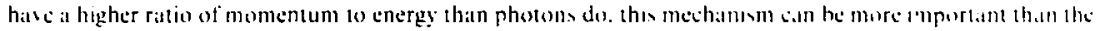

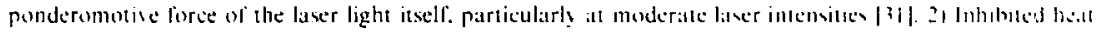

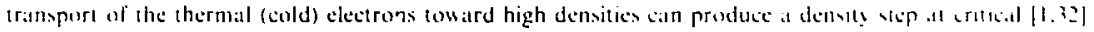

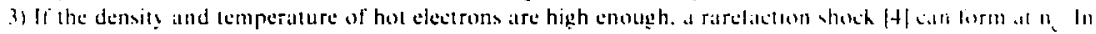
this stlatliun the underdense plasmil consists entirels of hot electrons

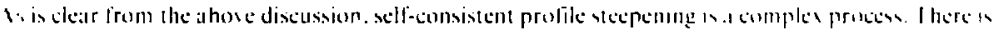

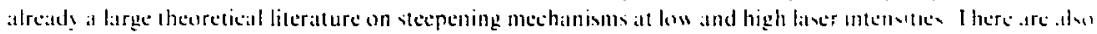

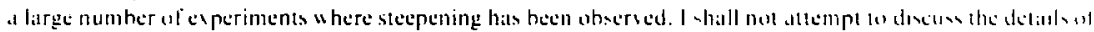
protile vecpentng further in the present report.

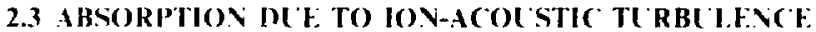

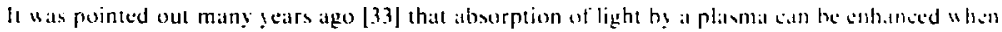

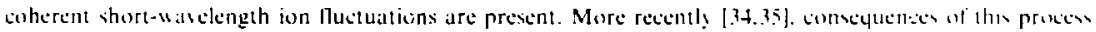
for high-powe: !aser-plasma interactions have heen explored. As we mentioned in S:ellan 2.1. the Waull

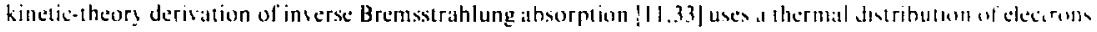
and randomly distributed (uncorrelated) ions. However in the presense of soherent ion turbulense with lluse

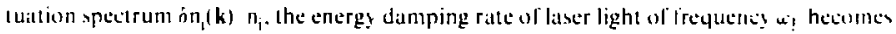

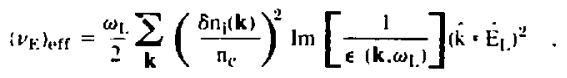

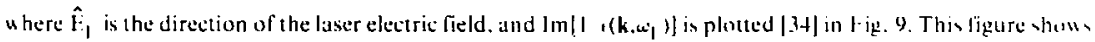

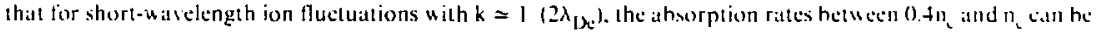
substantial if the level of ion fuctuations on $n_{1}$ is large enough. The optimum density fir absorption vartev with the ralvelength of the ion fluctuations.

Detailed consideration of this mechanism for laser-target expertments with pulse lengths $i_{1}<$ IIE) $_{\text {ps }}$ (sec Refs. $[3+4]$ and [35]) indicales that for $n_{c}>n_{c} .3$ and $T_{c}>5 T_{1}$, ion lurbulence might contribute up lo an extra 20\%; to the total absorption. Atsorption due to ion turbulence would add to the fraction athsorbed h: 

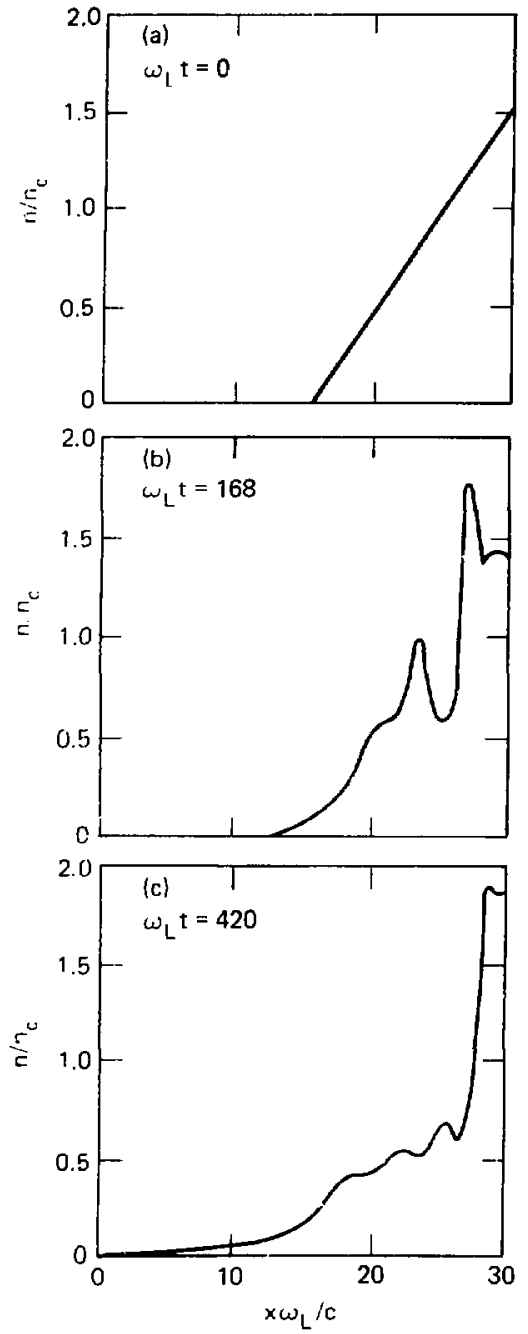

FIG. 8. Development of a steep density profile during resonance absorption, from particle-in-cell computer simulations $[29]$. The angle of incidence is $24^{\circ}$, and the frec-space incident laser intensity in $10^{16}$ $W / \mathrm{cm}^{2}, \lambda_{\mathrm{I}}=1.1 \mathrm{~kg} \mu \mathrm{m}$. The initial electron $1 \mathrm{em}$ perature is $4 \mathrm{ket}$. 


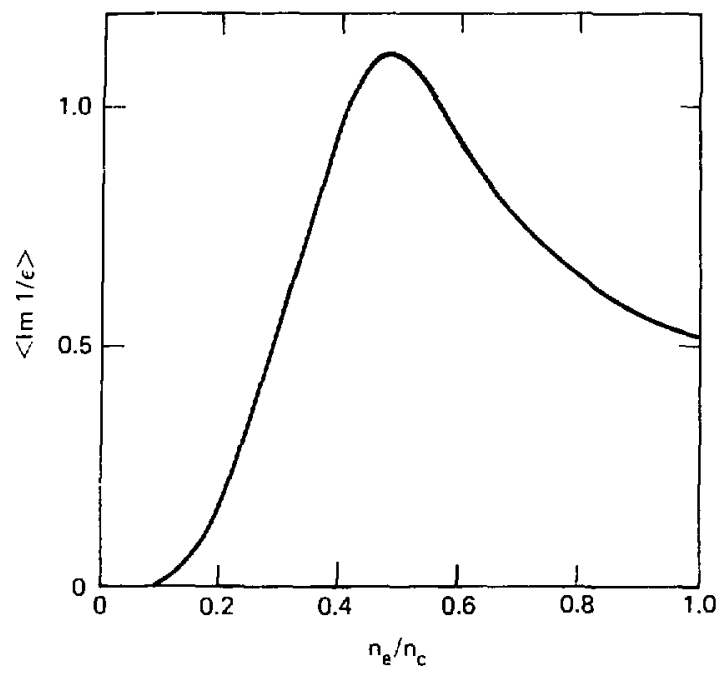

FIC;. 9. The imaginary part of,$-1\left(k, w_{1}\right)$, as a function of plasma density [.34]. The brackets denote an average over a uniform spectrum of ion fluctuations between $k=k_{[} / 2$ and $k=k_{1}$.

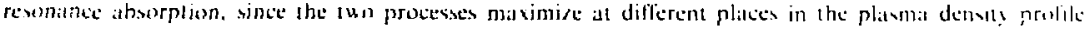

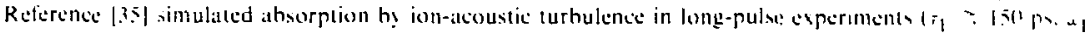

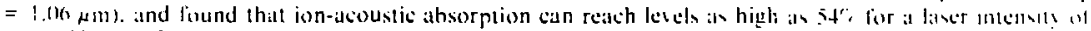

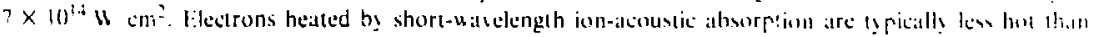
electroms heated hy resonance absorption [Fys. (30) and (31)]. The theoreticat upper lime un the flustuathen

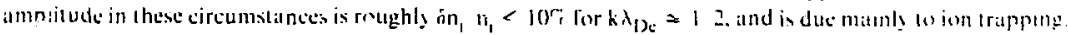

The atetal soures and magnitude of short-watelength ion turbulence in lancr-produced planmis

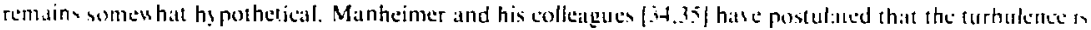

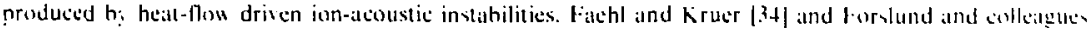

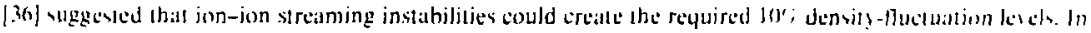

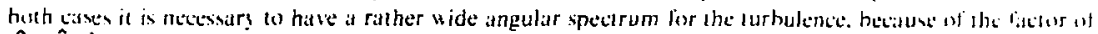

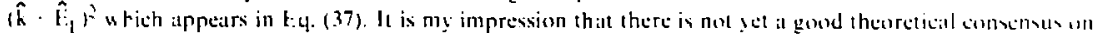
the expeced magnitude and angular spectrum of ion turbulence. Fortunatels for the theorelicitin, :on tur-

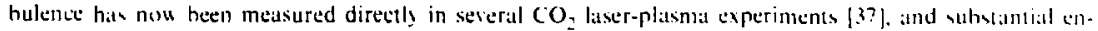
hancements in the ion fluctiation level over thermal noise have heen se' n. Although the angular vpectram hase not yel heen welt-characteriged experimentally, these measurements strongly incleare the plausibilit! ul sh:orption due wo iun-acoustic turhulence.

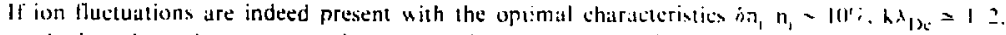
$\mathbf{T}_{\mathrm{s}}>S \mathbf{T}_{1}$, and a broad angular spectrum. the are in principal capable al increasing the eapected ahworptoun level considerably. The maximum absorption of ahout $200^{\circ}$ due to ion turbulence citleulated for vhorl-pulne experimests [34] is quile comparahie with the resonance absorption lesels of 20-30\%" expected for mased p. mel s polarioations. For long-pulst experinents, a more relevant comparison is the ratio af the optimal unacoustic absorption rate [E.4. (37)] to the inverse Bremsstrablung absorption rite [F4. (13)]: 


$$
\frac{\left(\nu_{V}\right)_{\mathrm{eff}}}{\left(\nu_{\mathrm{k}}\right)_{\mathrm{H}}} \equiv \frac{10}{Z}\left(\frac{T_{\mathrm{e}}}{1 \mathrm{keV}}\right)^{3 / 2}\left(\frac{\lambda_{\mathrm{L}}}{1 \mu \mathrm{m}}\right) .
$$

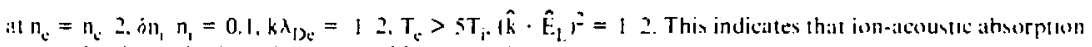
can be dominant for low $-Z$ targeds and laser wavelengihs $\lambda_{I} \geq 1 \mu \mathrm{m}$, provided thal a large enough regian obl plasma is present al the required optinum densils.

It summary, in this section we have discussed three different laser light absorption mechanions. Inverse Bremblrahlung is due to classical electron-ion collisions. It incresses with target $Z$. w ith plasma dem illy. and with the length of underdense plasmil. and it decreases at high plasmat temperatures. It is Ihus strongen lor low latser intemsities, short laser watelengths. and long laser pulsts. Inverse Breminstrahlung mas be mon. Innearl! reduced al high later intensit! or high target Zs.

Reronance ahsorption. hy contratst. tends to dominate al high laser intensities and hort liner filuach. Beciase it depends on the cxcitation ol resonant electron plasmat ostillatiens at the critical iurface, resonatnce aborption is bolh angle- and polarization-dependent. The theoretical aboorption peaks al silo-60)"; in $\Gamma$ pularsation, implying that for mived potarization the ahsorption should be athout half this ialuc. The crille.l

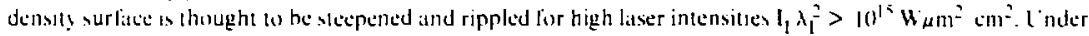

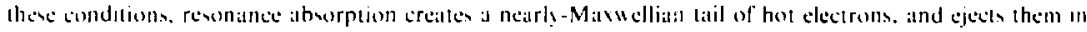
the dircollon oi decreasing plasma denvit?

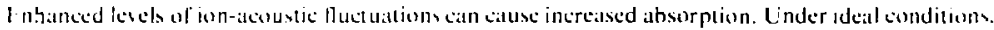

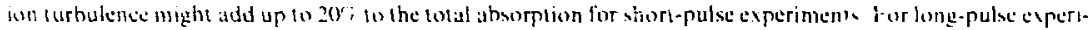
ments. kn turnulence absorption can be larger than inserse Bremsstrahlung for low-7. targets and for laser

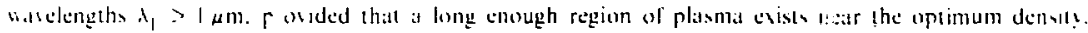

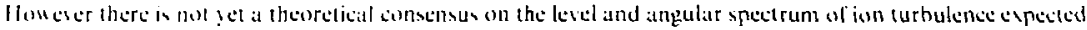
in laser-produced plasmis. 


\section{STIMLLATED SCATTERING AND FILAMENTATION: NONLINEAR EVOLLTION}

In this section we discuss stimulattd scattering. whish mugh reduce later light athorrtum heluw the values calculated in Section 2. and filamentation. which might enhance nonuniformitio an the modsut last

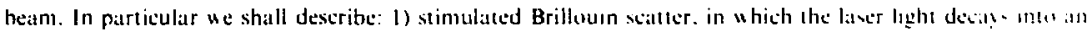

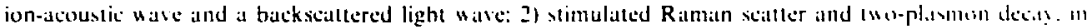

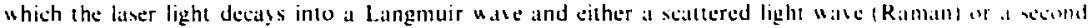

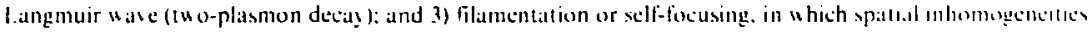
initially present on the incident laser heam ean he amplified.

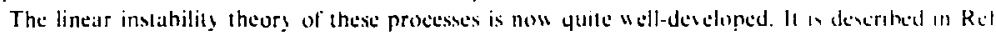

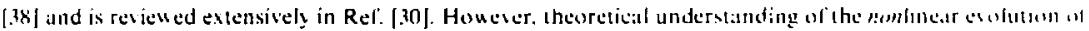

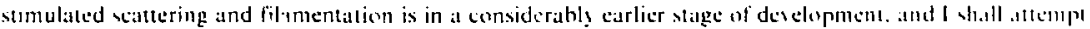
here to strthesie the major conctusions to date.

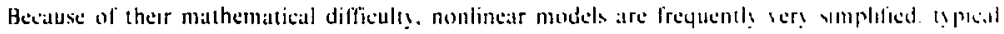
theoretical calculations include only one nonlineitr effect al a time in order to ket the problem whbles

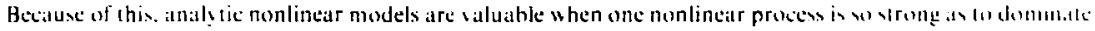
ower other competing processes. On the other hand. computational studes can gits insthit mo how ecter.t

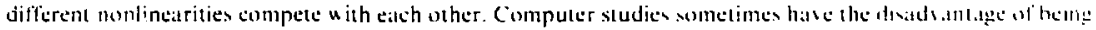

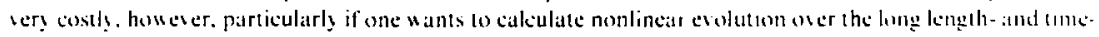
scalcs dimolied in large reaclor-sired laser fusion targets.

The particular nonlinearilies which dominate stimulalled stallering and libamemtatmon are wenthe

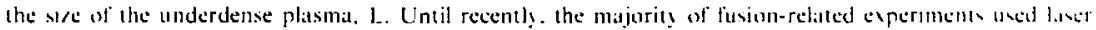

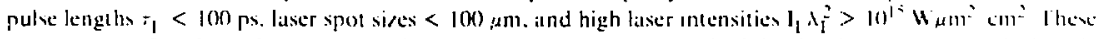

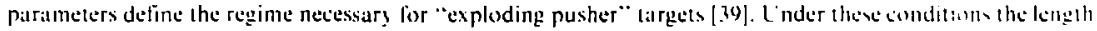
of the uriderdense plasma typieally does not exceed 10 -20 vacuum wisclengths $\left(1, \lambda_{1}<20\right)$. With with s

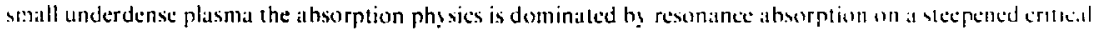

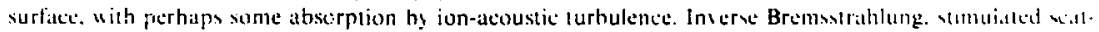

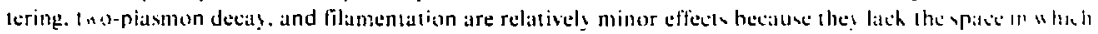
(1) grow.

B. contrast. present and future experiments will emphaside more gentle, ablatse amplusoms. I he consequent longer laser pulses. larger focal spots, and lower laser intensities lend lo create a larger regtan , 1!

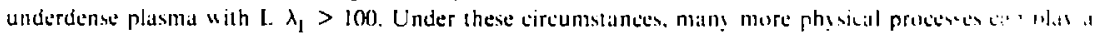

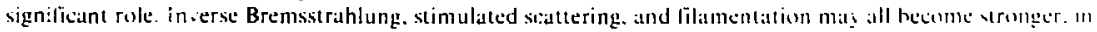
a large underdense plasma whose sise is many times the linear growth kength for these imstahiluler

\subsection{STIMILIATED BRILIOLIN SCATTERING;}

Stimulated Brillouir: scattering (abhreviated as SBS) has the potential of causing largt pr:mature reflection of the incident laser light before it reaches the critical density. and of limang the encrẹ that catn reach critical. The incident laser light decays into an jon-atoustic nave and a reflected light wase which can leave the plasma. $\omega_{1} \rightarrow \omega_{i a}+\omega_{R}$. The physical mechanism for this process is shoun schemalically in rig. 10 . An initial lou -frequency density perturbation on produces a transverse current $\propto$ ont $E_{1}$. due to the oscillaltsr! motion of electrons in the laser electric field $E_{\mathrm{L}}$. This transverse current products a rellected light wate with field $E_{R}$. The ponderomotive force $\left(E_{t} E_{R} / 8 \pi\right)$ of the incident and reflected light ualses cart in turn cituxe tnhancement in the original density perturbation $\delta n$. and thus exponential growth, provided thatl the freyuency and wavenumber of the three waves satisfy the conditions

$$
\omega_{\mathrm{I}}=\omega_{\mathrm{R}}+\omega_{\mathrm{ia}}, k_{\mathrm{L}}=k_{\mathrm{R}}+k_{\mathrm{ia}} .
$$




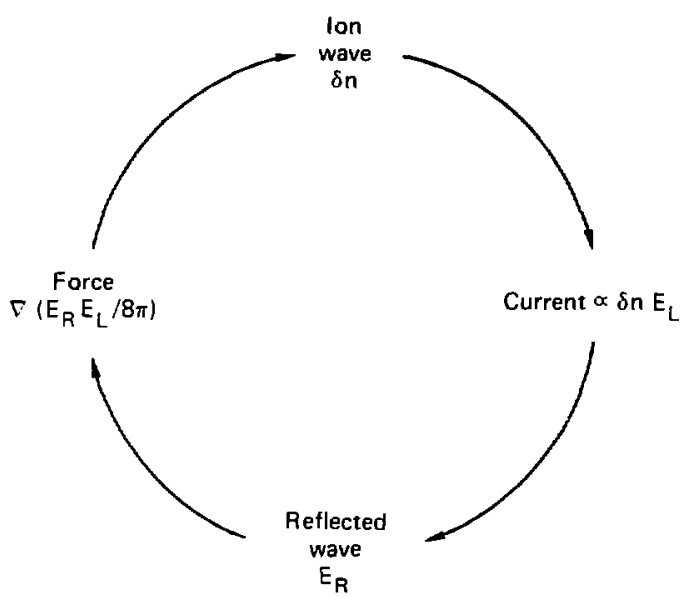

FJ(i. 11. Feedhack mechanism for growtî̀ of stimulated Brillouin seattering.

for the simplest caise where

$$
\dot{u}_{1} \gg u_{\mathrm{pu}} . \mathbf{k}_{\mathrm{l}} \| \mathrm{k}_{\mathrm{R}} \text {. }
$$

the malching con titions imply that

$$
\begin{aligned}
& k_{1.1}=2 k_{1} \simeq 2 w_{1} c . \\
& k_{R}=-k_{1} \simeq-w_{1} c . \\
& \omega_{R}=w_{1}-2 k_{1} c_{s} .
\end{aligned}
$$

The nonlinear evolution of SBS in short underdense plasmas was studied in Ref. [40|. Subscyucht numerical simulations by Kruer, Valeo. und fstabrook [4l] indicated that at high laser intensitios whero $2 I_{1}$ c $\gg n_{c} \Gamma_{t}$. momentum deposition in the ions due to Brillouin-scattering cause the densits profile to steepen. As a consequence of this profile steepening. the SBS reflectivily decredses aller an initial iransilem. The process is illustrated in Fig. 11. from Ref. [H1]. Such limitalion of reflestivily in the short-pulse, highintensily reginte has been seen in Nd-glass laser experiments [42]. Recent high-power $\mathrm{CO}_{2}$ laser experiments [4.3] are also in this regime.

If there is a very large region of underdense plasma. profile steepening oceurs itt a much slower relative rate and SBS can be much strunger, particularly when $2 \mathrm{I}_{\mathrm{L}} \cdot \mathrm{C} \leqslant \mathrm{n}_{\mathrm{e}} \mathrm{T}_{\mathrm{e}}$. Under these conditions a wide range of ply sical nechanisms may determine the nonlinear evolution of SBS. Among these 1 shall discuss the following. If ion- $v$ ave siluration by trapping or wavebreaking. 2) nonlinear ion heating. 3) the effect of light rellected from the critical surfice, 4) competition between SBS and inverse Bremsstrahiung absorption. 

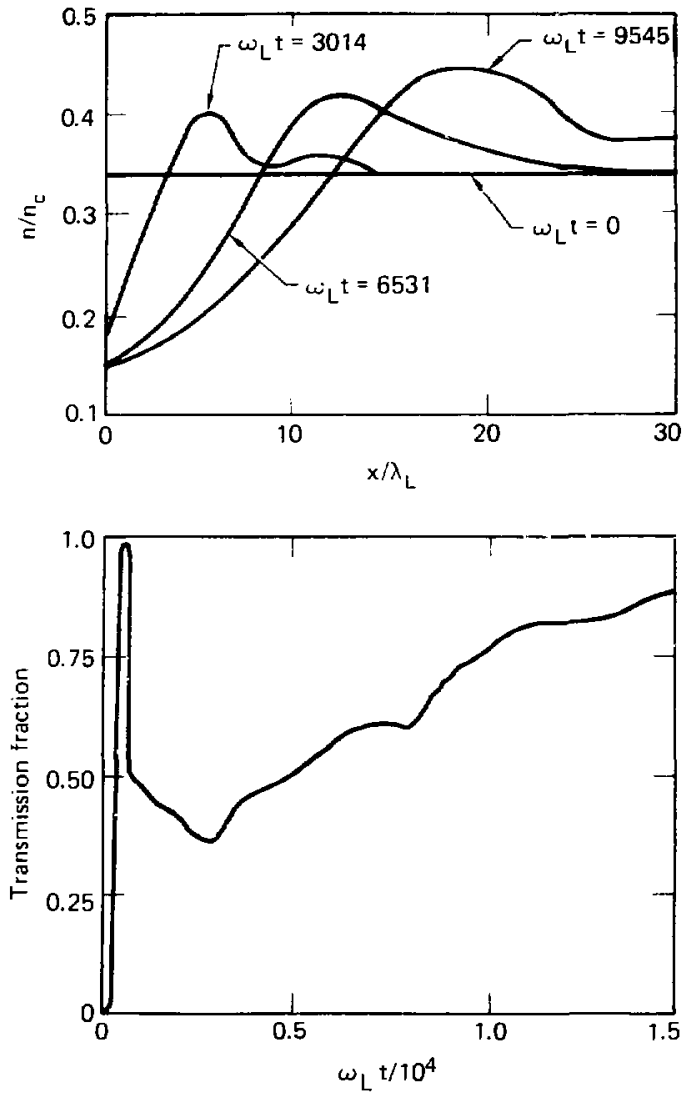

FIC. 11. I.mitation of stimulated Brillouin scattering by profile steepening [41]. when $2 I_{1} / c \gg n_{e} T_{e}$. The laser comes from the left. The top figure shaws the time evolution of the density profile. The bottom figure shows that as the profile steepens, the average transmission fraction increases towards unity due to the suppression of SBS. Parameters are $l_{l .}=5 \times 10^{15} \mathrm{~W} / \mathrm{cm}^{2}, \lambda_{l}=1.06 \mu \mathrm{m}, T_{\mathrm{l}}$

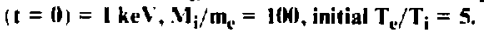

\section{I.: Ion- $W$ ave Saturation by Trapping or $W$ avebreaking}

One way in which the growth of SBS inight be saturated is to limit the size of the relative ion density perturbation. on $n_{1}$. Here $n_{1}$ is the background ion density. It is clear physically that on, $n_{1}$ must be $<1$. However in reality this limit may be considerably lower than unity, due to wavebreaking of the ion waves [44] or due to the fact that large-amplitude jon waves can cause ion trapping [45]. Wavebreaking and trapping are 
most likely to occur at high laser intensities, and lead to estimates of $\delta n_{i} / n_{i}$ between 10 and $20 \%$. When $\delta n_{j}, n_{i}$ is a (known) constant, the amount of SBS can be estimated from the following simple model [45]. Consider a plasma of length $L$ and uniform density $n_{e}=Z_{n_{i}}$, and assume that SBS is far above the convective threshold but is not an absolute instability (for example because the plasma outflow is supersonic in the lab frame. or because the ion wave damping is not very small). Then in one dimension the equations of evolution of the incident wave's vector potential $A_{i}$ and the backscattered wave's vector potential $A_{b}$ are

$$
\begin{aligned}
& \frac{\mathrm{d} A_{i}}{d x}=-\left(\alpha \frac{\delta n_{i}}{n_{i}}\right) A_{b} \\
& \frac{d A_{b}}{d x}=-\alpha\left(\frac{\delta n_{1}}{n_{i}}\right) A_{i} . \\
& \alpha=\frac{\pi}{2} \frac{n_{p}}{n_{c}} \frac{1}{\lambda_{1}}\left(1-\frac{n_{e}}{n_{c}}\right)^{-1 / 2}
\end{aligned}
$$

The sum and difference of Eqs. (39i1) and (39b) mas eateh be integrated from $x=0$ (n) L. to ohtain

$$
\frac{A_{i}(L)+A_{b}(L)}{A_{i}(0)+A_{b}(0)}=\frac{A_{i}(0)-A_{b}(0)}{A_{i}(L)-A_{b}(L)}=\exp \left[-\alpha\left(\frac{\delta n_{i}}{n_{i}}\right) L\right]
$$

For the cuse where $A_{h}(L) \ll A_{1}(1$,$) , this s ields the SBS rellectivin [4=1$

$$
R=\tanh ^{\prime \prime}\left[\alpha\left(\frac{\delta n_{i}}{n_{i}}\right) L\right]
$$

This expression shows that when the underdense plasma is large. the rellectivit! cian be suhstantial even when $\delta n_{1} n_{1}$ is nonlinearly limiled to a verz small value. For example consider an underdenst plasma with $n_{e} n_{c}=0.1$, and let us limit the ion wive amplitude to in, $n_{i}=0.01$, at valus ten times smaller than the ientrapping estimates mentioned abose. Then Eq. (41) says the reflectivily $\mathrm{R}$ it ili be less than 50 '" only lor $\mathrm{L} \lambda_{1}<\mathrm{n}(\mathrm{m})$. This condition is relatively easy lu violate with the large targels ens isioned for lusion reactors. which have diameters un 10 a fraction of a centimeter, and which thus have underdense plasmas w hich can be: thousands of wavelengths lorg for $\lambda_{1}=1,06-\mu \mathrm{m}$ laser light. Wi are henee motisated to look for other phỵsical mechanisms which might nonlinearly linuit SBS to a louer level of rellectivity.

\subsubsection{Yonlinear lon Heating}

Computer simulations of strong SBS indicate [4+] that a heated tail on the ion distribution is crestled in the nonlinear state These nonlinearly healed ions arc shown in Fig. 12. Physicalls, the energy souree lor such ion heating is the fraction $\omega_{1 \mathrm{la}} \omega_{1 .}=2 \mathrm{c}$, w of the incident light energy which is given to the ion wate during SBS.

Recently Kruer and colleagues [45,*6] have suggested that nonlincar ion heatting of this type might be able to limil SBS by inereasing the damping rate of the ion waves. To sea why increased dimping could lımı SBS. we solve again Eq. (39) for the reflectisity in a finite uniform plasma. How ewer this time we are con eerned with the case where the ion wave damping $n_{1}$ is large $\left({ }_{i} \omega_{1: 1}>1 k L_{G}\right.$. where $L_{G}$ is the convective grisuth length for SBS). We assume that the ion wave amplitude ón, $n_{i}$, is drisen bs the ponderomotive force of the : $u_{0}$ light waves $A_{1}$ and $A_{b}$. so that on $n_{1} n_{1}$ is given by

$$
\frac{\delta n_{1}}{n_{1}}=A_{b} A_{i}\left(\frac{Z k_{i a^{2}} e^{2}}{2 m_{\mathrm{e}} M_{i} c^{2} \nu_{j} \omega_{i a}}\right)
$$



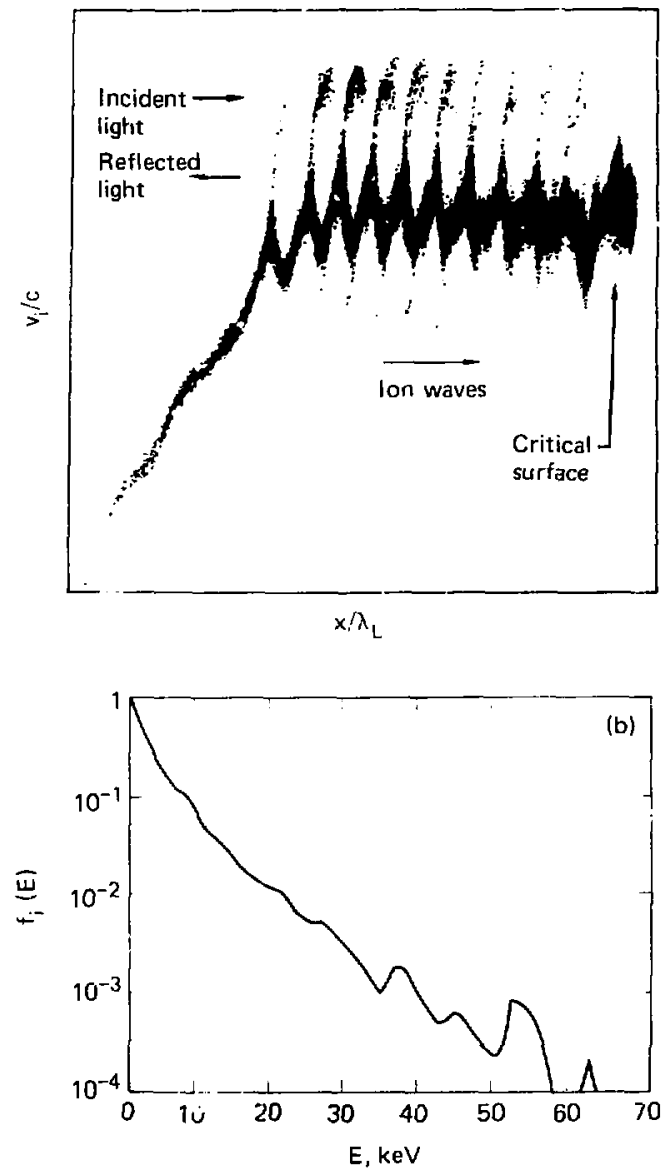

F1G. 12. Nonlinear ion heating during SBS, from computer simulations by $K$. Estabrook. a) lon nhase space, showing large-amplitude ion acoustic waves. Parameters are $1_{L}=2 \times 10^{16} \mathrm{~W} / \mathrm{cm}^{2}, \lambda_{L}=1.06$ $\mu \mathrm{m}, \mathrm{T}_{\mathrm{e}}=2 \mathrm{keV}, \mathrm{T}_{\mathrm{e}} / \mathrm{T}_{\mathrm{i}}=3,19.5^{\circ}$ angle of incidence. $\mathrm{b}$ ) lon disiribution function in the nonlinear state $\left(v_{0} / c=0.1\right.$, initial $T_{e}=10 \mathrm{keV}$, initial $T_{i}=3 \mathrm{keV}, n_{\mathrm{e}} / n_{\mathrm{c}}=0.7 . \mathrm{L} / \lambda_{\mathrm{L}}=20$ ). Note the pronounced heated tail. 


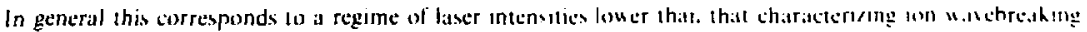

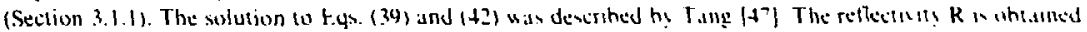
from the equation

$$
\begin{aligned}
& R(I-R)=\frac{I_{1}}{I_{1}}\left\{\exp \left[Q_{H}(1-R)-R\right]\right\} .
\end{aligned}
$$

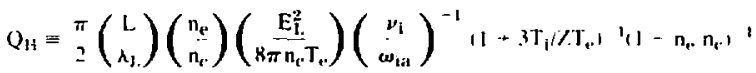

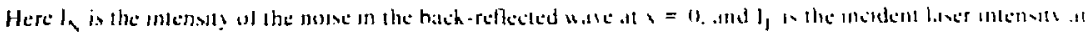

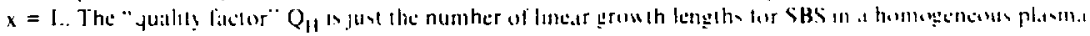
of linglh 1 .

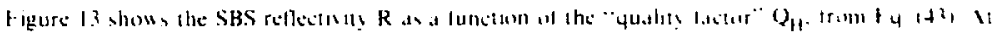

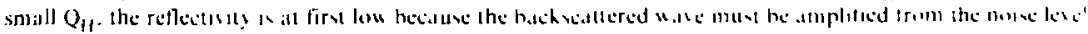

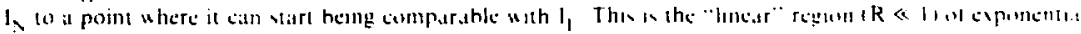

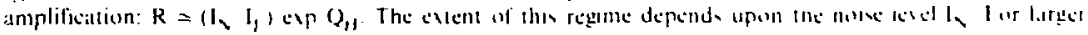

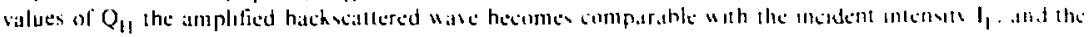

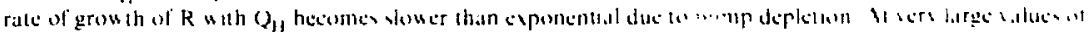
$Q_{11}$ the reflectislt? saturate at $R \cdot 1$. and the pump a,d

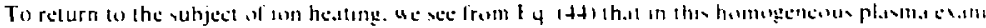

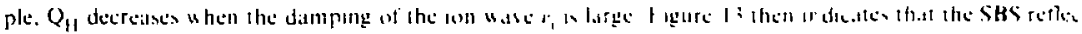

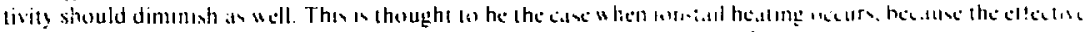

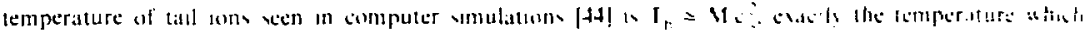

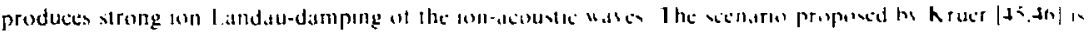

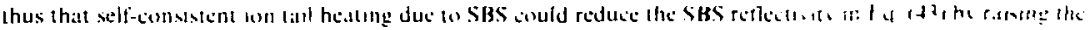

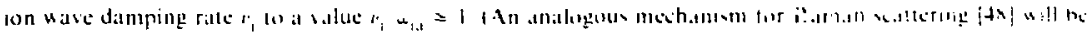
discussed in the following rectuon

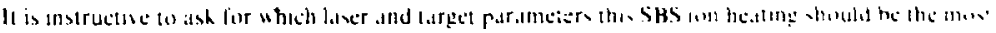

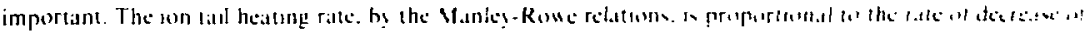
the incident light wate due to SBS les, ei lod d d

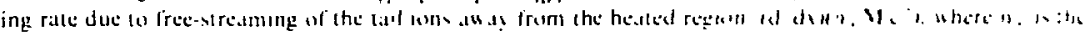

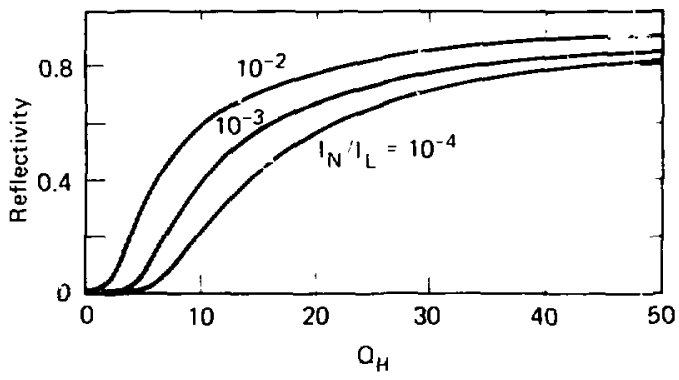

FIC. 13. SBS reflectivity $R$ as a function of the "quality facto:" $Q_{11}$ for a homogeneous plasma. Curves represemt wlutions of F.q-1 + , i, for three different values of the noise level: $l_{1} l_{1}=114$. 11 '? ant 10? 2 . 


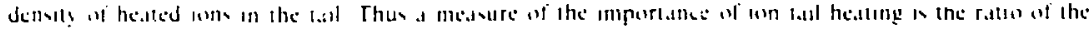

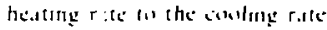

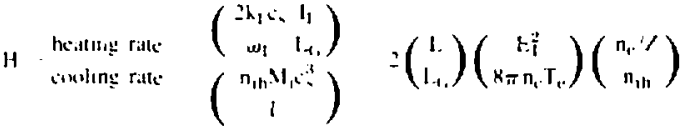

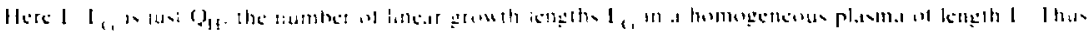

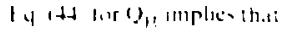

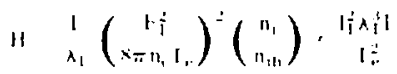

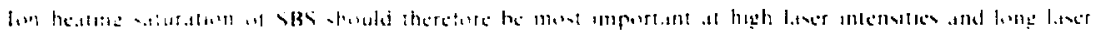
w.t.ten!!!!?

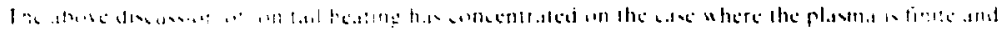

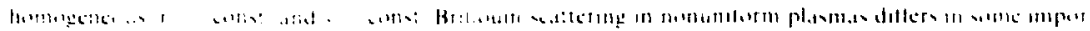

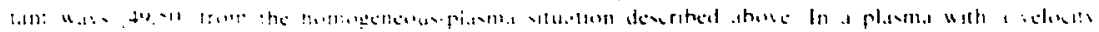

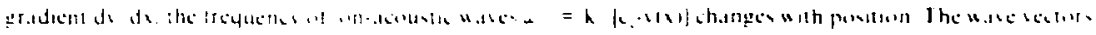

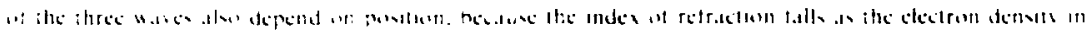

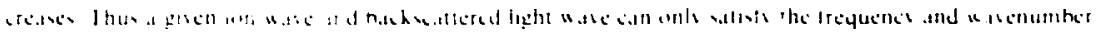

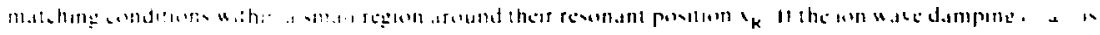

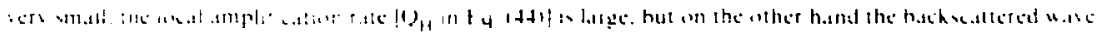

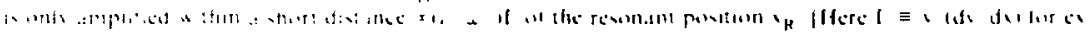

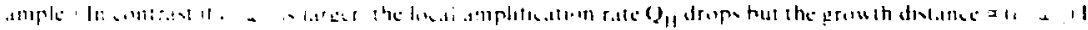

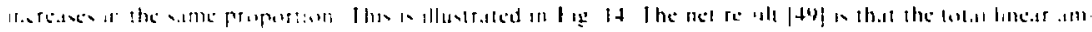

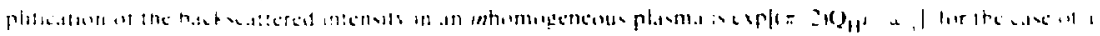

Smali

damping

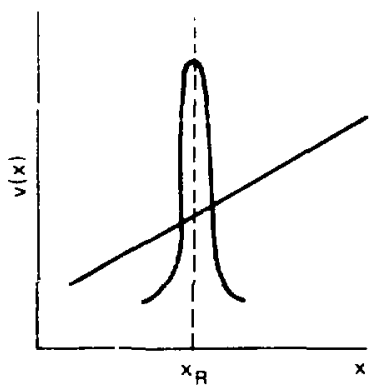

Large

damping

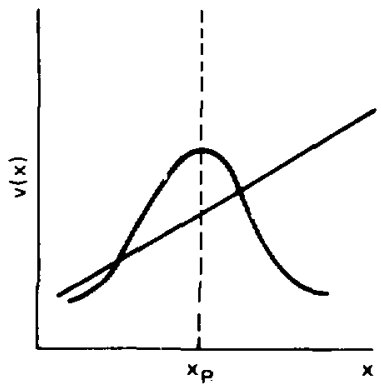

HIf. 14. Tichematic amplification profiles for SAS in a strongly inhomogeneous plasma. The total amount of amplification. integrated over the whole placma profile. is independent of the ion nasce damping rate. 
plasma of size $\mathrm{L}$. This exponentiation is independent of the damping rate, hecause $Q_{\mathrm{H}} \alpha_{\epsilon_{\mathrm{la}}}{ }_{1}$. Thus although nonlinear jon heating increases the damping of the ion waves $r_{1}$. Refs. $[49]$ and [50] predict that the resulting higher damping does not thange the linear growth of SBS in in inhomogeneous plasmat. Reference [51] hat corroborated this fact in computer simulations of strongly inhomogeneous underdense plasnlas.

I hus we conclude that nonlinear ion heating will he effeclive at limizing the grow th of $S B S$ in vilu. lions when the plasma is effectively finite and homogeneous. so that F.4. (43) and (4+) appl!. The condilun fior this 10 to the case is given b! Pesme el al. [49] as

$$
\omega_{\mathrm{i}}^{\nu_{\mathrm{i}}}>\mathrm{i} \text { L. }
$$

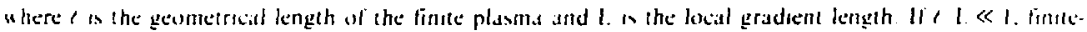

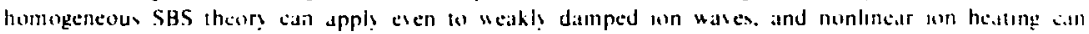

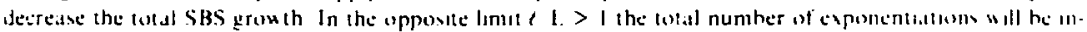

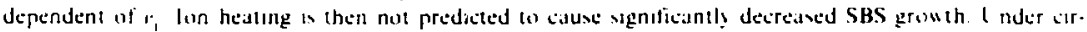

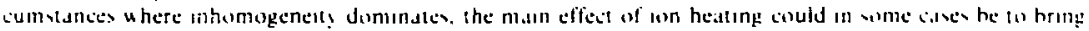
SBS doun wa th collise:nal threshold

\subsubsection{Fiffect of I.igh: Reflected from the ( ritical Surface}

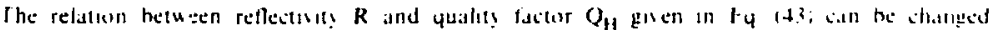

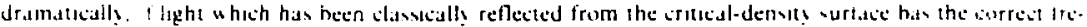

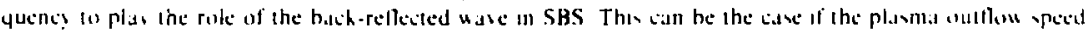

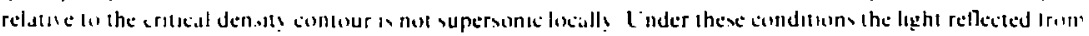

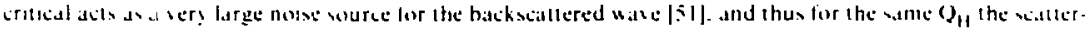

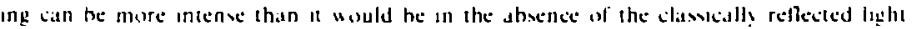

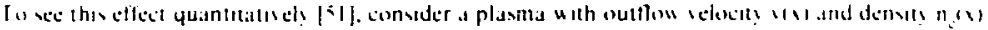

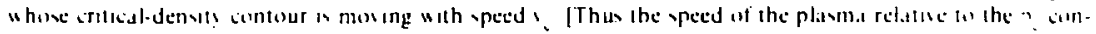

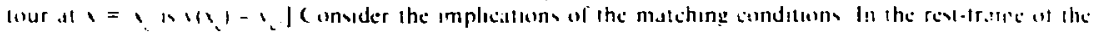

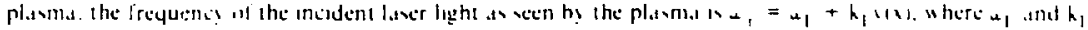

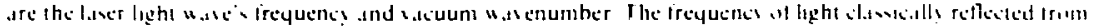

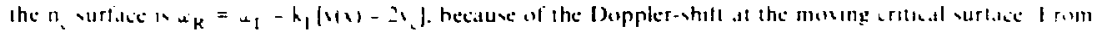

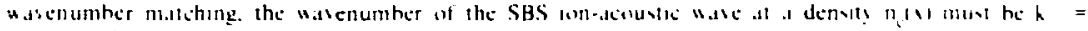

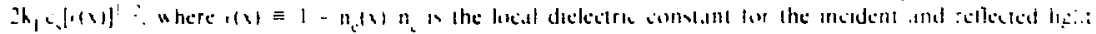

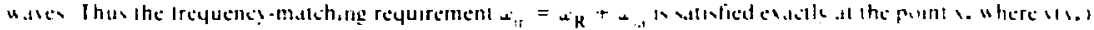

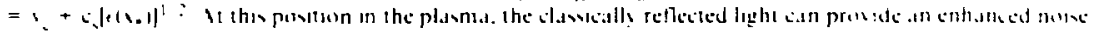

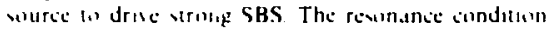

$$
\therefore\left(x-1-x=\left[\epsilon(x .1]^{12} \leq 1\right.\right.
$$

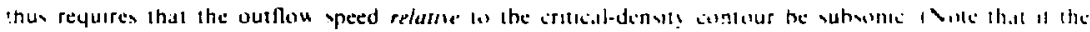

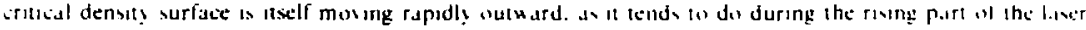

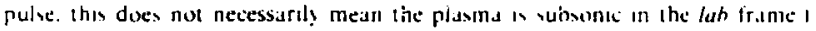

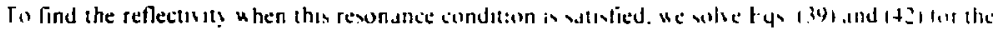

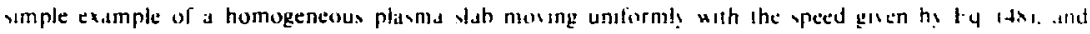

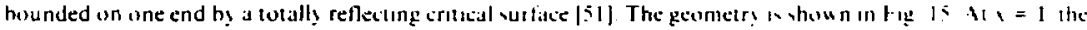

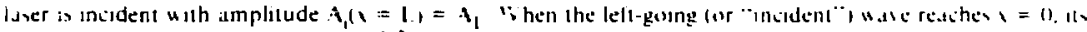

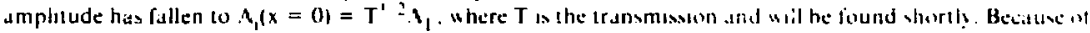

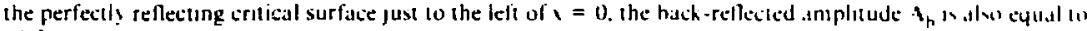
$T^{j}:_{1}$ at $=0$ 

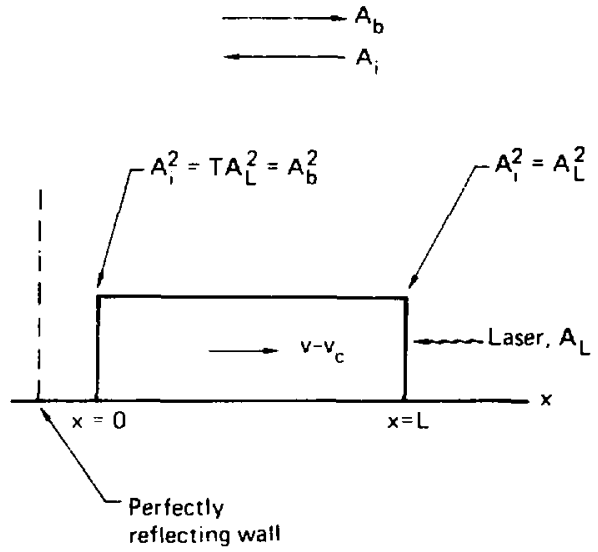

H IC. I5. Houndary condition for walculation of SBS including light rentected from critical surface |51|. The transmissient coefficient is I. I lec out uart speed of the uniform plasma relative to the critical density contuint ins. '...

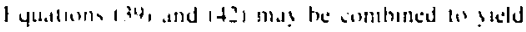

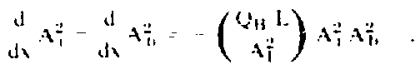

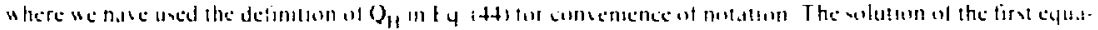

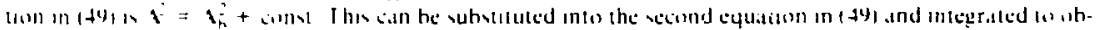
$1.1+11$

$$
r=\frac{1}{1+v_{11}}
$$

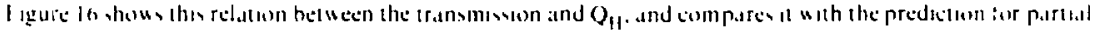

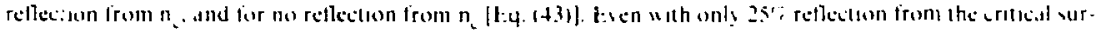

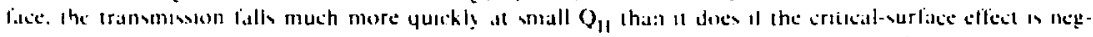

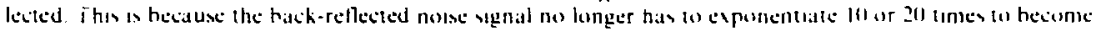

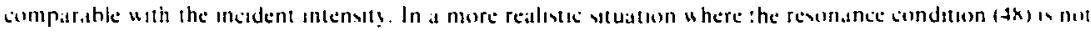

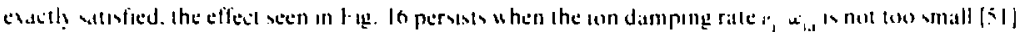

There art several yuestions about SBS with light reflecled from n. which will need to he addresed

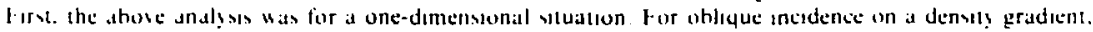

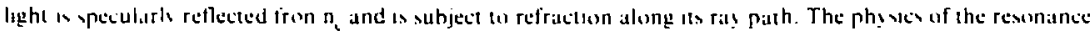

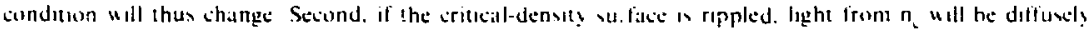

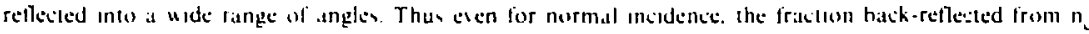

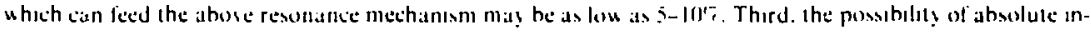

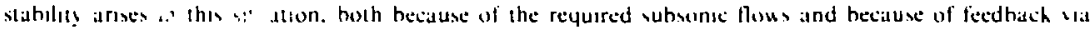




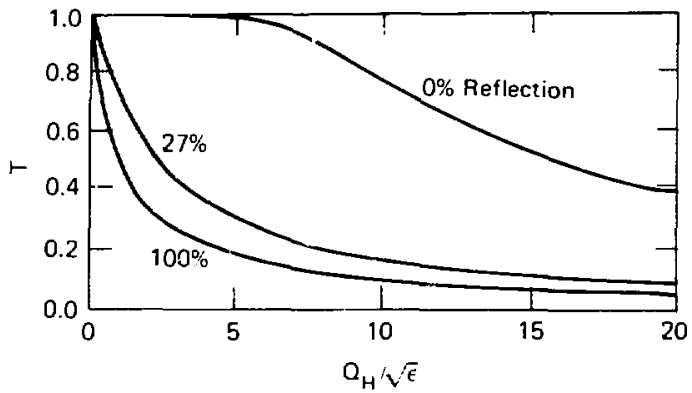

FIC: 16. SBS transmission coefficient |51| T. sersus quality factor $Q_{11} \mid$ F.4. $\left(H+H_{1} \mid\right.$. The curve labeled "Or' reflection" represent: SBS which grous onls from thermal noise, with noise level $I_{2} \cdot I_{f}=10^{-4}$. The other tho curves shon SBS transmission coefficients including the effect of light reflectec from the eritical surface, with reflection fractions from the critical surface of $27 \%$ and $1010 r_{r}$, respectively. The curs (abeled "1001\%" is given by F.4. (5) I. All three of these curves are for exact resonance. F.q. $1+8)$.

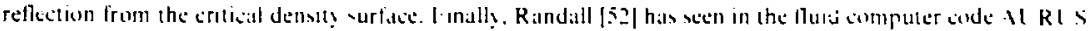

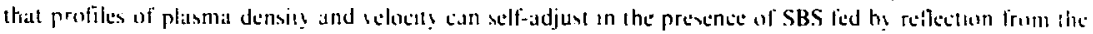

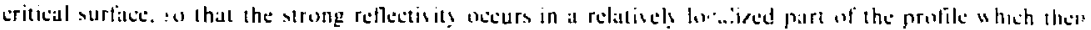

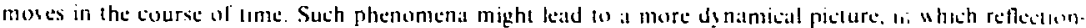
driven SBS oceurs in different parts of the underdense plasmal at diflerent times in the laser pule. a dhe profiles sell-adjust wo the vattering.

\subsubsection{Competition Between SBS and Inserse Bremsitrahlung thorotion}

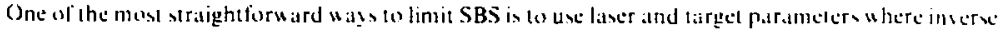
Bremsstrahlung is strong When absurplion is rapid enough. the dotancs oser w hich SBS call grew wh linuted to a fer times the absorption length for inserst Bremsstrahlung. $a_{1}^{-1}$. Thu if the grouth length for SBS 1

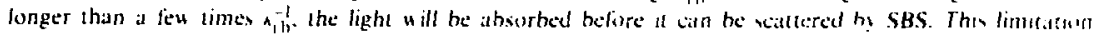
mechanism is particularly effectise for short-natelength lasers, where Llassicil absorptun lends la be large.

In it uniform plasma, the outcome of the competition hetueen SBS and invere Bremestratulung is

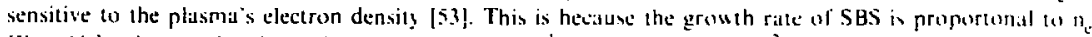

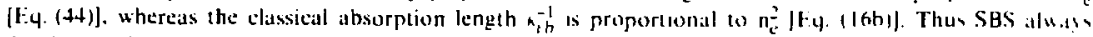
dominates if the density is lou enough. and absorptiun wills if the densily is high enough.

However in a laser-produced plasma with a gradient in densil from $n_{c}=0$ a $n_{c}=n_{c}$. the mas be-

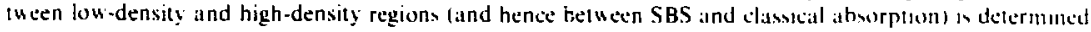
by the characteristics of the profile. We can illustrate this effet by tbe following ample edample fist]. (in)uder srong orverse Bremsstrahlung in a spherical expansion with densily profilet

$$
n_{c}(r)=n_{c} \cdot\left(\frac{r_{0}}{T}\right)^{\beta}, \beta>1 .
$$


and with constant coronal temperature. In the absence of Brillouin scaltering. the radius $r_{1 h}$ al which imisre

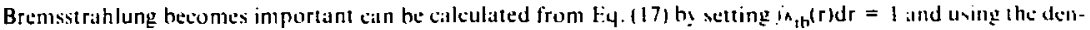
sits profile (51). Then in the presence of SBS, we ciun roughly parametrise the Brilloun reflectus! b! an andugue of the guality lactor $Q_{11}$ discussed in Section 3.1.2 ahose:

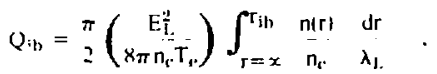

which is the number of SBS gain lengths in onc absorplion lenglh.

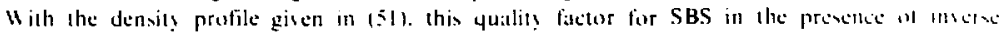
Bremsstrahiung scallsis as

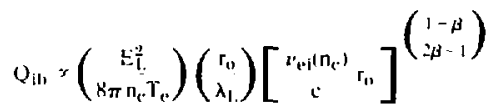

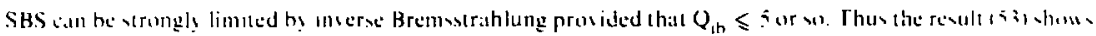

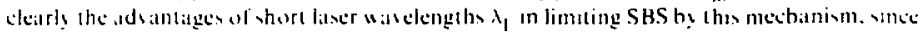

$$
0_{14} \times \lambda_{1}\left(\begin{array}{c}
+3-1 \\
2 \beta-3
\end{array}\right) .
$$

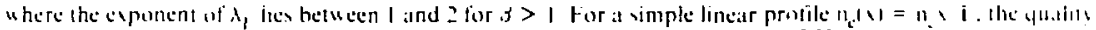

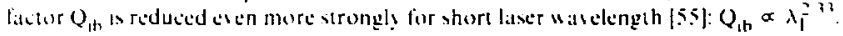

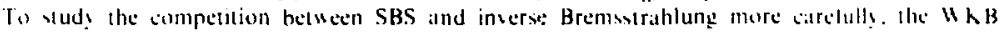

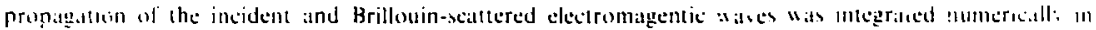

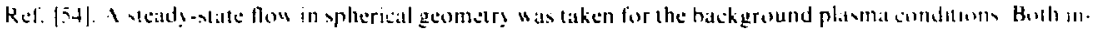

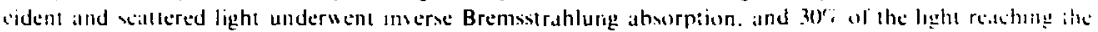

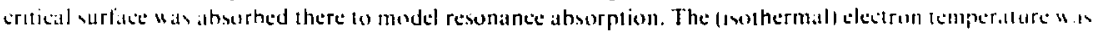

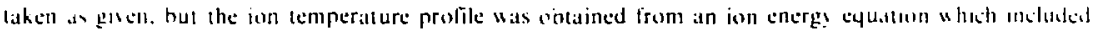

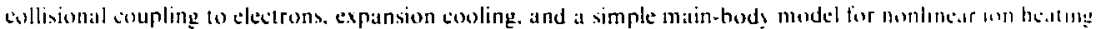
due (o) SBS [Ho]. A representatise result cian be illustrated hy uving the conditions dextribed in I lat. $1^{-}$. whech

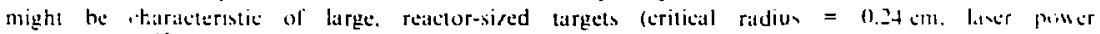
$P_{1}=1+5 \times 10^{12} 11 . T_{t}=1.5 \mathrm{keV}$ in the coronal.

The resulting steady-state ahsorption and Brillouin backscatlering are sboun in Fig. I $\mathrm{x}$ for thres dit. ferent laxer wavelengths: $\lambda_{1}=0.3 \mu \mathrm{m}$. $0.5 \mu \mathrm{m}$. and $1.0 \mu \mathrm{m}$. If there were no SBS or invere Bremustrohlung:.

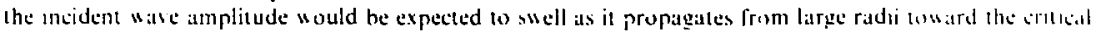
radius $r_{2}=1124 \mathrm{~cm}$. both due to spherical convergence $\left(r^{2} E^{2}=\right.$ canst.) and due 6 the decrease an the arubp

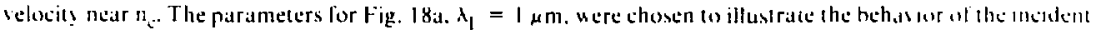
and Brilkuin-scallered waves when there is no SBS stabilization by inverie Bremmtrahlung. Ths nothur.t swelling described atove is completely overcome by strone SBS at low densitice. As the incident wate approilches $r_{\text {g }}$ its amplitude does increase somewhat. but betause the wave has alread heen depleced hi SBS onls $f^{\prime \prime}$, of the laser light energy is ahsorbed.

rigures $18 b$ and 180 shom the stabilization of SBS that occurs at shorter laser Matclengthe. For $\lambda_{1}=0.5 \mu \mathrm{m}$ (1-ig. 18h). one is just entering the regime where inverse Bremsstrabiung becomes vignalicant There is still sume SBS which depletes the incident beam al lou density, hut inserse Bremsulrahlung is vulficiently strong as the wave approaches $n_{6}$ that the total absorption has risen to 25\%"

At the shortest laser wavelength $\lambda_{t}=0.3 \mu \mathrm{m}$ (Fig. 18c). inverse Bremsstrahlung stabilization M ver? strong. The low level of SBS allows the incident wave to swell freely as it propagates lou ard smaller radir. Al 


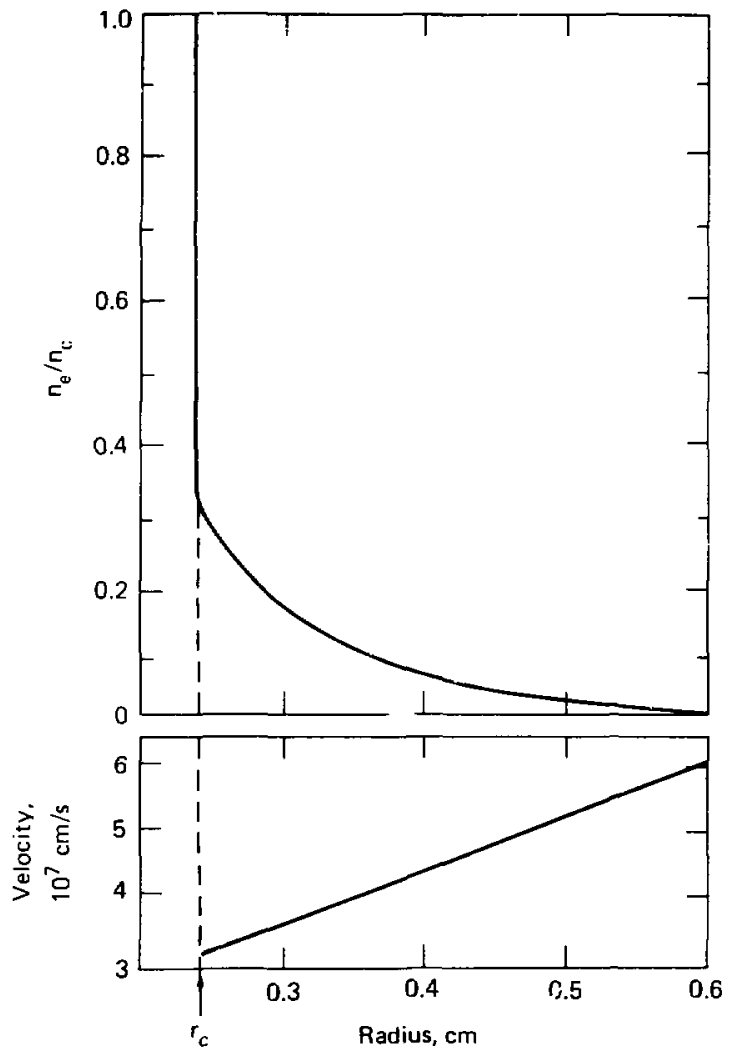

HI(;. 17. Densit? and velocit? profites used for numerical study [54] of SBS. including effects of inverse Bremsstrahlung absorption. Spherical target of critical radius $r_{c}=11.24 \mathrm{~cm}$ was irradiated nith laser power $P_{1}$.

$=1.45 \times 10^{14} \mathrm{~W}$. (Coronal electron tempcrature nas $1.5 \mathrm{kel}$

high denvities imserse Bremsitrahiung is sufficiently poten! to overcome the swelling and attually deplete the

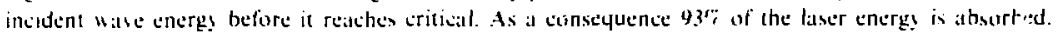

Ths !s pe of numerical work contirns the potential importanee af inverse Bremsstrahlung for the Gabilisalion of Brilluuin all laser wavelengths less than one micron.

The results of the abose discussion of SBS physics lead to the follow ing overall conclusions. As of the present ume. there seem to be seseral ways to reduce Brillouin scittering:

- Ion Harchreaking. At the highest laser intensities and longest laser wat clengths, ion watebreaking or trapping can limit the iol.- wave amplitude to :0-20\%. However if the length of the underdense plasniat is ieveral hundred vacuum wavelengths or more. SBS can be large nevertheless. 

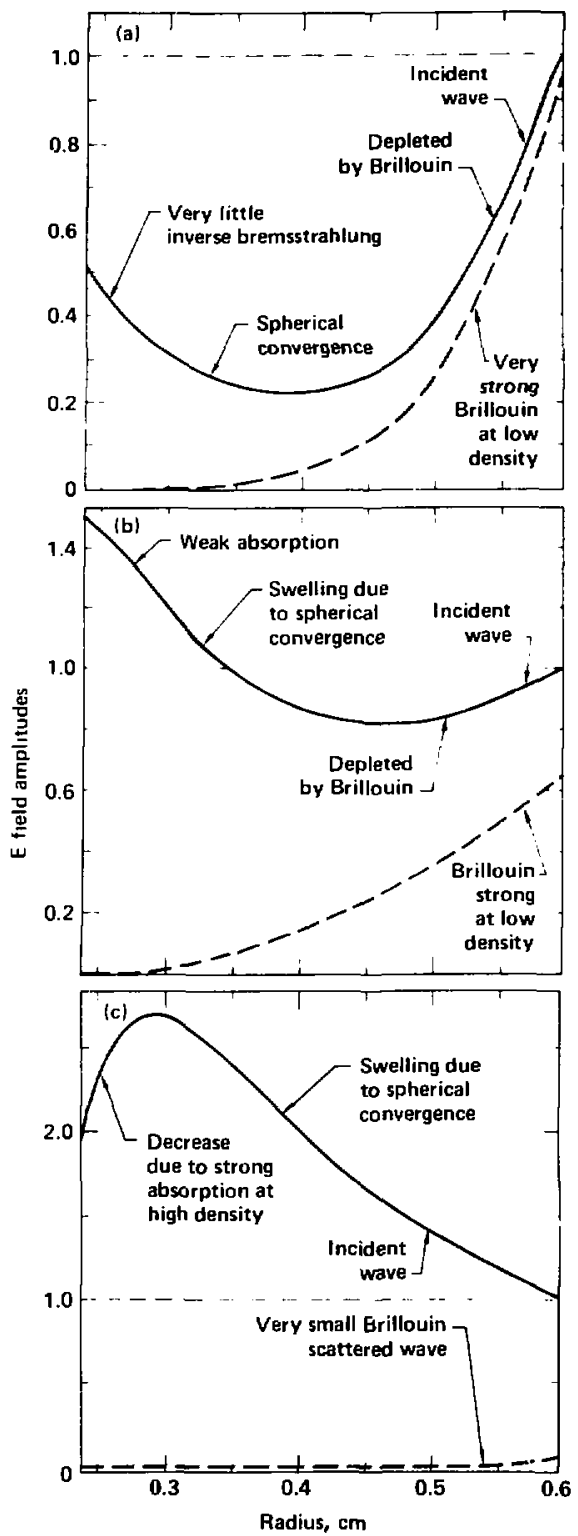

FIG. 18. Electric fieid profiles for incident isolid line) and backscatterad (dashed line) light waves. including eífects of SBS and inverse Bremsstrahlung absorption [54]. Plasma conditions are described in Fig. 17. Profiles are shown for laser wavelengths a) $\lambda_{\mathrm{L}}=1.0 \mu \mathrm{m}$ (4\% absorption). b) $\lambda_{\mathrm{L}}=0.5 \mu \mathrm{m}$ (25\% absorption). and c) $\lambda_{L}=0.3 \mu \mathrm{m}$ (93\% ahsorption). SBS decreases as the laser wavelength becomes shorter. 
- Vonlinear ton Heating. This is most important for laser intensities and wavelengths just below the wastbreaking linit. By raising the damping rate of the ion wave. ion tail heating tan decrease the total SBS gain in a nearly uniform plasma. The effect is weaker in a plasma with strong gradients.

- Inverse Bremsstrahlung. In the complementary regime of shorter laser wavelengths and fower laker intensities. strong inserse Bremsistrahlung absorption can limit the grewth distance for SBS. In this calse the geometrieal length I. used to find the SBS exponentiation is replaced by the (shorter) absorption length l.shis.

The follow ing two additional stabilization mechanisms have not been discussed in the present report. but they are thoroughly described in Refs. [56] and [57]:

- Broad laser Bandwidth. If ine spectral w idth of the laser light is larger than the eflective SBS gain width. the SBS grouth can he significantly decrealsed.

- Irregularities in the Backgromel Plasma. For reactor-sized targets SBS is predicted to he large not

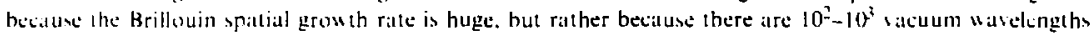
witilahle w grom in. I nder these conditions a process which destroys the coherence of the incident, bilckstatlered. and con-acoustic wases can thus diminish the convective amplification considerably. replacing the gcumetricid length ivalable for growth hy the (shorter) coherence length. it can ilso raise the instiabilis! thresholds ilcourdingly.

\subsection{STIMI IATFE RAMAN SCATTERING AND TWO-PIASUON DECAY INSTABILITY}

In stimulated Raman seatlering [38.40.48,54,58,59]. the incident laser light wate decalss into an electron plama uscillation and a scatlered electromag atic wave. Since the frequency of the plasma wase (pu) is

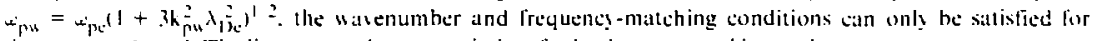
denstas $n_{e}<n_{i}+$. The linear grouth rate maximises lor backseatler, and is equal to

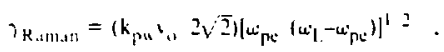

Wherc: $v_{11} \equiv \mathrm{CH}_{1} \mathrm{~m}_{\mathrm{z} \mathrm{u}_{1}}$.

W the yuarler-critical surface $n_{e}=n_{e}$. a second process called the two-plasmon decily instat vilits

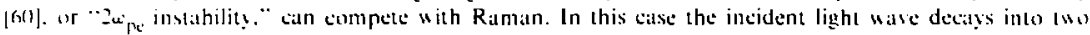

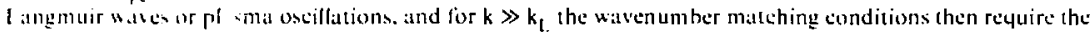
1 angmuir walles to propagale almost opposile each other al angles near $45^{\circ}$ to the incident $k_{1}$, of the later. When $k=k_{1}$. landau damping causes the $k$ s of the two plasma wases to hecome unequal and shifts their relative angles atal from $45^{\circ}$. This is the case for conditions appropriate le many laser fusion targets. The

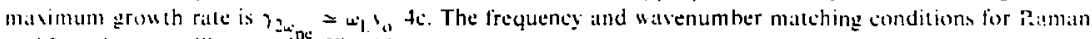

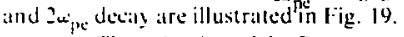

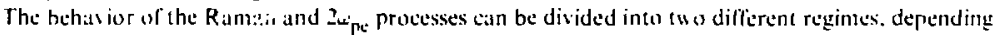
"Ill the bille of the locil density $n_{e} n_{e}$. In the region near one-yuarter of the critical densit!. $0.2<n_{c} n_{c} \leqslant 0.25$. Ramian and $2_{u^{\prime}}$ oecur together. Raman backstalter in particular is an absolute in-

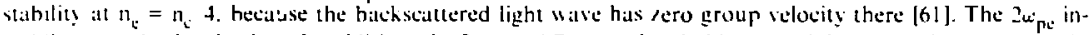
stabilats can alsos he absolute. In addition. the zupe and Raman thresholds due wo inhomogeneit? are relativels low $\mid 50]$ neis $n_{6} .4$.

As a conseyuente of the low threshold and absolute nature of the instabilistes, the nonlineatr

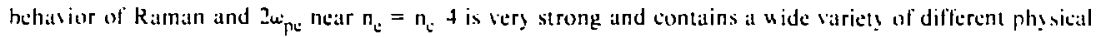
processes. Particle-in-cell computer simulations al high laser intensity [62] shou that in this regime the instability seems to uperale in bursts. The rough chronology is as follows [6?]: If one hegins w ith a relativedy gentle densit! gradient near $n_{s}$ t. the Raman and $2 u_{\Gamma e}$ instabilities are mixed logether and grow rapidly from noise. When thes reach large amplitude, the punderomotive toree $\left(E^{2} 8 \pi\right)$ due 10 all the different plasma wates is strong enough to drive large ion density fluctuations. At the same time a heated electron tatil is generated [4X]. In Ref. [62] the instahilities were damped primarily hy the strong ion density louctuations. 


$$
\left.\begin{array}{l}
\vec{k}_{L}=\vec{k}_{R}+\vec{k}_{p w} \\
\omega_{L}=\omega_{R}+\omega_{p w}
\end{array}\right\} \begin{aligned}
& \omega_{p w}=\omega_{p}\left(1+3 k_{p w}^{2} \lambda_{D e}^{2}\right)^{1 \cdot 2} \\
& \left|k_{R, L}\right|=\frac{\omega_{R, L}}{c}\left(1-\frac{n_{e}}{n_{c}}\right)^{1 / 2}
\end{aligned}
$$

Two-Plasmion Decay

$$
\left.\begin{array}{l}
\vec{k}_{L}=\vec{k}_{p_{1}}+\vec{k}_{p_{2}} \\
\omega_{L}=\omega_{p_{1}}+\omega_{p_{2}}
\end{array}\right\} \begin{aligned}
& k_{L}=\frac{\omega_{L}}{c}\left(1-\frac{n_{e}}{n_{c}}\right)^{1: 2}=\frac{\sqrt{3}}{2} \frac{\omega_{L}}{c} \\
& \omega_{p_{1}, p_{2}}=\omega_{p}\left(1+3 k_{p_{1}, p_{2}}^{2} \lambda_{D_{e}}^{2}\right)^{1 / 2}
\end{aligned}
$$

FIC; 19. Wavenumber and frequency matching conditions for the Raman and two-plasmon decay instabilities.

which locilly steepened the profile sufficiently to push the instabilities helow their inhomogeneits thresholds. Higure 20 illustrates the steepened profile.

Once the profite is steepened and the hot electrons are generated, the instabilities can mo longer cuntinue to gros. The ion waves and hot electrons gradually dissipate. the profilt relaxes. and condtions are arppropriate for at second hurst of instahility growtb.

Relerence [63] discusses another nonlinear mechanisn for the $2 u_{\mathrm{po}}$ instabilit! at n. A. uhich hav not heen observed in computer simulations at high or moderale laser intensitics.

Healed electrons from the instabilities at $n_{\mathrm{o}} / 4$ are a major preheal concern. For a high-inlemsil?. steep-profile irradiation sush as that of Ref. [62]. the lime-averaged fration of the litser light energe in the heated elactron tail is <lor: the temperature of these tail electrons can be quite high: $T_{h}=75 \mathrm{kel}$ tor at plasma with background temperalure of $10 \mathrm{keV}$ and an incident laser intensily of $10^{16} \mathrm{~W} \mathrm{em}^{2}, \lambda_{\mathrm{I}}=1.06 \mu \mathrm{m}$ [62]. Future targets. such as those intended for eventual reactor lasers, are expecled to have underdenas plasmas that have longer spatial extents in the nejghborhood of $n_{c}: 4$. Under these circunstances. the instabilities at $n_{i}+$ are capable of putting as much as $30-40 \%$ of the laser energy into hot-clectron laals. These tails can be extremely hot: for example. Ref. $[6-4]$ found $T_{h}=110 \mathrm{keV}$ for $\mathrm{I}_{\mathrm{L}}=3 \times 10^{15} \mathrm{~W}: \mathrm{cm}^{2}, \lambda_{\mathrm{l}}=1.0 \mathrm{k}$ $\mu \mathrm{m}, T_{\mathrm{t}}=3 \mathrm{keV}=3 r_{\mathrm{i}}$. for a nat plasma slab 21 vacuum wavelengths long at $n_{\mathrm{e}}=0.23 \mathrm{n}_{\mathrm{c}}$.

The second interesting regime for Raman scattering [64] occurs at intermediate densities whore $n_{e}<0.2 n_{e}$ but $n_{\mathrm{e}}$ is not so small that the plasma wave is heavily damped. (Strong damping takes place when $k_{p u} \lambda_{D_{e}}>1$ 3.) In this intermediate-dersity regime the $2 w_{p e c}$ processes cannot occur, and Raman is convective except for exact sidescatter [65]. Thus Ramas is less violent than it is near $n_{a}=n_{a}: 4$. In addition the intensity threshold due to inhomogeneity is higher than it is at the quarter-critucul surface.

In this regime the nonlinear behavior is less complex, and computer simulations at high laster intensity indicate [64] that self-consistent electron tail heating can limit Raman sculter. The argument is quite analogous to that described earlier for ion tail heating in Brillouin scattering. Figure 2! shows i typical healed electron distribution. which has a nearly Maxwellian tail of hot electrons with characteristic tenperature 


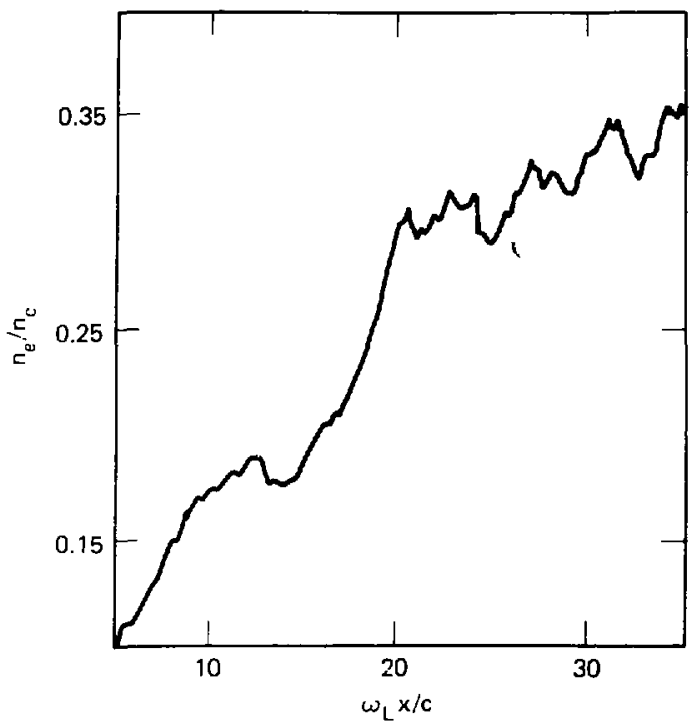

Flíi. 20. Steepened electron density profile near the quarter-critical density surface, due to the tro-plasmon decay and Raman instabilities [62]. Computer simulation parameters are $t_{0} / c=0.1$, initial $T_{t}=1$ ker. $. \mathrm{I}_{\mathrm{i}} / \mathrm{m}_{\mathrm{c}}=100, Z / \mathrm{T}_{\mathrm{e}} / \mathrm{T}_{\mathrm{i}}=1$.

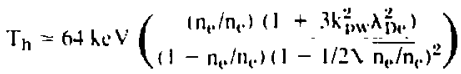

$$
\begin{aligned}
& \mathrm{n}_{\mathrm{e}}<<\mathrm{n}_{\mathrm{c}}, \mathrm{k}_{\mathrm{puw}} \cdot \lambda_{1 \mathrm{x}}<\frac{1}{3}
\end{aligned}
$$

The heated electron temperalure is appropriate to provide damping for the electron plasma wave.

The consequences of electron tuil heating in Raman [65] are similar to those of ion tail heating in Brillouin. For a homogeneous medium. the Raman quality lactor (analogous to Eq. (44) for SBS) is

$$
Q_{H} \simeq\left(\frac{k_{p w^{2} L}^{2}}{8 k_{R}}\right)\left(\frac{e E_{1}}{m_{e^{2} \omega_{L}}}\right)^{2}\left(\frac{\nu_{p w}}{\omega_{p e}}\right)^{-1}
$$

where $k_{p u}$ and $\nu_{p u}$ are the wavenumber and damping rate of the plasma wave. In a homogeneous medium the heated electrons decrease $Q_{H}$ by increasing the plasma wave damping "pa. Then hy the Raman analogues of Eq. (43) and Fig. 13, the reflectivity $R$ is decreased as well. A consequence of the lower reflectivity is a populiation of hot electrons with $50 \mathrm{keV}<T_{h} \leqslant 100 \mathrm{keV}$. For a strongly inhomogeneous medium well above the 


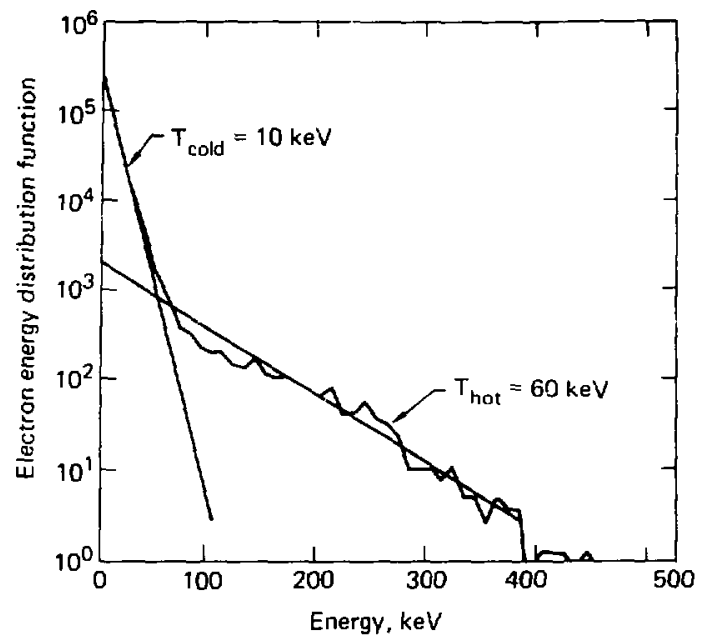

Fic;. 21. Electron distribution function produced br Raman seattering. from computer simulation by $K$. Estabrook. The healed electron tail is evident. This 1-D simulation used an incident laser intensity of $1016 \mathrm{~W} / \mathrm{cm}^{2}, \lambda_{1}=1 .\left(16 \mu \mathrm{m}\right.$, initial $T_{\mathrm{s}}=10 \mathrm{keV}$, and density profilu rising from $n_{\mathrm{e}}=\mathbf{1}$ to $\mathrm{n}_{\mathrm{c}}=0.41 \mathrm{n}_{\mathrm{s}}$ in a distance of $70 \lambda_{\mathrm{l}}$.

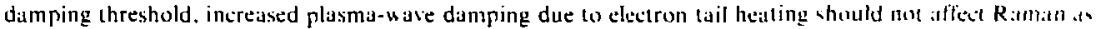
strongly [49]. This is analogous to the result for SBS.

As was the case with SBS. Raman sealter may additionally be limited hy instre Bremntrithlung ah. sorption or broid liaser bandwidth. We discuss these in turn.

The absolute instabilities at $n_{c}=n_{c} 4$ occur over a very narros rallye of densto. Thus the mam way by which inverse Bremsstrahlung could affect them is by diminishing the laser intensity that actuall? reisher the $n_{c}+$ surface. If the local intensity is diminished enough. Raman and 2upe could be purhed belou threshold. Numerically this process is not importunt until [64.65] the laser willelength iv at frattull of . micron. or else until the laser intensity is $\leqslant 10^{13} \mathrm{w}^{\prime} \mathrm{cm}^{2}$.

The physies of inverse Bremsstrahlung stabilisation of Raman is somewhat dillerent in the cumcs: tive regime $n_{e}<0.2 n_{c}$. The process has not yet been examined in detail. But becituse inverse Brom watrahlung falls ofl at lou densities as $\left(n_{\mathrm{e}} / \mathrm{n}_{\mathrm{c}}\right)^{2}$. it seems numerically more difficul to find a situation where cmugh light could be classically absorbed in the very underdense plasma to seriously affect Ranan saitering there. In the

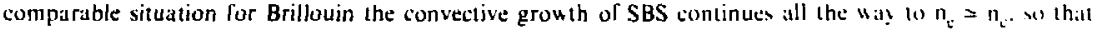

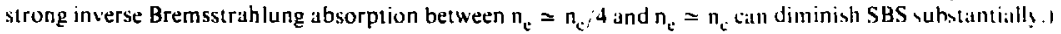

As was the case with SBS. broad laser bandwidth may also reduce the grow th of Ramian watlering

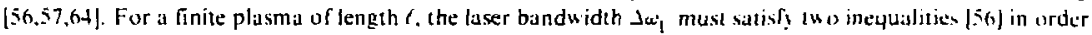
to decrease Raman growth:

$$
\frac{\Delta \omega_{\mathrm{L}}}{\omega_{\mathrm{L}}}>\frac{\gamma_{\mathrm{0}}^{2}}{\omega_{\mathrm{L}}^{2}}\left\{\begin{array}{l}
\omega_{\mathrm{L}} / / \mathrm{c} \\
\omega_{\mathrm{L}} / \nu_{\mathrm{pw}}
\end{array}\right.
$$


Here $d_{p}$ is the plasma wave dimping rate and $\gamma_{0}$ is the Raman temporal growth rate. Typically the se inequalitis mean that the minimum required bandwidth to stabilize Raman is larger than that for SBS. Computer simulations [65] indicate that such wide-bandwidth or muhiline lasers can effectively reduce Raman sciatler in some parameter regimes, particularly for laser intensities less than a factor of 10 above threshold.

Competition between Raman sidescatter and backscatter was assessed in Ref. [66], for $n_{\mathrm{e}}<n_{\mathrm{s}} 4$. Recent experinents at the Lawrence Livermore National Laboratory indicate that Raman sidestatter ean be significant.

\subsection{FIL.AIFNTATION AND SELF-FOCUSING}

Filamentalion and seif-fotusing refer to the process by which an intensity modulation initially present on the laser beam can become more pronounced as the light propagates through the plasma toward the critical density surfice [38.67]. If the initial inlensity moduiation involves only a small part of the liser beam. the process is gentrally called filamentation. Self-focusing describes the mechanism when it involves the latgescale intensity proiile of the laser beam as a whole.

The physits of lilamentation or self-focusing at high laser intensity is illustraled schrmatically in F.je. 22. A region of initially higher $\mathrm{E}^{2} / 8 \pi$ pushes plasma aside because of its additional light pressure. The conseyuent lous plismat density $n_{e}$ increases the index of refraction of the plasma

$$
n=\frac{k_{1} c^{\prime}}{\omega_{l .}}=\left(1-\frac{n_{t^{2}}}{n_{\mathrm{L}^{\prime}}}\right)^{1 / 2}
$$

in the high-intensily region. thus bending the wave front as shown in Fig. 22. Sinec wate energs flus propagates perpendicular to the wave front, the curvature of the wave front products at focusing effect which increitses the light intensity still more.

This is an unstable process which onvectively amplifies any intensity inhomogeneity initially present on the laser bean. Since high-pouter laster beams are generally far from uniform (sec tig. 23). thes shoul. a principle proside ample initial inhomogeneities for the plasma to amplily.

Theoriss for the nonlinear consequences of litanentation fall into two contrasting sategories: 11 The litament lorms and is able to remain more or less intatet while it propagates to the eritical density surfatce. 2) The lilament is not able to retain its shape over substantial distances after it fornts. due to the disruplice slfects of stimulated suttering. diffraction, or fefration in the plasma. We will discuss these alternatis es in lurn. and try to indicils their consequences. $1:$ is not yet clear whth of the ano scenarios is more likel! w ocicur.

\subsubsection{Filaments Stay Infact and Propagate to the Critical Surface}

If this is the cilse. filamentation could have major implications for processes such ad electron heating and absorption at the eritical surfice. and for the structure of laser-produced de magnetic bields.

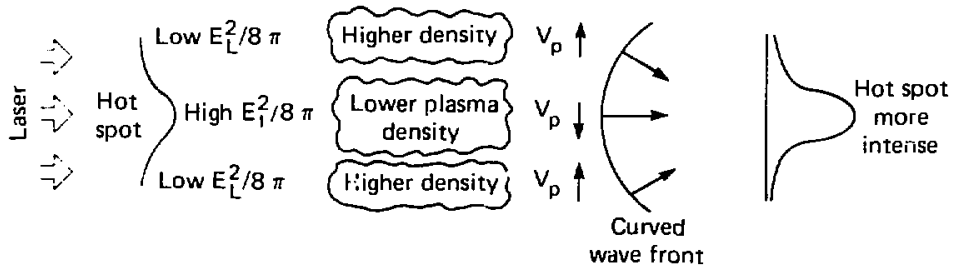

FIC: 22. Physical mechanism for filamentation driven by the ponderomotive force. 

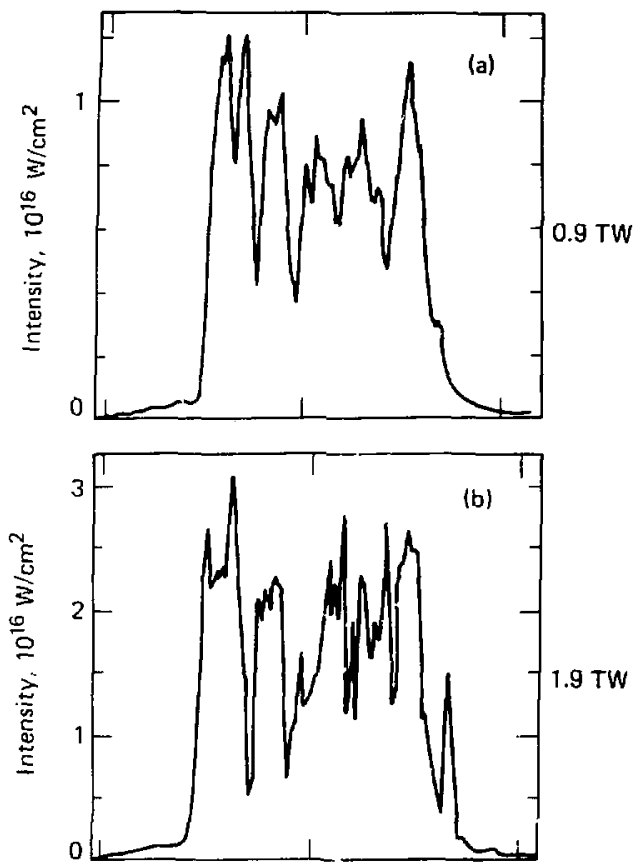

FIG. 23. Spatial profiles of the Argus laser focal spot at three different incident laser powers $\left(1 \mathrm{TW}=10^{12} \mathrm{~W}\right)$. These sians, taken at the Lawrance Livermore National Laboratory in 1977, show substantial spatial 1.9 TW modulation at terawatt laser powers. In the years since 1977, beam relaying techniques developed by J. Hunt and colleagues have resulted in considerably better beam homogeneity. (Data shown here are from $W$. Simmons, D. R. Speck, and J. Hunt.)

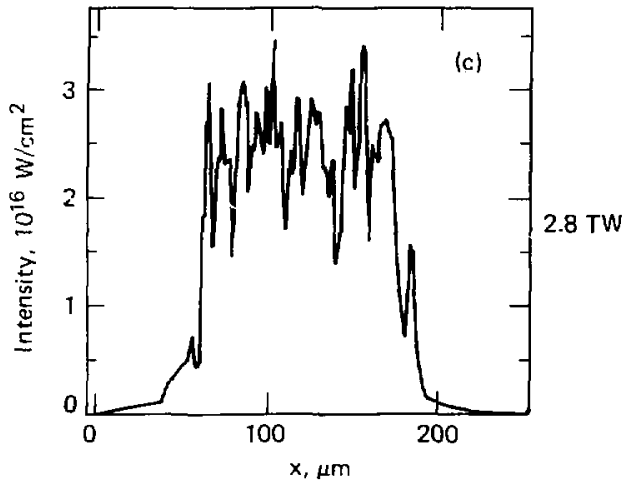


Kruer has recently proposed a sample model for host-clectron generation in a filantent that redches $n_{\text {, }}$

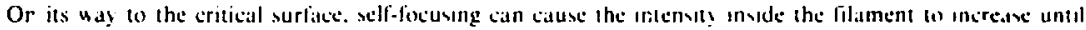

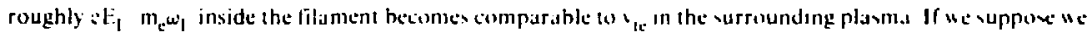

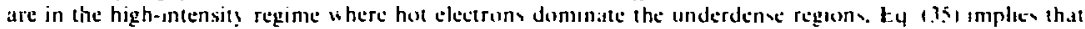

$$
\left(10^{15} \frac{\mathrm{I}_{\mathrm{L}}}{\mathrm{W} / \mathrm{cm}^{\overline{2}}}\right)\left(\frac{\lambda_{\mathrm{l}}}{1.06 \mu \mathrm{m}}\right)^{2}=2.2\left(\begin{array}{c}
\mathrm{T}_{\mathrm{h}} \\
1 \mathrm{kel}
\end{array}\right)
$$

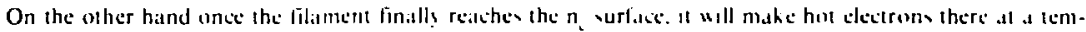

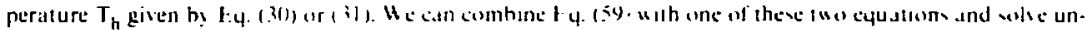

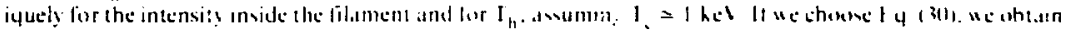

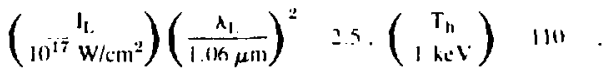

wherets 1:4. (3) yitds

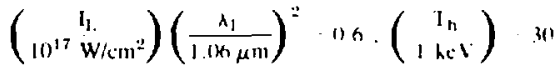

$(t h)$ h)

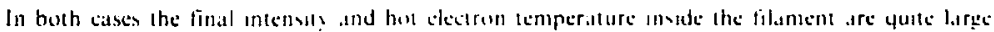

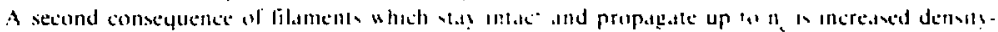

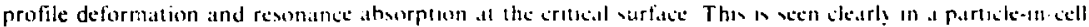

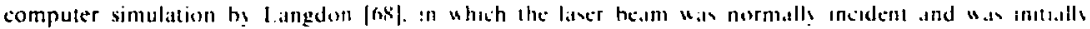
spatially modulated by a factor al t acrom the incident beam prolile. The litament whesh resuled trom the in-

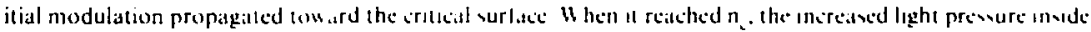

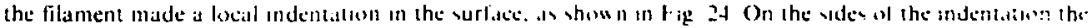

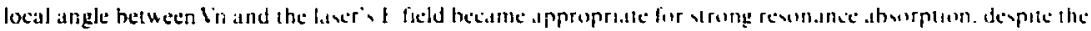

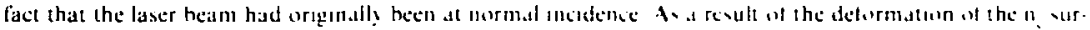

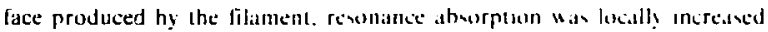

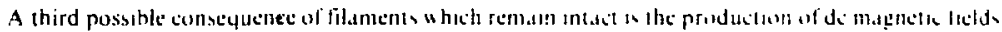

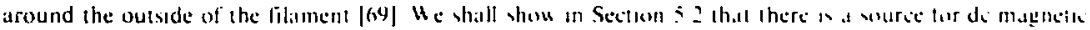

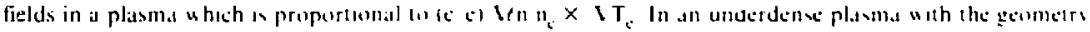

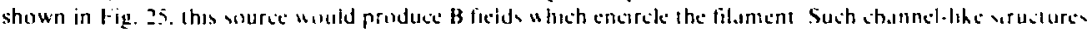

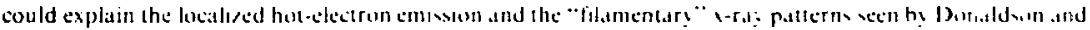

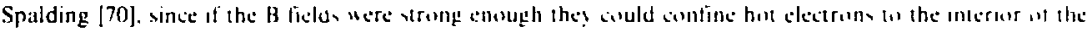

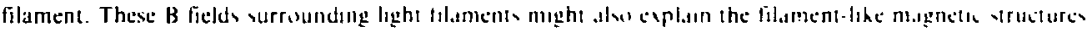

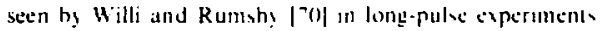

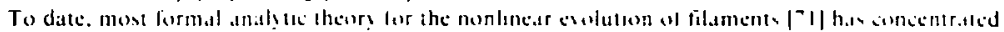

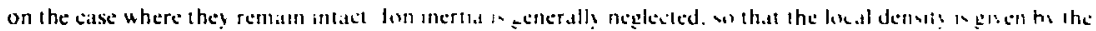
quasistatic relantion

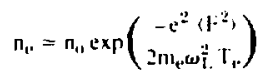

Inil

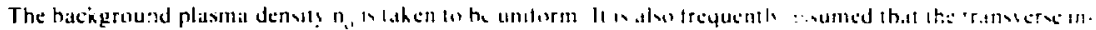

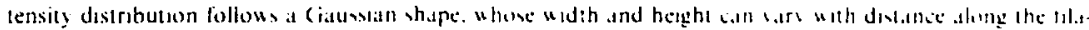
ment.

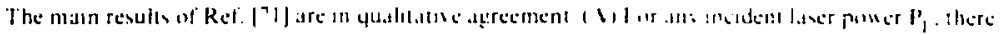

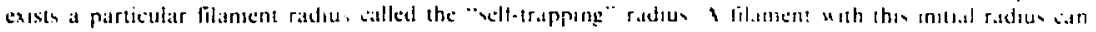

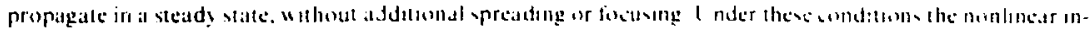

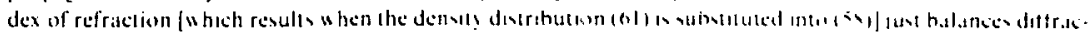

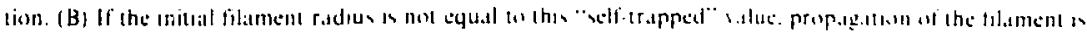




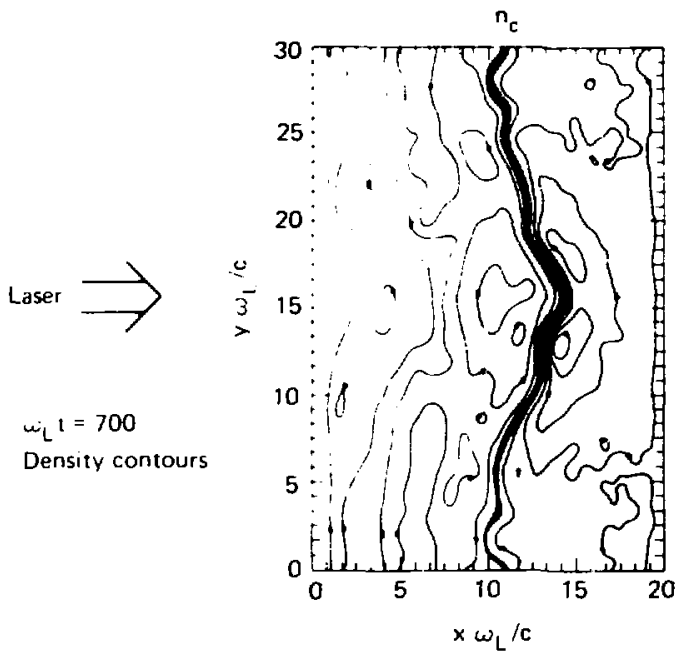

FIf. 24. Indentation of the critical-densily surface, caused by patial modulation of a factor of $t$ across the incident laser beam profile. This figure show s isodensity contours from a particle-in-cell compuler simulation hy $A$. B. I.angdon [6\$]. Simulation parameters neer $I_{t}=10^{16} \mathrm{~W} \mathrm{~cm}^{2}, \lambda_{1}=1.166 \mu \mathrm{m}$, initial $T_{e}=5 \mathrm{keV}, \mathrm{M}_{\mathrm{i}} / \mathrm{m}_{\mathrm{e}}=$ I(R). $I_{c}, T_{i}=3, w_{1} I=7($ M).

wallatury. a houn in f-le. Zh. The fil:ment begins to come to a strong focus due to the ponderomotive non-

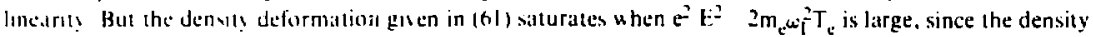

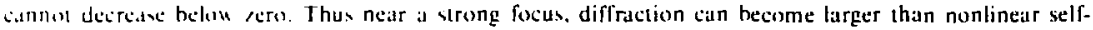
locusng. and the filancoul spredus out in radius again. If the filament is assumed to aluays maintain a neurly Gaunlin intenel! prolile. this prosess of inward focusing and outuard diffaction is predicted to repeat indetinusty

\subsection{2 filaments Fall tpart Before Thes Propagate Very Far}

The secind scenario for the nonlinear exolution of filaments implies that they cannot stably propagate ferr long distances in the plasma.

Thers are sereral possible reasons for lack of filament stability. Several years ago. Valen [72] showed that lilamenty in two dimensions san be unstable to bending perturbations, where an initially straight filament become kinked and distorted. The geometry is shou in Fig. 27a. If this kink or bending instability is found in persw in three dimensions with the full exponential density nonlinearity (61), it would be difficult for a filament w propugate for long distances.

When the background plasma density is above $n_{c}=n_{c}$ t. a quarter-critical density surface can be form: $\cdots$ un the walls of a filament, because of the ponderomotive density depression at the filament's center. When th. ociurs, langdon and Lasinski [73] showed in computer simulations that a vigorous form of the Ino-plasmon decal instability can producc electron acceleration inside the rilament. Figure $27 \mathrm{~b}$ shows the strongly modulated electrostatic potential which resslts from the $2 \omega_{p c}$ decay process inside the filament. The 


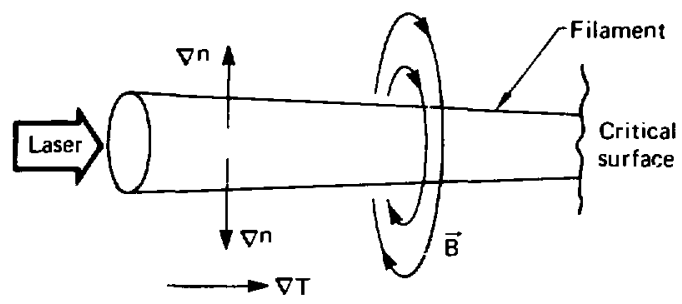

FIG. 25. Mechanism for production of $\mathrm{n}_{\mathbf{c}} \times \$ \mathrm{~T}_{\mathrm{t}}$ magnetic field surrounding a light filament [69].

tuo-plasmon decay and electron acceleration at as an energy drain on the light inside the lijament. thus depleting the internal high-intensity region.

More recently. nonlinear phenomena which accompany the "repeatted foci" show $n$ in rig. 26 have begun to be investigated. Lasinski and Langdon [74] have follused numericalls the evolution of a locusing filament w ithout making a Gaussian-shape hypothesis for the intensily distribution. The found that while the central part of the beam underwent the predicled repeited foci [71]. the outer part of the beam did not participate. Figure $27 \mathrm{c}$ shows that only the inner part of the beam remains to propagate intact in the manner of rig. 26.

In related work. Randall [74] has considered the enhantement in Brillouin backstaltte which ociturs u hen a filament begins to focus to high intensities. He finds for some experimental conditions that during the focusing process, much of the light in the filament can be Brillouin backscallered before the focus itself is reached. This is illustrated in Fig. $27 \mathrm{~d}$. Thus the work of Lasinski and Randall setems to impls that a "real" filanent would not be likely to survive more than one or two repeated foci. both due to SBS and due wo nonhomologous behavior of the exterior parts of the beam.

As the reader will have gathered from the above discussion, theories for the eventual fate of lilamenlation are not yel definitive. In particular, nonlinear phenomena oecurring near a strong focus halve only recently begun to be explored. It seems to me that this issue of the physies neitr strong lioci is crucial to understand, because only with very special initial conditions can a filament propegate in a "self-trapped" manner [7I] without beginning to focus.

For very low laser intensities and collisional plasmas, filamentation driven by the Joule heating nonlinearity can sometimes become competitive with the ponderomotive force-driven mechanism. This process is reviewed by Sodha et al. [71]. and was discussed in Ref. [75] for an applicalion to the earth's ionosphere.

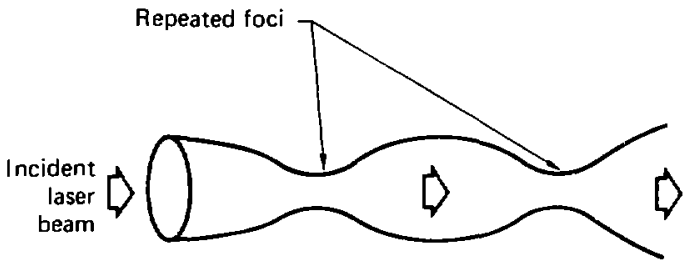

FIC. 26. Schematic picture of "repeated foci" predicted hy nonlinear theories of self-focusing $|7| \mid$. 

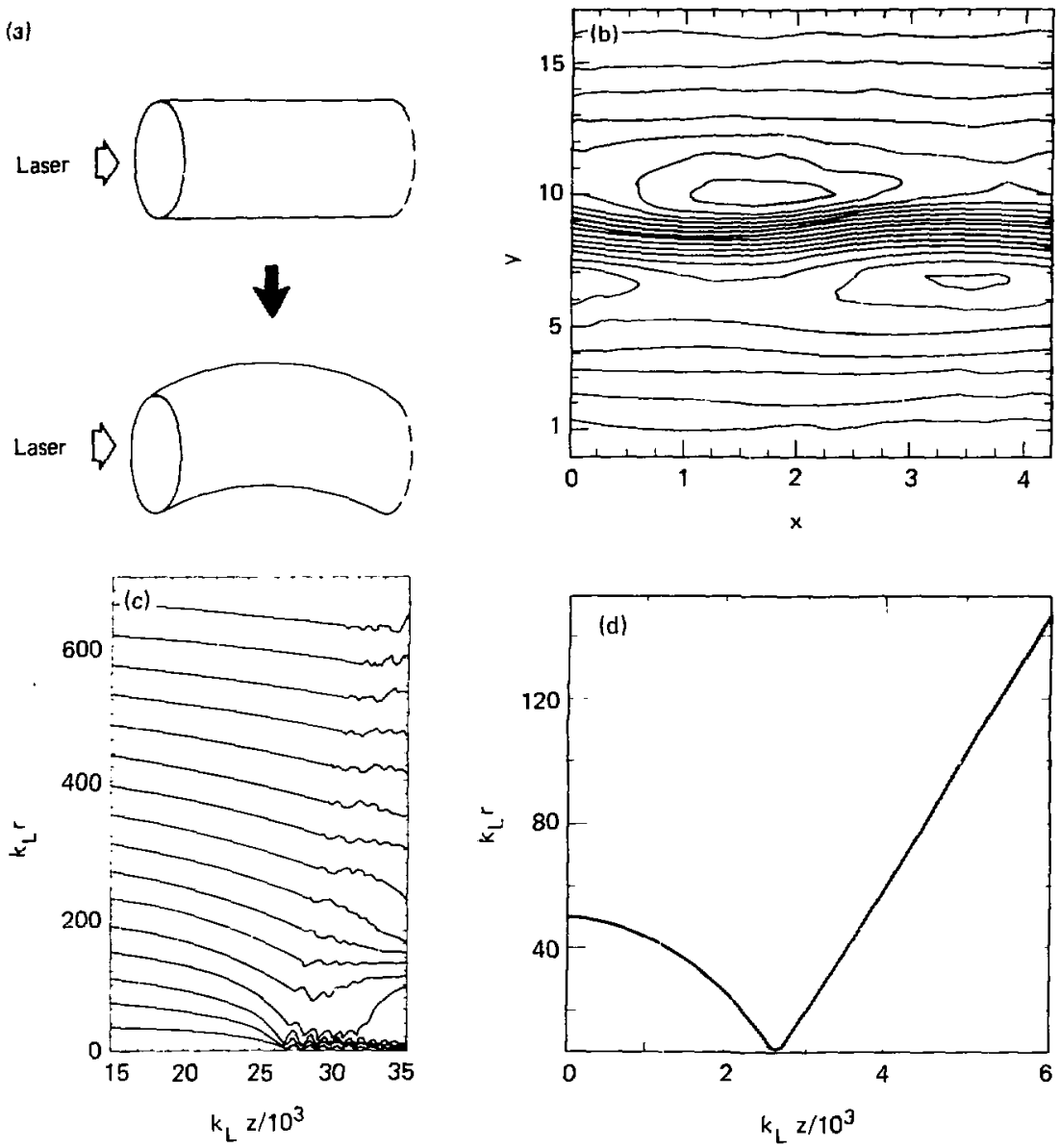

FIG. 27. Four ways in which the integrity of a light filament might be destroyed before it reaches the critical surface. In all four cases the laser beam is incident from the left, a) Bending instability [72]. b) Two-plasmon decay instability inside a filament $[73\}$. The figure shows contours of electrostatic potential $\varphi$. The modulation is due to the two daughter-wave plasmons produced by the decay instabijity. The units of distance are $2 c / \omega_{L}$. c) Lack of participation of the outer parts of the beam in the self-focusing process. from a calculation by Lasinski and Langdon [74]. These flux contours would have remained equally spaced if all of the initially Gaussian beain had self-focused together. d) Effect of Brillouin scatter near a nonlinear focus, from calculation by Randall [74]. The mean radius " $r$ " of the filament diverges indefinitely after the first focus, because strong SBS has depleted the beam intensity and hence weakened the self-focusing nonlinearity. 


\section{INHIBITION OF ELECTRON THERMAL CONDUCTION}

\subsection{INTRODUCTION AND BASIC CONCEPTS}

An essential feature of laser fusion targets is that laser energy absorbed in the corona must be effectively conducted tuward colder, high-density regions of the target. Figure 28 illustrates a typical temperature profile for a thick initially-5olid target. A large inward hewl flux from the critical surface towards high-densits regions means that newly heated material at the -urface of the cold dense target will expand out uard rapidl! . Then by conservation of momentum the cold remuinder of the tirget gets a bigger insard push due to the rocket effect. Figure 29 illustrates this process. Conversely. inhibiled heat flux leads to slower outuardexpansion of the blow-off. The inner parts of the target then implode less viporously.

When the mean fret path $\lambda_{\text {mip }}$ is small compared to the temperature gradient seale length $1_{-}$. the classical heat flux in a plasma can be written as

$$
\mathbf{q}=-\kappa \nabla \mathrm{T} \mathrm{ergs} / \mathrm{cm}^{2} \mathrm{~s} .
$$

where to order of mignitude

$$
\kappa \nabla T \simeq\left(\frac{\lambda_{m f v}}{L_{T}}\right)\left(n T v_{t}, v_{t} \equiv \sqrt{T / M}\right.
$$

If electrons and ions have equal temperalures and densities. the first two factors $\left(\lambda_{\text {mip }} L_{-T}\right)(n T)$ are the same for both species. However because the electron thermal speed $v_{\text {ic }}$ is larger than the ion thermal speed by the factor $\left.\left(M_{1} \prime^{\prime}\right)^{\prime}\right)^{\prime}$ it is the electron thermal conductivity which dominates in Eq. (63). Thus in a plasmat. II w the rundom walk of the electrons which curries heat from hot regions to cold regions.

Classical transport coefficients are calculated assuming the plasma is sufficient! collisional that $\lambda_{m i p} \ll L_{n} . L_{T}$, where $L_{n} \equiv n|d n ; d x|$ and $L_{T} \equiv T_{/}|d T, d x|$, and assuming that " ${ }_{\mathrm{c} 1} \gg$ at. Under these conditions the electron distribution function is locally Maxuellian. and the electron heil 1]ux is [10.19]

$$
\mathbf{q}_{e}=-\kappa \nabla \mathrm{T}_{\mathrm{e}} \mathrm{ergs} / \mathrm{cm}^{2} \mathrm{~s},
$$

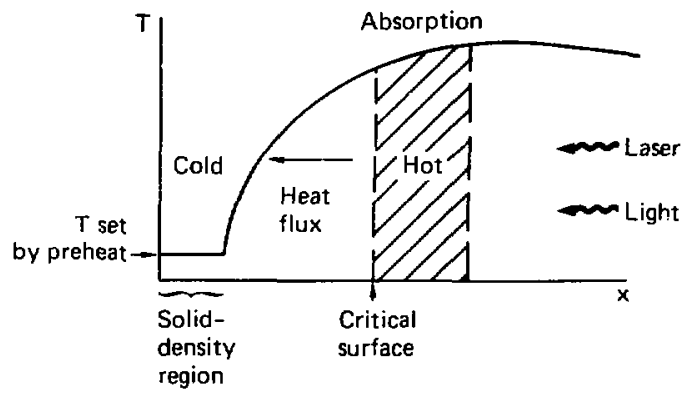

FIG. 28. Typical form of electron temperature profile in a laserheated initially solid target. The temperature is high in the corona where laser absorption occurs, and cold in the high-density regions. Thus an inward heat flux flows from $n_{e}=n_{c}$ toward higher densities. 


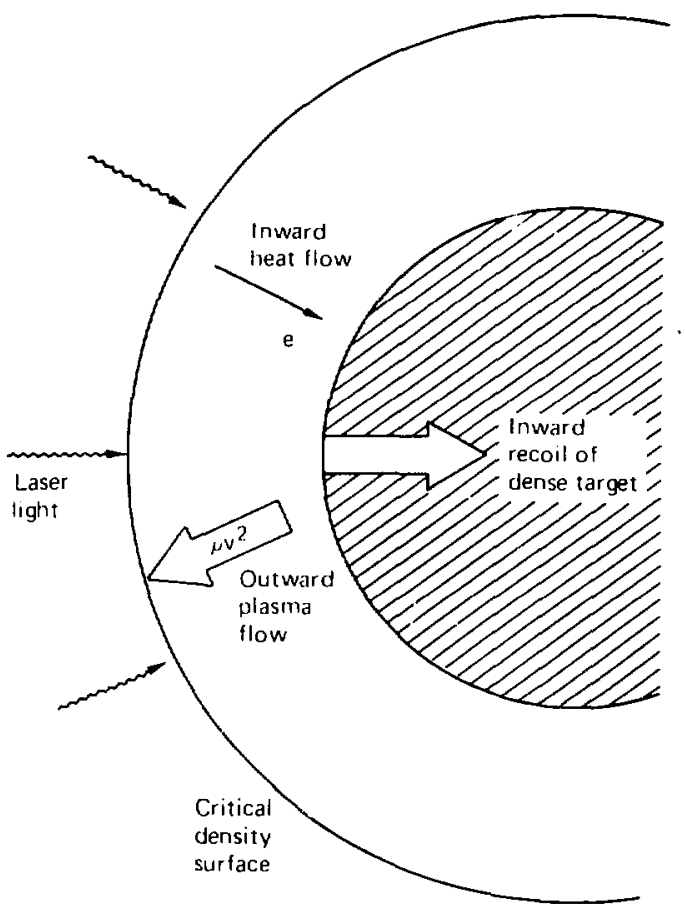

FIC. 29. Insard elettron heat flow produces an outhard now of newly heated plasma, in a spherically illuminated target. In the presince of this hot plasma outflor, the dense part of the target recoils inu ard to conserve momentum. The amount of insard heat flux plays a crucial role in determining the magnitude of the rocketlike recoil and implosion.

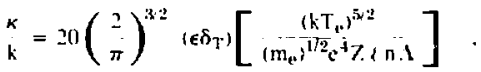

$$
\begin{aligned}
& \epsilon \delta_{T} \approx \frac{0.095(7+0.24)}{1+0.247} 110 \pm 10 \% 1
\end{aligned}
$$

The filctor in 1 is the usual Coulamb logarithm. Nole that a depends on density only weakly. through tn 1.

In an underdense plasma. these classical trinsport coefficient cuan be modified by the presence al intense laser light. Since the Coulomh collision rate in proportional to $5^{-3}$. the oucillati"g velerill! $v_{10}=e E_{1} \quad \mathrm{Im}_{\mathrm{e}} \mathrm{u}_{1}$ of arl electron in the laser electric field $\mathbf{F}_{1}$ can modify collisional transport uhen $s_{0}$ hecomes comparable with the electron thermal speed s.. This subject has been discusised in detail in Ref. [76]. 
In general the population of "hot" or suprathermal electrons due to resonance absorption $v:$ Raman scattering does not obey the condition $\lambda_{m i j} / L_{n} . L_{T} \ll 1$, except at very high background densities. Thus instead of describing the beat flux due to suprathermals by Eqs. (64) and (65). one is driven teward a description which explicitly recognizes the collisionless nature of the hot-electron component.

The issuc of heat transport in laser-produced plasmas has gained prominence recently, because of a large budy of experimental evidence at laser intensities $I_{1} \lambda_{1}^{2}>10^{14} \mathrm{~W}_{\mu} \mathrm{m}^{2} / \mathrm{cm}^{2}$ that the heat flux is well below the values in Eqs. (64) and (65) jredicted by classical thermal conduction. The relevant experiments are reviewed by $\mathbf{H}$. Ahlstrom in an accompanying report. Most of the experiments give data on the transport of thermal. rather than suprathermal. electrons. The experimental iechniques include $x-r a y$ line spectroscop! [77]. continuum x-ray spectra and target absorption [78]. and the disassembly time of thin-foil targets [79]. Virtually all of these experiments imply thermal-electron heat transport that is significantly below the classical prediction of Eqs. (64) and (65). both for laser pulse lengths in the 100-ps range [77-79] and it; the 1-ns range [80]. A lea experiments have specifically addressed the transport of suprathermal electrons [81]. The latler

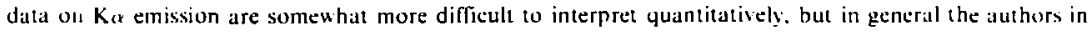
Ref. [81] concluded that transport of hot electrons was not strongly inhibited. This result appears to be in contlict witis those of Banner and Mead [77] and of Fabbro [79]. who inferred that suprathermals were strongls inhibited. The apparent contradiction here clearly needs to be resolved.

Transport rates depend sensitively on knowled ge of spatial gradients and time behavior. For wample the ypical evolution of the electron temperature obeys an equation such as

$$
\mathrm{n}_{\mathrm{e}} \frac{\partial \mathrm{T}_{\mathrm{e}}}{\partial \mathrm{t}} \times-\frac{\partial}{\partial \mathrm{x}} \kappa \frac{\partial \mathrm{T}_{\mathrm{t}}}{\partial \mathrm{x}} .
$$

Thus in order to decide experimentally whether the value of a predicled by F.ys. $(64)$ and (65) in alcuritle, it is necessary to know the derivatives abl and adx. However in nost transport experiments [77- ib] the data are integrated over either spate, time, or both. so that the gradients are not yet measured Jirectly. Hence the interpretation of the results is generally accomplished with the aid of numericil hydrodyanic computer modsts of the experiment. which provide a theoretical prediction of the values of aat and ans needed in $\left.5.4 .16^{7}\right)$.

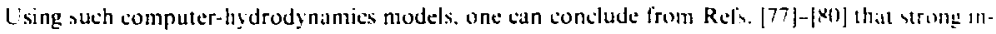

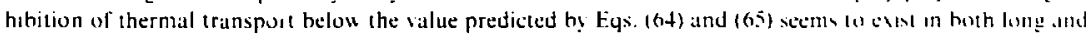
short-pulse irradiations. and in both high-Z and lou-Z targets. In addition, the deduced transport wems to be inhibited hoth inuard toward high-density regions. and laterally touard the exterior ol the lance por, 小1. lustrated in Fig. 30. The quantilative salue of the electron heat thux deduced from these escronents is roughl!

$$
\begin{aligned}
& \mathbf{q}_{1} \leq-\left(\begin{array}{c}
k \\
20
\end{array}\right) \nabla \mathrm{T}_{4} \ldots \\
& q_{e} \leq-\left(\begin{array}{c}
1 \\
30
\end{array}\right)\left(n_{e} T_{e^{2}}+t_{t e} \frac{\nabla T_{e}}{\nabla T_{e} \mid} .\right.
\end{aligned}
$$

$($ (h)

(hxh)

where $A$ is given in Eq. (65).

However, the reader should remember whes, using these numbers that tbey alre only ar relathle alle: numerical-hydrodynamic models lrom which they were derived. When conduction wirongly inhibued. canmputer codes typically show very steep gradients of temperature and density. The numeratal resula then hesume: sensitive to the linite size of the eones in space. and to the finite-dilferente algorithms uned wo whe the he:al

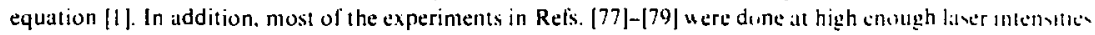
that the heat flux carried by suprathermal electrons was probably the sane urder of magnitude as that carried by thermals. Because the numerical treatment of suprathermal electron transport in bydro codes is vill someu hat incomplete in the collisionless regime. the influence of suprdthermals on the inlierred tramport inhibition of the thermal population remains uncertain.

In the remainder of this section. we shall describe mechanisms u hich might be calpabie of reducing electron heat transport to the low values implied by experiments. Euc. (obl. We shall treit in turn: large do 


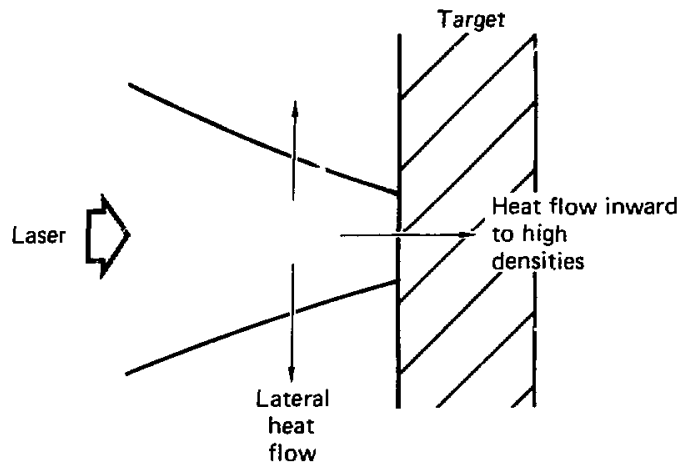

FIG. 30. This figure points out the distinction between lateral heat now in the plasma corona and inward heat flow from the critical surface toward high-density regions. The two processes may be influenced by rather different physical mechanisms.

magnetic lields. ion-acoustic turhulence. Weibel instabilities, and improved calculations of the "Llassicill" values for thermal and suprathermal heat llux.

\subsection{IOC MAGNFTIC FIELIDS}

1.arge-scale de magnetic hields have been observed in laser-produced plastmis. with misimum amplitudes af a fen times $10^{6}$ gauss. The mechanisms responsible for producing such fields will be destribed in detail in Section 5 . For the purposes of the present discussion. we shall confine aurselves to ask nng w hat hund nf Iransport inhihition such megagauss-size magnetic fields might produce.

A well-ordered large-scale de magnetic field slows electron Iransport across B w hen the electron 1 .armor radius $y_{1} \equiv v_{1 e} m_{e}$ e eB is less than the collisional mean free path $\lambda_{m f}$. Linder these condituns the vep-

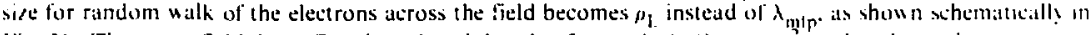
lig. 31. The cross-field heal flux is reduced by the factor $l+\left(\lambda_{m p} \rho_{l}\right)^{2}$ under these circumstintices. Numercially, we recall from Eq. (I? that

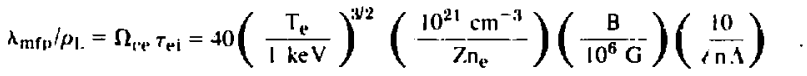

B! looking for conditions where !! $\ldots \tau^{\prime} \gg 1$, this equation can be used 10 show when well-ordered megag.tuss-si/ed magnetic fjelds cause significant transport inhibition. We consider a moderate- $Z$ target $\langle Z$ - 20). For a laser with $h_{1}=1 \mu \mathrm{m}$. E.q. (69) shows that a l-MG field can inhibil tranport of hol olectrons with $T_{e} \gg 1 \mathrm{ket}$ eren al densities of 2-3 $n_{\text {. }}$. However it is harder 10 inhibit colder electrons. due 10 the $T_{c}^{3}$ - dependente of $\lambda_{e 1} p_{l}$. A thermal electron with $T_{e} \simeq 1 \mathrm{keV}$ would only have !? $\mathrm{ce}^{T}$, $\gg 1$ at densities above 11$)^{21} \mathrm{~cm}^{-2}$ if the magnetic field nere greater than several megagauss. Conversely, a well-ordered I-MG B field could inhibit electrons with $T_{t}=1$ keV only at densities well below $n_{\mathrm{t}}=10^{21} \mathrm{~cm}^{-3}$.

If ue retall the distinction made in Fig. 30 between lateral transport and in uard transport into denst: material. we can conclude from the above discussion that a well-ordered I-MG B field would he capable ef inhibiling the lateral transport of both thermal and suprathermal electrons. at background densities belou $10^{21} \mathrm{~cm}^{-1}$. On the other hand transport into high-density material is more difficult to inhibut. Inhibition at 


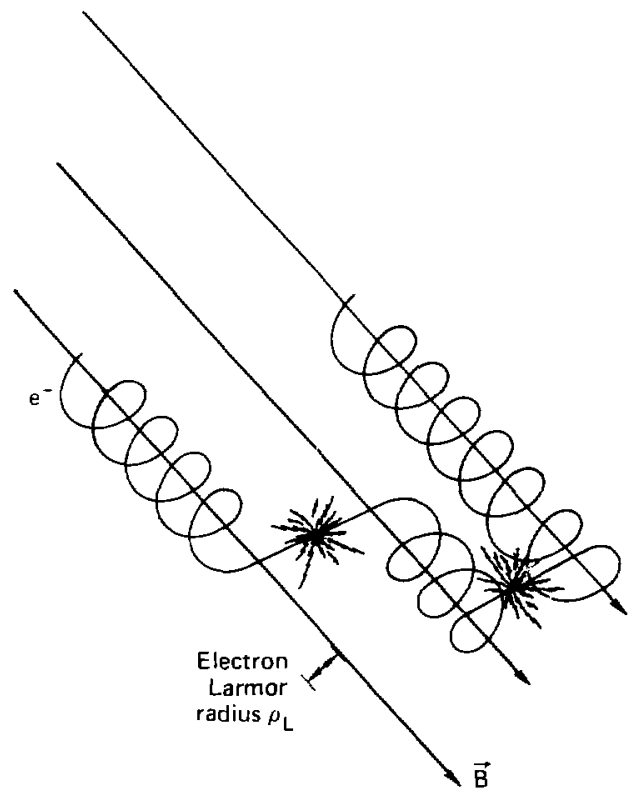

FIC; 31. Cross-ficld diffusion of an electron in a strong magnetic field. The effectise step-size for the electron's random walk is the I.armor radius al.

demstien al $2-3 \times 10^{21} \mathrm{em}^{-3}$ is expected wh be strong only for suprathermal electrons or for $B$ lields closer to II) 116

\subsection{IO)-.ACOI STIC TI RBI I.EYCE}

1.arge coherent tluctuations in the ion charge density are a second possible mechanism for transpert ubhobun. Short-wavelengh ion lluctuations with spatial stales $-\lambda_{\text {1)e }}$ cause the electrons to scatter from wherent wo tharge bunches instead of from indsidual ions. The resulting stronger stallering reduces the etcetron mean free path and the electron thermal conduction.

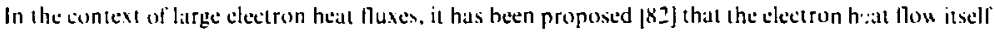
coutd gese rive to ion turbulenete sia the ion-atoustic instabilits. The phy sieal basis lor such a mechanism is illustrated in fig. 32. whish shows the ion and electron distribution lunetions in the prestence of an elect:on heat thu $\mathbf{q}_{\mathrm{g}}$. The iuns are tiken to be considerably colder than the eletrons, so their distribution is narrou. The electron distrihution is distorled lor $s_{3}<0$ bezause heat is being tarried in the $-x$ direction by electrons with speeds $|+|>,b_{1}$. To asoid a net current tluw, the electron distribution for $v_{1}>0$ is skewed sumew hat to the right. lorming the "return current" of colder electrons. 


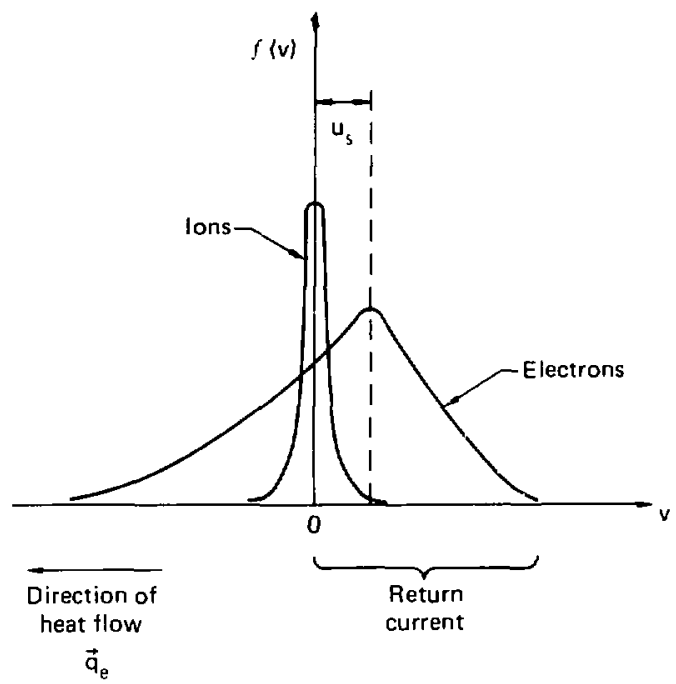

FIC. 32. Flectron and ion distribution functions in the presence of an electron heat nux $q_{e^{-}}$W wen $u_{h} \gg c_{3}$ and $Z$. $T_{k} \gg T_{i}$, the ion-acoustic instability grows rapidly.

Because of the return-current, the peak of $f_{g}(v)$ oceurs at $v_{1}=+u_{4}$, ratther than at $s_{1}=0$. Betucell $b_{\text {, }}$ $=0$ and $x_{x}=+u_{1}$, the ions see a negative slope on the electron distribution function, and a L.andau-t $\leqq p e$ in-

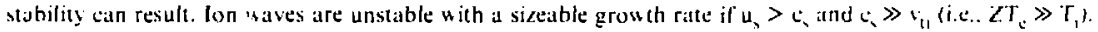
The wave vector $k$ of the ion-acoustic waves is parallel to - 4 .

The details of this ion-acoustic instability depend on the choice of initial distribution lunction fig). Forstund and Bickerton [82] studied the collisional case where the electron mean-free-path is small compared to the temperature gradient scale length, $\lambda_{\mathrm{m} p} \ll \mathrm{L}_{\mathrm{T}}$. These authors used at distribution function taken frem collisional transport calculations [83]. which gave an elfective drift speed for the return-current equall to $u_{v}=0.44\left(\lambda_{m i n} L_{T}\right) v_{t e}$ for $Z=1$. For $T_{c} \gg T_{j}$. the collisional distribution was predieled to be unstable when

$$
\begin{aligned}
& u_{\mathrm{s}}>c_{\mathrm{s}} . \text { or } \\
& \frac{\lambda_{\mathrm{mfp}}}{L_{\mathrm{T}}}>2.3\left(\frac{\mathrm{m}_{\mathrm{e}}}{\mathrm{M}_{\mathrm{l}}}\right)^{1 / \mathrm{t}} .
\end{aligned}
$$

In contrast. Manheimer [82] studied ion-acoustic instabilities in nearly collisionless systems. In this case there is no longer a unique self-consistent choice for $f_{d}(v)$, since in the absence of collisions an electron distribution turn always carry more heat just by shifting a lew electrons to very high velocities in the direction of $q_{e}$. Manheiner chose a simple form of $f_{e}(v)$ which is nearly Maxwellian: 


$$
\begin{aligned}
f_{e}(v)= & \frac{n_{0}}{\left(2 \pi v_{t_{e}}\right)^{3 / 2}} \\
& \exp -\left\{\frac{\left(v_{x}-u\right)^{2}+v_{y}^{2}+v_{z}^{2}}{2 v_{t_{e}}^{2}}\left[1+\frac{Q}{3 n_{e} m_{e} v_{t_{e}}^{3}}\left(\left[\frac{v_{x}-u}{v_{t_{e}}}\right]^{3}-3\left[\frac{v_{x}-u}{v_{t_{e}}}\right]\right)\right]\right\} .
\end{aligned}
$$

It is assunted that $\left.q_{c}<132\right) n_{e} m_{c} v_{t e}^{3}$ and $Z=1$. The first four moments of $(71)$ are $n_{c}=n_{a} v=$ wh.

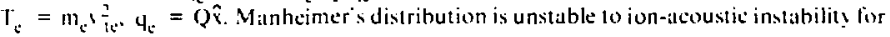

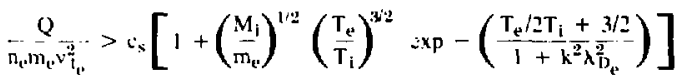

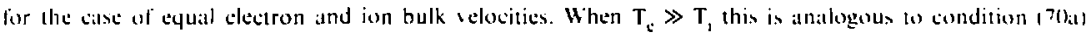
derived for thes collisional distribution function.

From the point of view of transport inhibition in laser-heated plasmas, one must also $h$ num the effect of a given atmoun of ion turhulence on the plasma transport coeflicients. In this latler areat. no rest theoredcal consensus wists vel. Published estimales for the effective collision frequencs pen range from Manheimer" comparatively large value $|\times 2|$

$$
\nu_{i \cdot f f}=\frac{1}{3}\left(\begin{array}{c}
\delta n_{i} \\
n_{i}
\end{array}\right)^{2} \omega_{i m}
$$

(1) I Indmian is vers small value [x+]

$$
v_{\mathrm{eff}}=3 \times 10^{-5} \omega_{\mathrm{ln}}\left[\begin{array}{cc}
\mathrm{T}_{\mathrm{e}} & u_{s} \\
\mathrm{~T}_{\mathrm{i}} & v_{\mathrm{te}}
\end{array}\left(\begin{array}{c}
\mathrm{m}_{\mathrm{e}} \\
\mathrm{M}_{\mathrm{i}}
\end{array}\right)^{1 / 4}\right]
$$

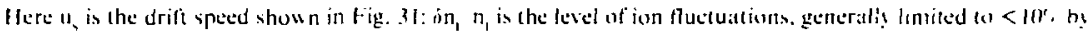

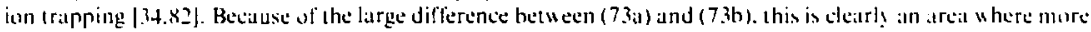
computational and theoretical work is needed. The relevant computer simulations are resiened in an article by Meid $[8.5]$.

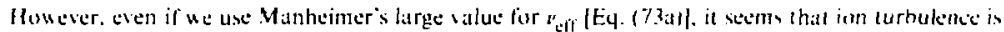
not able to limit heat flow at densities above about $10^{21} \mathrm{em}^{-3}$. the eritical densits for $\lambda_{1}=1 \mu$ m. The reawning is an follows. Fsen with a sery large turbulente level on, $n_{1}$. it is numerically dillicult lo make "cil in (7.3a) larger than the elassical collision frequency ${ }^{2}$. For example consider on, $n_{1}$ as large as $\left(1.1\right.$. and take $n_{c}=10^{21}$ $\mathrm{cm}^{-3} \cdot \mathrm{T}_{\mathrm{c}}=1 \mathrm{keV}, Z=20$. Then from (73a) the ion turbulence produces an elfective collinion rate " $\times 10^{12} \mathrm{~s}^{-1}$. whereas the classical collision frequency is ${ }^{\prime e}=8 \times 10^{12} s^{-1}$. Under these conditions the turbulenes hus little or no effect. since $v_{\mathrm{ei}}>$ "etl.

Furthermore. there is reason to think that on, $n$, maly not he as large ats the lor'; blluc used above.

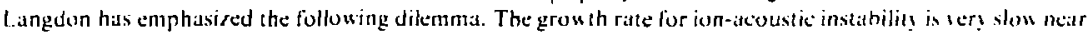
the threshold $\left(u_{s}\right)_{m m}=c$. The growth-rate and angular spread of the ion wates do not becoms substantial un-

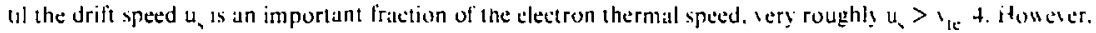

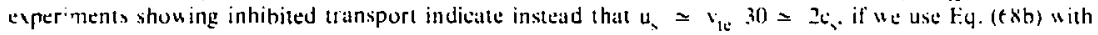
$s=2$. This experimentally inferred atue for the drift speed does not scem to be high enough wo provlute fast-grouing ion-acoustic turbulence with a broad angular spectrum.

$W$ ' thus emerge with the following (rather uncertitin) picture of the role of ion turbulence in transport inhibition. The heal flux deduced from experiments seems to be large enough to exceed the thresholds for ion-acoustic instability. Eqs. (70) and (72). Thus one would predict theoretically that ionacoustic turbulence should be produed, although the growth-rate and angular spread may not be large. lon 
turbulence has been observed [37] in recent $\mathrm{CO}_{2}$ laser-plasma experiments. and it mal also he prenduced h! processes unfelated to electron heat Mou, such as multi-species ion streaming instabilities [34.36\}.

The largest uncertaints arises when we try to estimate the effect of such jon turbulence on tram port. Fen the most generous estimates for the effective collision frequenes are not hig enough lo compele wh

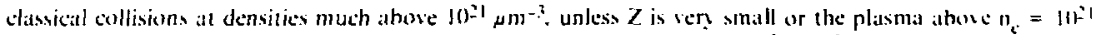
$\mathrm{em}^{-3}$ is wery hat. If most of the latser light absurpion occurs at densities $\geqslant 1\left(\mathrm{r}^{21} \mathrm{~cm}^{-3}\right.$. as would he the caxe fier a) resonance abooption. $\lambda_{1}=1 \mu \mathrm{m}$ or b) most absorption processes. $\lambda_{1} \leqslant 0.5 \mu$ m. we are therefore led to 1 he

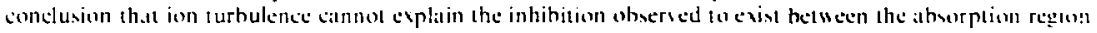
and higher demsit! regions.

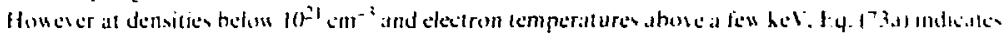

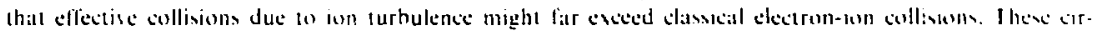

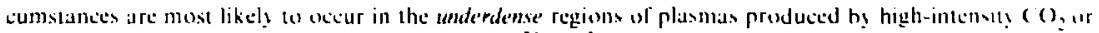

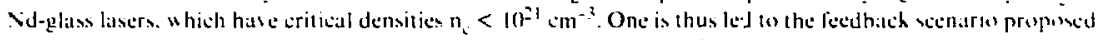

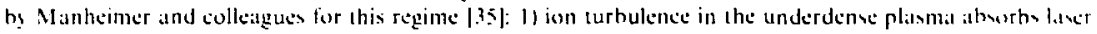

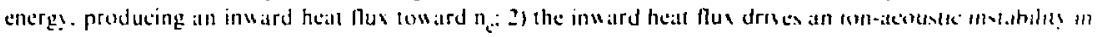
the underdense plasma: 3) the ien-itcouste instability limits the heat flus, thus matmianing the necess.trs lugh

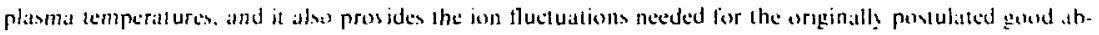

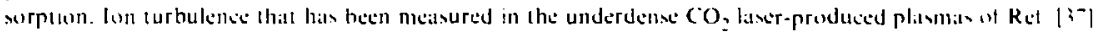
mas lit rather well unte thes sort of scellarws.

\subsection{W FIBEL INSTABIITIES.}

Ion-acoustic turbulence is not the only procts which can he dricen unstabie bs clectron heal llus.

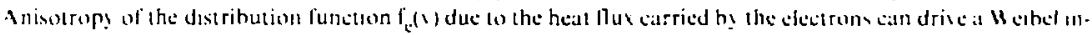

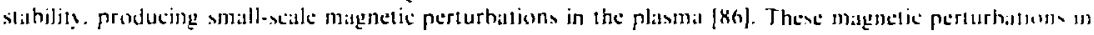
turn are capable of reducing the slectron heal thou by stallering the electsons.

The physics of a Weihel-lype instibility is hest illustrated hy the sery imple cuample wown m

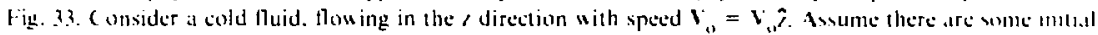

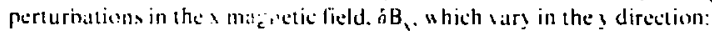

$$
\delta \mathbf{B}=\dot{\delta} \delta \mathrm{B}_{\mathrm{x}} \mathrm{exp}\left(i k_{y}\right)
$$

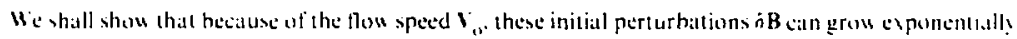

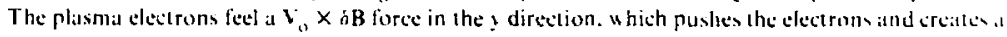

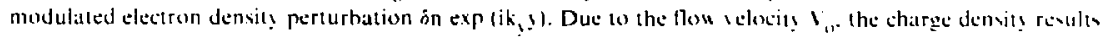
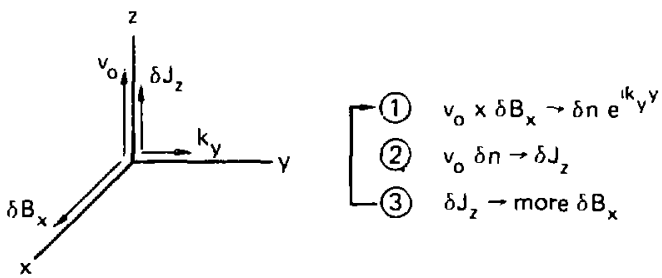

FIC. 33. Simple example of a Weibel type instability. The plasma has a zero-order velocity $V_{0} \hat{\boldsymbol{z}}$, and an initial perturbation in the magnetic freld $\hat{x} i B_{k} \exp \left(i k_{,} y\right)$. The $F_{0} \times \dot{b}$ force results in a perturbed current which enhances the original magnetic perturbation. 
in u plasma current $\delta . J \propto \hat{z} V_{0} \delta$ in exp(ik,y). Finally, via Maxwell's equations the current $\delta J$, produces mort of the original magnetic perturbations $\delta B$. and thus the process grows exponentially.

The Weibel inslability considered by Ramani and Laval must be treated by kinetic rather than fluid equations, but its basic physics is similar to the above simple example. The heat flux qe replaces the cold-fluid

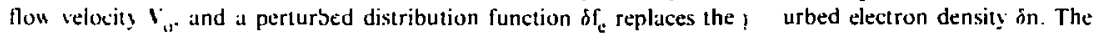
mechanism which produces magnetic perturbations is the same. Maximui. growth octurs for perturbation nave-cectors $k$ which a : perpendicular lo $q_{k}$. just as the simple fluid example had $k \perp v_{0}$. The kinetic casc uas solved by Ramani and Laval in the limit [86]

$$
\lambda_{\text {inst }} \ll<\lambda_{\text {:nf }} \text { } 1<L_{\text {T }}
$$

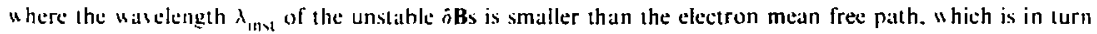
smiller than the temperature gradient seale length.

The Weibel instability produces magnetic perturbations $\delta \mathbf{B}$ which vary in space on scales smaller

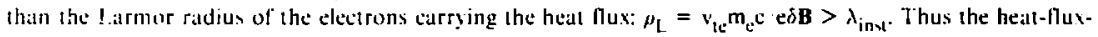
carry ing elccirons are dellected by maty small encounters with the magnetic perturbations ob. Ramani and J.aral's extimate for the consequent effective collision frequency is [86]

$$
v_{\mathrm{eff}}={ }_{\mathrm{L}_{\mathrm{T}} \cdot \mathrm{T}}\left(\begin{array}{c}
\mathrm{L}_{\mathrm{T}} \omega_{\mathrm{PH}} \\
\mathrm{C}
\end{array}\right)^{13} .
$$

It is this ellective colliston frequeles which determines the eflective mean free path $\lambda_{\text {mir }}$ and stale length $L_{T}$ to he used in 1:4. (75).

If we compare the Weihe collision freyueney (76) with the maximum predicted collision frequeney dus (o) ion-ilcoustic turbulence. E.4. (73:1). we find that all $\mathrm{T}_{\mathrm{e}}=2 \mathrm{keV} . \mathrm{n}_{\mathrm{e}}=10^{21} \mathrm{~cm}^{-3}$. on $\mathrm{n}_{\mathrm{s}}=0$. I. 1he effective collision frequenc! due to 1 eibel is larger than the maximum estimate for ion-acoustic when $\mathrm{L}_{\mathrm{T}}<10 \mu \mathrm{m}$. The llicibel process has seseral theoretical advantages over ion-acoustic turhulenes as a transport-inhibition

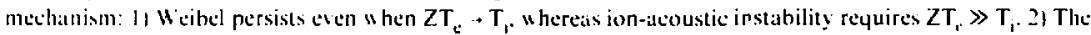
angular spectrum of ion-icoustic turbuience is rather narrow when the heat flux is small, and thus slectrons "wilh velucity nearly parallel to $\varphi_{\mathrm{e}}$ are not strongly sattered by the ion wares. For Weibs, on the other hand.

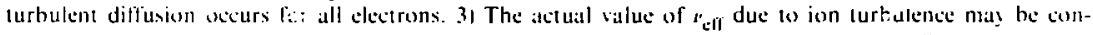

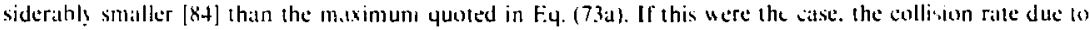
Weihel in 1:4. (76) would domina e that of iton-acosstic turhulenct.

In summalry, Weibel instatidities driven by electron hed flow sem theorelically promising as a wa! to inhibit transport. However. thers are several theoretical yuestions shich remain to be addressed. Th: saturation nechanism lor the magnetic perturbations needs to be identified more definitivels. and the relatise importance of modes with $k$ exalty perpendicular to the heal hux should be assessed. The inlluence of a hatckground magnetic field on the grow th of mignetic perturhations and on the subseyuent xaatlering of eletarons needs to be considered. Finally, the nonlinear response ol balckground temperature and densil! gradients to the Heibet instability needs to be studied.

\subsection{IMPROVED CALCLIATIONS OF "CLASSICAL" HEAT FLIX}

In this section we defiae "classical" 1ransport as that due to electron-ion Coulomb collisions (perhaps in the presencte of large-scale magnetic lields) excleding the effects of the various micre-institbilities and small-scule magnetic fields we hate discussed abote. We consiter the possibility that if we are not cilculating "classical" transport correctly, we may mistakenly conclu !c that an "anomalous" mechanisn is needed to explain the low electron heat fluxes seen in experiments. To phrase this in a different way. Ey. (68:a) indicates that heat flow is slower than the value $-\kappa \mathrm{VT}_{e}$, where the numerical value of $\kappa$ is calculated hy Spiter [19.83] and Braginskii [10]. In the present section us ask whether the classical value of $\mathrm{A}$ might actually be considerably lower than that derived by Spitzer and Braginskii. due to a variety of different physical effects. We 
consider separately the heat flux expected for thermal "cold" and for suprathermal "hot" elestrums, hecaunc the jssues are sumewhat different for the two tuses.

\subsubsection{Classical Heat Flux for Thermal Electrons}

The classical calculation of the heat conductivits a by Spiter and Hirm [8.3] utilise an asympus

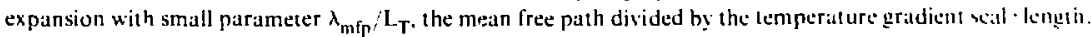
For the expansion to converge it is necessary that $\lambda_{\text {mf }}, L_{T}$ he much less than unity.

Recently Gray and Kilkenny [37] insestigated the values of $\lambda_{\text {min }} \mathrm{L}_{\mathrm{p}}$ for which Spil/er and Hairm: calculation begins to fail. Their criterion for lailure was that the electron distrihution function fol he:atme negative for electrons with $|x|$ in the range $2.3 x_{\text {te }}<|v|<3 v_{\text {te }}$ since it is these electrons which eirry move af

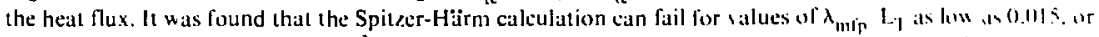
equivatently at values of $q_{e} n_{e} m_{e} v_{\text {ic }}^{3}$ as bu as 0.03. Referrigg to Eq (68). we sece that this lature al the: classical calculation oceurs just when $\lambda_{m}{ }_{\Gamma} . L_{\Gamma}$ is nearly equal to the value 1.30 inferred experimentalis, In this case it seems clear l.o:at an inproved calculation of a is needed. valid lior values of the mean liee pith (1.61) il,

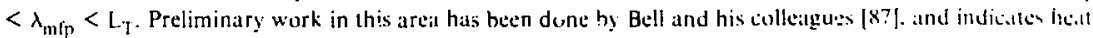
tluxes lower thin those predicted by Spitzer and Hïrm.

A second physical process which might decrease the dassical heat Mux belos the Spitcre-thirm taluc was suggested by Landgon [18]. As described previously in Section . A. incerse Bremssirahlunt ahourptmu

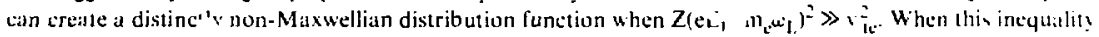
is obeyed. Fig. 5 shows that the high-relocity tail of the distribution is lower than it would be fur at Mat-

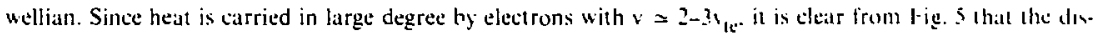
tribution produced by inverse Bremsstrahlung will carry less healt than an equivalent Matwellian w.itsld. Although quantitative ealeulations of this effect in a temperature gradient have nol bet been dont. prelimintar! estintates [18] suggest that the heat flux may lie as much as a factor of w w o helow the Spit/r-H:irm viluc [k.3].

\subsubsection{C lassical Heat Flux for Suprathermal F.lectrons}

The problem of linding a description of hot-eictron transport that is buth nhy sically acuratc and numerically tractable remains very diflicult. As : . . onsequence the role of suprathermal slectron in trathporl inhibition is still unclear, since refined calculations of hot-electron tra psporl are difficull lo (ande hy even in the absence of niero-instabilities and magnetic lields. Recall that in most experiments where tramspurt inhth. tion was deduced [77-79], a sizeable heat llux was present duc to hol clectrons. We are thus kefi to winder whether the deduced thermal inhibition was real, or whether it appeared only to "sover up" iniducyuacter ar numerical errors in the treatment of suprathermal-electron transport.

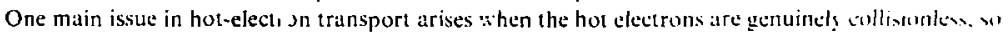
that $\lambda_{\text {nulp }} \gg L_{n}$. L $L_{T}$. The diffusion approximation, which is probably the most numeriealls efticient heselectron description [88], is no longer valid in this regime because there is nothing to ketep the elctron dintribution nearly isotropic. In particular. a corona dominated by collisionless hol electronscan at timen interat' only weakly with the dense collisional core of the target [89.90]. Consider the geometrs show in in f-ig. 34. where a large hot-electron corona of radius $\mathbf{R}$ surrounds a spherical core of dense material pell. When the coronal eleatrons have a mean free path $\lambda_{\text {mfp }}$ which is large compared to the radius $R$. the can bounce around in the corona many times before hitting the core. Under these conditions the heat flus insu the dunse material is $[90]$

$$
\left|u_{e}\right| \cong\left(\frac{R}{\lambda_{m f p}}\right) n_{e} m_{e} v_{t_{e}}^{3}, \frac{K}{\lambda_{m f p}} \ll 1 .
$$

(Recall that in the classical expression for the heat flux. Eq. (63), it is the inverse of $R \lambda_{\text {mip }}$ wich appcars.) If rne were using a phenomenological "flux-limited" expression for the heal llux. such is:

$$
\left|\mathrm{q}_{\mathrm{e}}\right|=\mathrm{fn}_{\mathrm{e}} \mathrm{m}_{\mathrm{e}} \mathrm{v}_{\mathrm{e}}^{3} \mathrm{e}_{\mathrm{e}}
$$

one would conclude that the "flux-limit" $f$ was $R / \lambda_{m f p} \ll l$ in this situation. This is suggestive of the lorm (68b) derived from experiments, where $f \bumpeq 1 / 30$. 


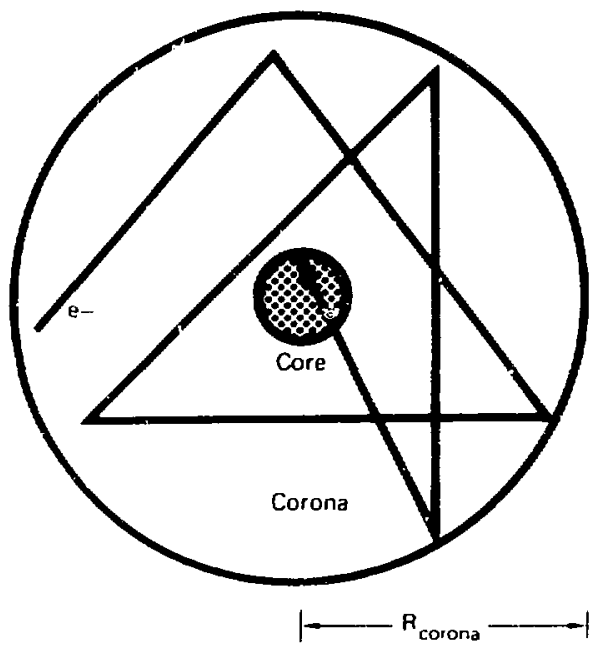

FIC: 34. Cieumetrs for corona-core decoupling |89,90|. If the whid angle of the denx-plasma cors is small as seen hy a bot co:zonal clectron, the electron can hounce many times in the corona hefore hitting the core and loving if energs thare.

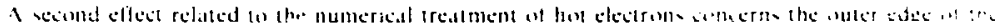

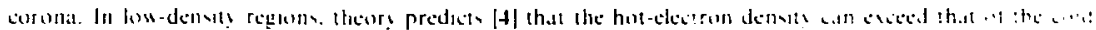

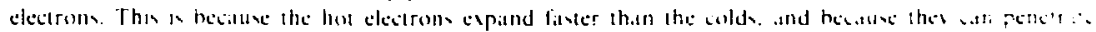

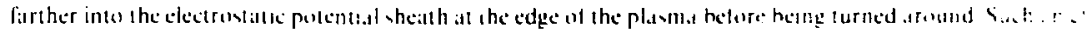

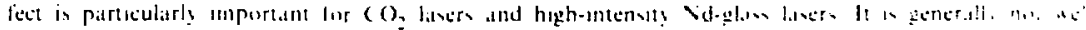

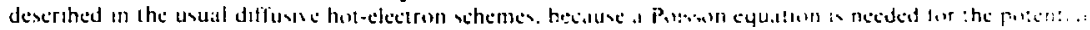

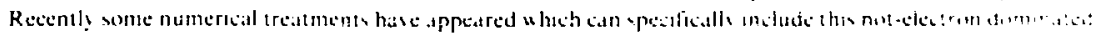
region in large hodrody hamk condes $\{91,92]$

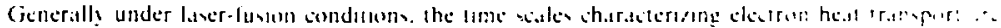

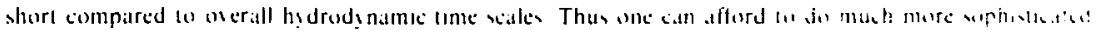

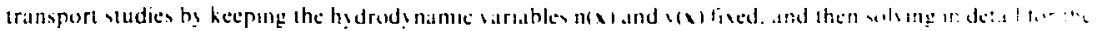

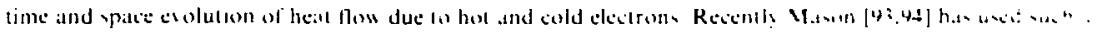

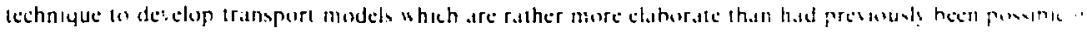

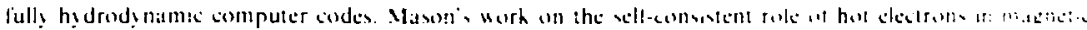

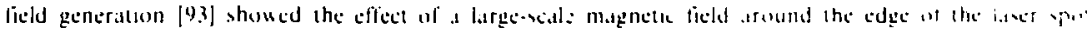

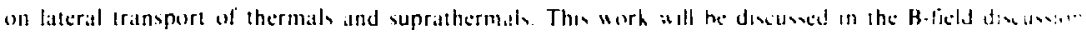
Section 5

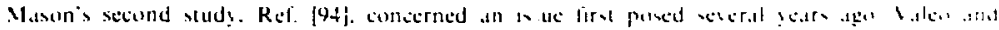

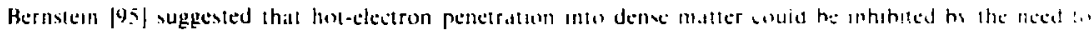

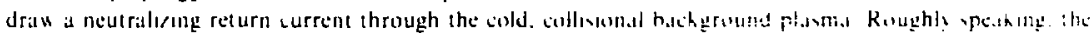
ero-current coindıion belween hos and cold electrons 


$$
n_{h} h_{h}=n_{r} \cdot v_{r} .
$$

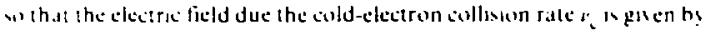

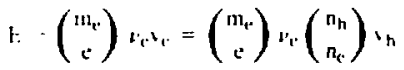

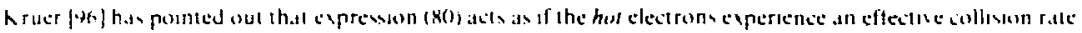

$$
r_{1 \cdot r f}=\left(\begin{array}{l}
n_{h} \\
n_{r}
\end{array}\right) r_{r}
$$

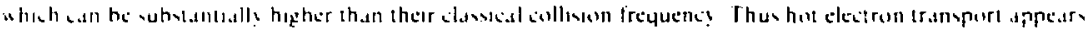
"inhihiled"

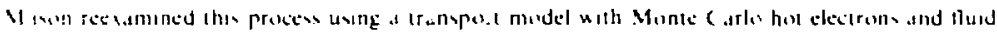

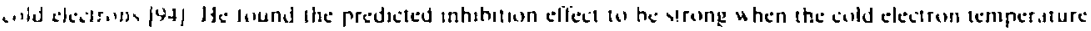

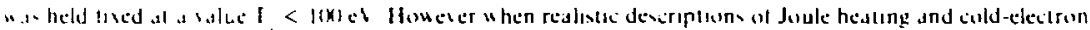

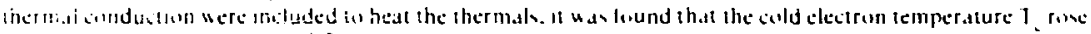

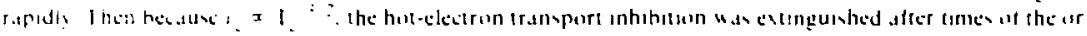

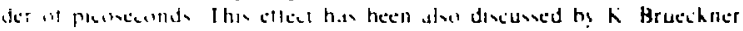

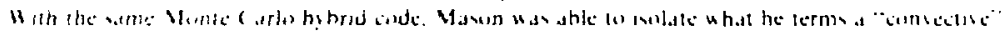

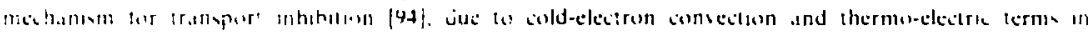

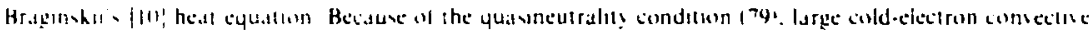

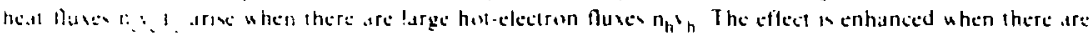

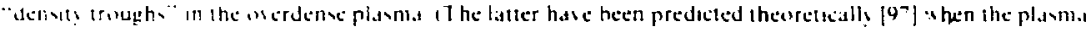

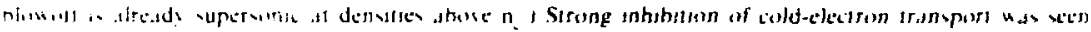

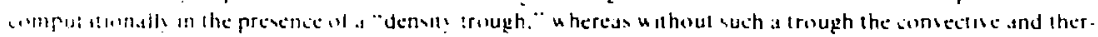

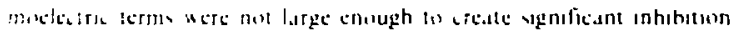

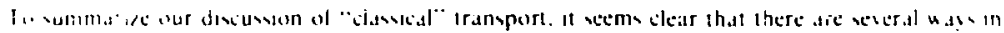

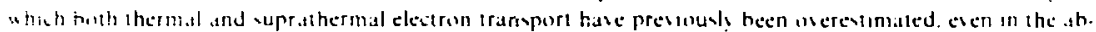

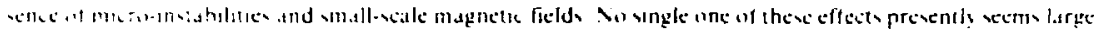

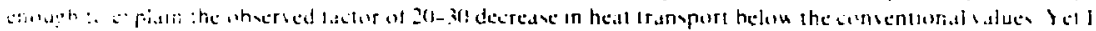

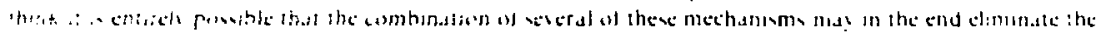

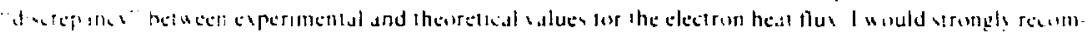

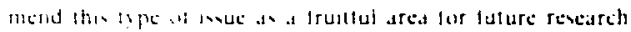




\section{PRODICTION OF LARGE DC MAGNETIC FIELDS}

\subsection{F.XPERIMFYTAL FIDENCE}

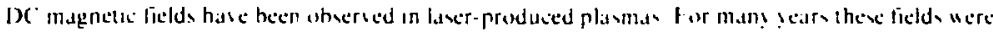

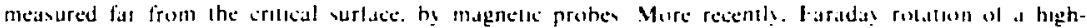

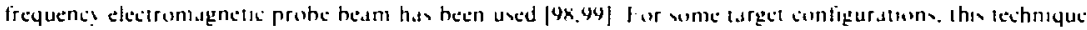

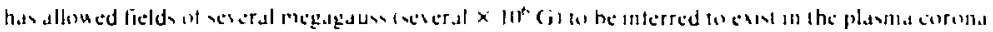

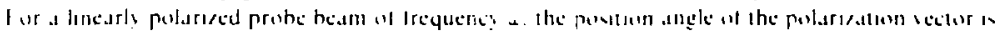
rualed bs an angle

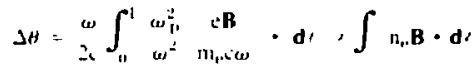

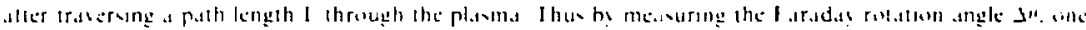

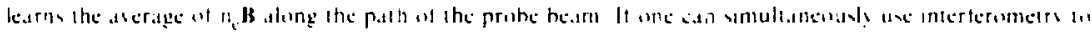

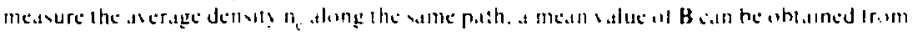

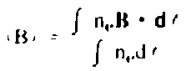

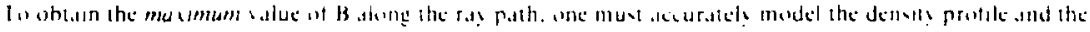
setracles of the probe hesm

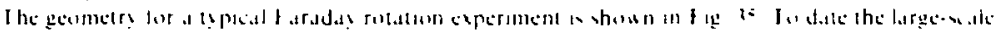

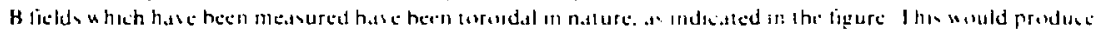

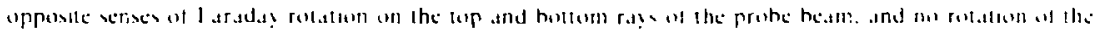

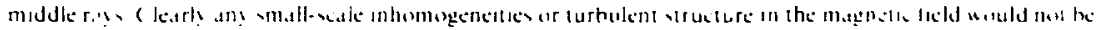

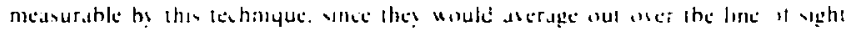

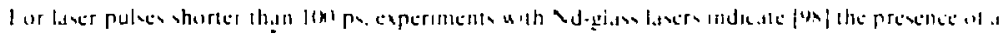

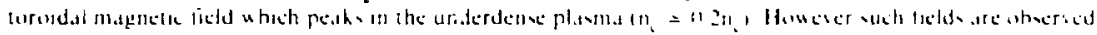

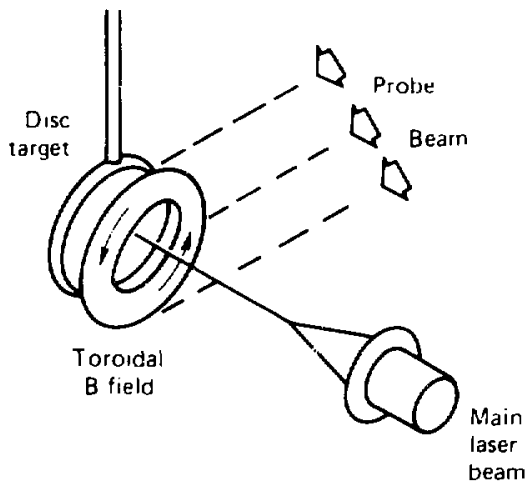

FIC. 35. Geometry for taradar-rotation measurement of the toroidal magnetic field on a disc target. 
(1) eaced $100-2(0) \mathrm{kg}$; only for targets larger than aboul $100 \mu \mathrm{m}$ in diametel. and onls when the larget diameler wat least sereral tumes larger than the focal pou dameter. These condituns suggest fo Rasen et dit |98| that the electrkal capacts of the larget mas plas an amportant role in short-pulse experiments Small

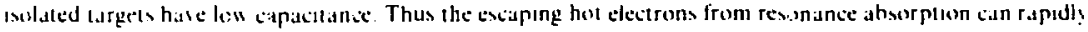
sharge the target wa high potential, with the resultong electric field imhibitang the furiher grous of current

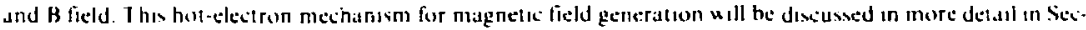
man 5.2 helus

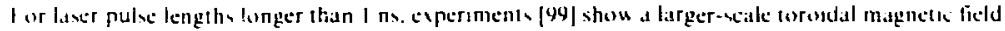

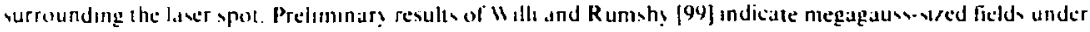

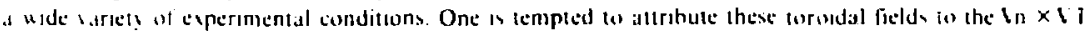

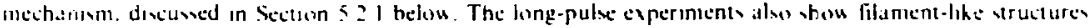

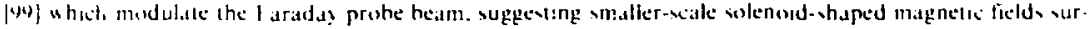

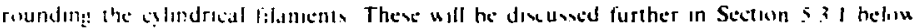

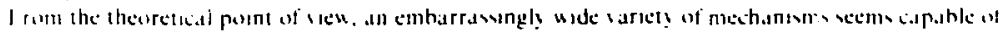

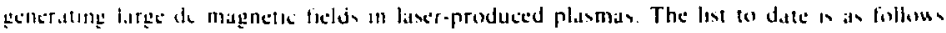

11 Mechanlam, revulting in large-sedte $B$ lields

$1 \quad 1 n_{c} \times \backslash r_{6}$ mechammom

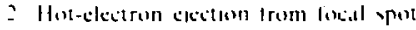

; Imsirmolic electron presure

$\therefore$ Vlcohaminm producing vmall-xide B liclds

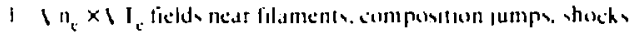

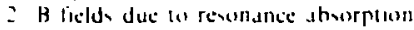

i Thermal imblabilite

I llethel muthhiltien

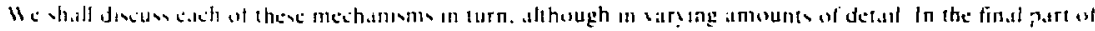

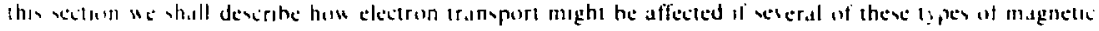

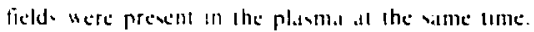

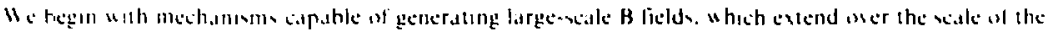
liner you in the larptet w/e

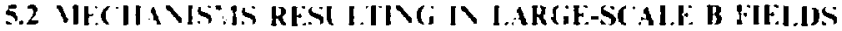

\subsubsection{The $\pi_{\mathrm{e}} \times \backslash \mathrm{I}_{\mathrm{e}}$ Wechaniom}

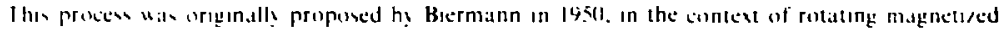

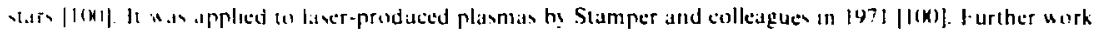

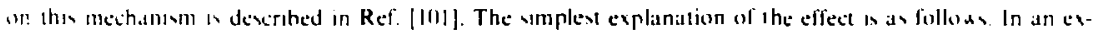
panding flasma. the clectron prewure lerce geves rise 10 at tharge-separation electric field

$$
\text { en, } \mathbf{F}=-\nabla \Gamma_{1} .
$$

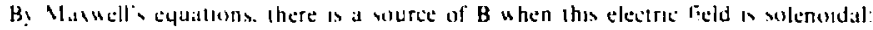

$$
\frac{\partial B}{\partial \mathbf{B}}=-c \nabla \times E=-\frac{c}{\mathrm{e}} \nabla l n n_{\mathbf{t}} \times \nabla \mathrm{T}_{\mathrm{t}} .
$$

I hus ihı mechantsm generates a de magnetce lield when there is an angle betueen the local densily and temperature gradients in the plasma.

Fur a target irradialed with one finite-sised laser heam, this is most likely to oceur in the outer teguns of the laser spot. as shown in Fig. 36. The densily gradient points into the solid-density target. whereas ne:ar the edge of the laser spot the temperature gradient points radially inuard. The result is a toroidal $\nabla n_{e}$ $\times \backslash T_{e}$ magnetic field around the outer parts of the laser spot. Since the intensily distrihution of tlat laser light 


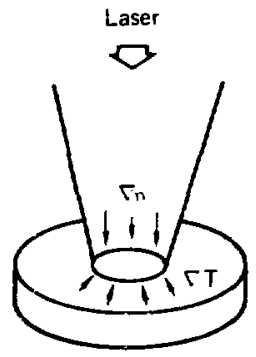

Siab target

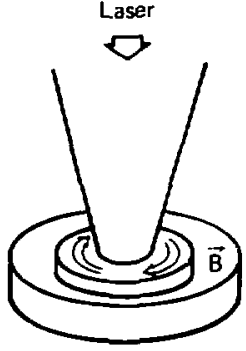

Slab target

FIC, 36. For a linite laser for:al spot, the presailing temperature and density gradients produce at toroidal dc magnetic field, by the ine $\times 1 T_{\mathrm{e}}$ mechanism.

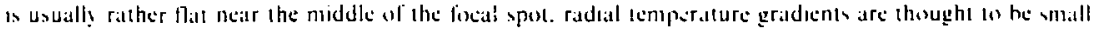

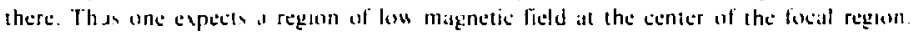

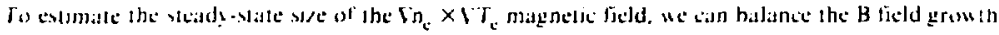
rate $(x+1)$ with convestion due to outuard tluid motsun at ielocit? 1 :

$$
\frac{c}{e} \nabla t n_{n_{1}} \times \nabla T_{*}=\nabla \times(\mathbf{V} \times B)
$$

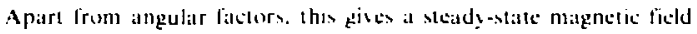

$$
\begin{aligned}
& B=\left(\begin{array}{c}
c \\
c_{s}
\end{array}\right)\left(\frac{T_{b}}{e L_{T}}\right) \cdot w \\
& \left(\frac{\mathrm{B}}{10^{\mathrm{f}} \mathrm{kiuss}}\right)=30\left(\frac{\mathrm{T}_{\mathrm{t}}}{1 \mathrm{keV}}\right)^{1 / 2}\left(\frac{1 \mu \mathrm{m}}{\mathrm{L}_{\mathrm{T}}}\right)\left(\frac{\mathrm{A}}{\mathrm{Z}}\right)^{1 \cdot 3}
\end{aligned}
$$

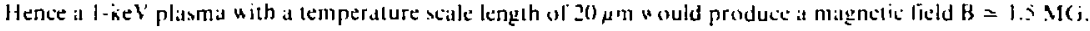
al placts where the density and temperalure gradients were at large angles relative to tach other.

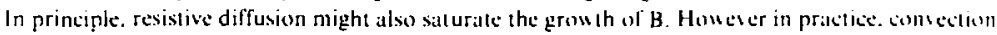
is generally larger numierically than resistise diffusion for all but the shortest "radient lengl to:

$$
\frac{\left(\frac{c^{2}}{4 \pi_{i} \sigma}\right) \nabla \times \mathbf{B}}{V \times B}=\frac{c}{c_{\mathrm{s}}}\left(\frac{\nu_{\mathrm{ei}}}{\omega_{\mathrm{p}}}\right) \frac{\mathrm{c}}{\omega_{p} \mathrm{~L}_{n}}=\frac{Z}{10}\left(\frac{1}{-\mathrm{keV}}\right)^{2}\left(\frac{1 \mu \mathrm{m}}{\mathrm{L}_{\mathrm{H}}}\right)
$$

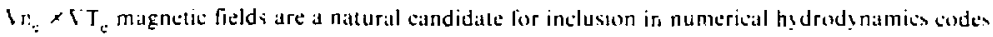

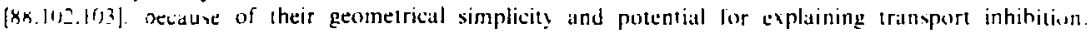
Howe:er eren in the absellet of a separate hol-electron population. calculation of $B$ tields can he quite a dilficlt undertaking from a numerical pount of sieu. Cislombalnt and Winsor $[10 H]$ pointed nut that the full

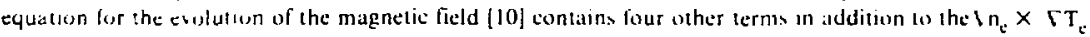




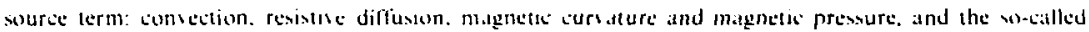
"thermal lorse" $[10]$

$$
-\frac{c}{\mathrm{c}} \nabla \times\left[\beta \nabla \mathrm{T}_{\mathrm{e}}-\alpha \hat{\mathrm{h}} \times \nabla \mathrm{T}_{\mathrm{k}}\right] .
$$

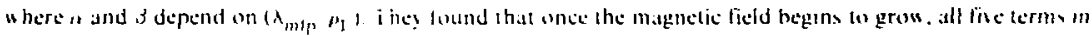
the magnetuc-field eyuation are of comparable s/e. Including the thermal forete term. This is unlortunste.

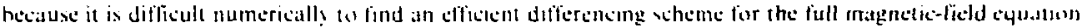
(barious authors had atlempled la whe at hy neglectung one ur more of the ererms.)

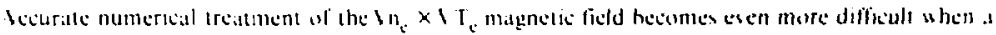

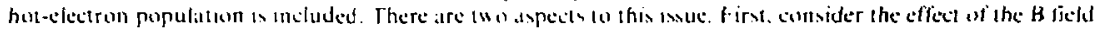

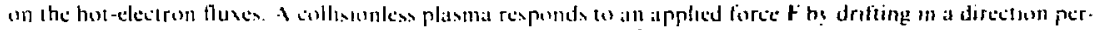

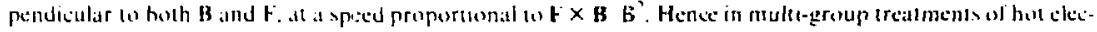

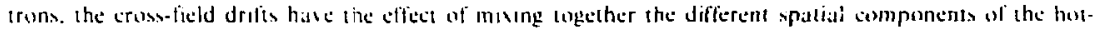

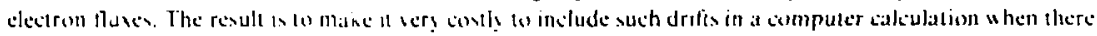

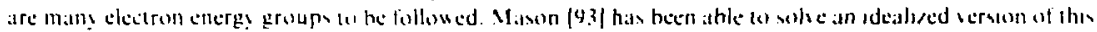

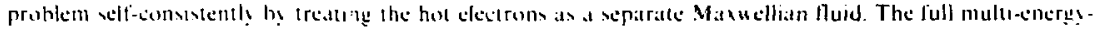
eroup prohlem remains unsulsed.

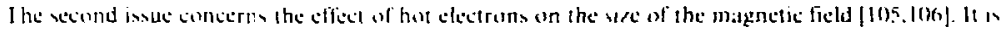

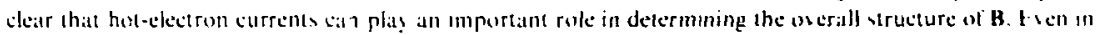

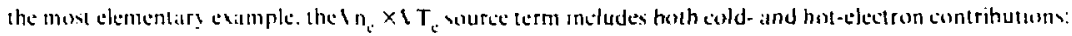

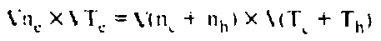

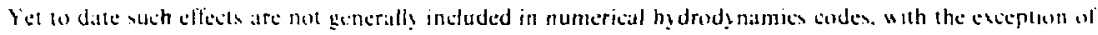
Masonis trampurt worh [9."

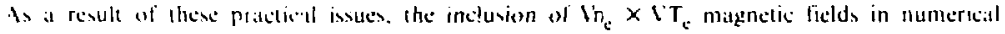
bydrodsnamice coder remain a difficult probien in the presence of suprathermil clectrons. The hydro codes with the most complete $b$-lield models do not in general include hesl-electron transport. On the uther hand. Lagrangian numercal hạdroḍnanies codes which include suprathermal electrons and which are ured

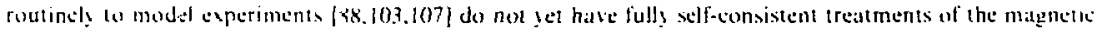
field interation wh hot electrons. Finally. the one transport code to date which does ireal $B$ field and hol

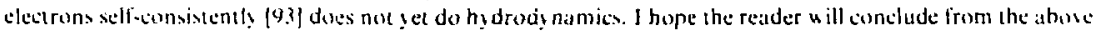

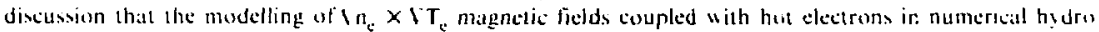
codes is a challenging and intportant resciarch area.

\subsubsection{Hot-Flectron Fjection from the Focal Spor}

Hot electrons produced by resonance absorption are accelerated preferentially in an watward direstion. i.c. down the densily gractient. Several gears ago it was pointed out [108] that if these hon electrons caused a return current 10 form in the colder regions ousside the focal spot, a toroidal mignetic field could result. Daw son called this the "[ Juntuin effect" [108], because of the geomers which is iflust rated in Fig. 37. The sense of the magnetic field is the same as that in the $\Gamma_{e} \times \& T_{e}$ mechanism described above. This concept hats been discussed recently hy Kolodner and Yablonoviteh [109].

Present understanding of the fountain elfeet mechanism remains only yualitative, becaluse the B field is senative to delails of the retur n-current spatial structure. Clearly the magnetic field will be smalt if the hos electrons are able lo draw a return current locally equal and opposite to $\boldsymbol{J}_{h+1}$ while they are still in the ficul spon. This might be the case near the center ol the spot, for example. The "fountain effect" is strongest near the spot edge. and thus would be expected to have the largest glohal effect for experiments with smatl focial spols. It could dominate in short-pulse, high-intensity experiments $[98,109]$.

Drouet [1 10] has used aire probes to measure return-current patterns similar to those predicted bs

Fig. 37 


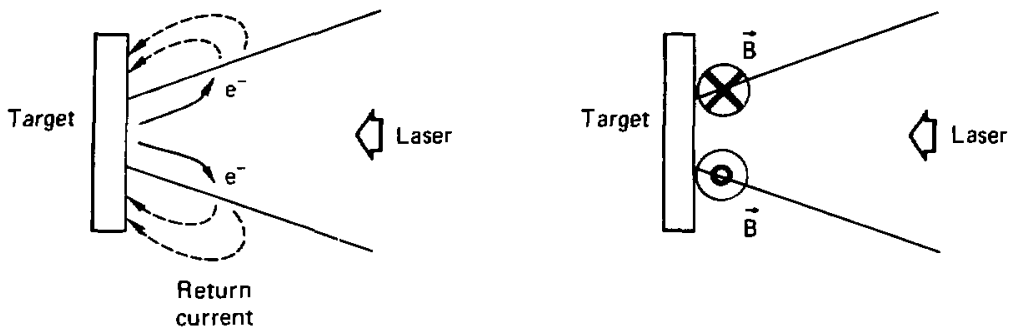

FIC. 37. Configuration producing a "fountain effect" magnetic field due to hot-electron ejection from a finite tocal spot $[108,109 \mid$. The details of such a field are sensitive to the exact return-current path and the target capacitance.

\subsubsection{Anisotropic F.lectron Pressure}

Eten when the electron density and temperature gradients are paralis. large-seale magnetic lictds can he produced in the coronia when the electron pressure censor is not isotropic. This eflect has been discussed in detail by Mora and Pellat [76].

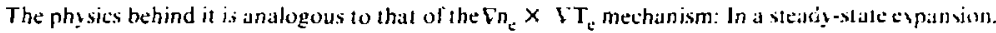
the electron pressure creales an electric field

$$
\mathbf{E}=\frac{-1}{\mathrm{en}} \nabla \cdot \mathbf{P}_{\mathrm{e}}
$$

where $P_{\mathrm{e}}$ is the full electron pressure tensor. The grow th of magnetic field is then

$$
\frac{\partial \mathbf{B}}{\partial t}=-c \nabla \times \mathbf{E}=\frac{\dot{c}}{\mathrm{e}} \nabla \times \frac{1}{n_{\mathrm{e}}} \nabla \cdot \mathbf{P}_{\mathrm{e}}
$$

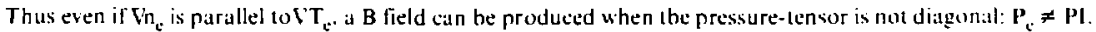
Mora and Pellat's kinetic-theory treatment ol this methanism [76] shous that B lields in the megiteauss range can be produced in the underdense plasma, and that p-polarication of the laser heam is preftered.

The three processes discussed above are capable of creating magnetic fields with large-sciale virusture, on the scale of the laser spot itself. The lotal large-stale shape is predicted to be wroidal, due we the lin. $\times \Sigma \mathrm{T}_{e}$ and "fountain effect" mechanisms. Because of the anisotropic-pressure mechanism. this toroidal B licld will be locally stronger in regions of the incident laser beam $\mathbf{u}$ hich correspond to p-pelarization. The Faridalsrolation experiments of Ref. [98] measured litrge-stale fields which were toroidal in shape. as predicled. However, our ability to model these fields quantitatively is not refined enough to learn the exact mivure af the large-scale mechanisms responsible for the observed field.

\section{3 .MECHANISMS PRODUCING SMALL-SCAL.F. B FIELDS}

In addition to the three processes just discussed, there have been yuite a few mechanisms proposed which would make Bs with small spatial scales. ranging from a feu vacium laser wavelengths to an electron mean free path. Because they lack large-scale coherence, such fields are difficult to observe by present 
Faraday-roliation leshniques which integralle along the probe's line us sigbl. However, we shall shou in Section 5.4 that if these small-scale magnetic perturbations do exist. thes can have a signilicant effect on the expected clectron transport coefficients.

\subsubsection{In, $\times 5 \mathrm{~T}_{\mathrm{g}}$, Fields near Filaments, Composition Jumps, and Shocks}

It is cleat that if the laser-produced plasmat contiuns density or temperature gradents with smail

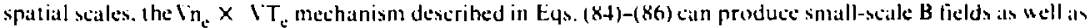
large-scale fields. We showed an example in Fig. 25 of a magnetic lield surrounding a filament. In this cast the

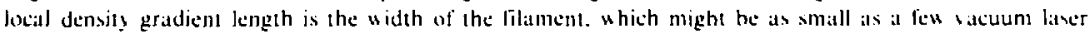

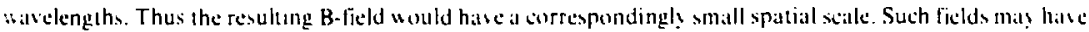
been whorred in Rel'. [99|.

In at simular sein. Tidman [111] has suggested that the strong local gradients near compostion jump

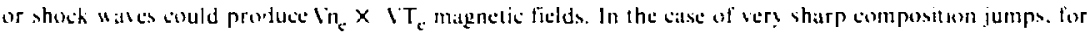
caimple. Tidman estimated that the spatial width ol the B field would be determined by siden ily resistive dif-

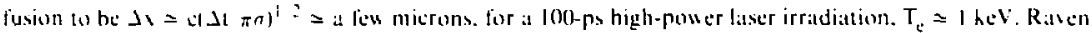
et al. [98] hate measured the large field produced by at composition jump.

\subsubsection{Vagnetic Fields due to Resonante Ihsorption}

Stamper and Tidman $112.11^{2}$ ] proposed malls sears ago that radianion pressure due to laser light absorptson could produce a de magnetic lield. (inder these circumstances one call imagine replacing the generat pressure tenor $P_{t}$ dixeused in Fys. $(88)-(89)$ by the electromagnetic stress tenser $\mathbf{P}_{\mathrm{K}}$. In the presente of absorption. I $\times\left(\backslash \cdot P_{R}\right)$ does not samis's for light of the appropriate polariation. and a de magnetic lield ean result

Resonaluce absorptoun has proven to be an interesting example ol this mechanism. because megagaus-sided de magnetic fields have been seen to accompany resonance absorption in computer simulalions [114.115]. Theory for the saturation of this process [76.115] shous megigauss-si/ed fields duc l1 renonanee absorplon consentrated in a very thin region just at the erilical-surlice laser. Because the region containing the large magnetic lield is less than a vatuun wavelength thich. B fields due to resonance absorplion are nol good candidates for explaining the inhibition of heat how touard high densitice [1/6]. Rather. the! probably add to the gencral level of small-scale periurbalions superposed on the werall toromdal magnetic ficld structure.

\subsubsection{Fieids due to Thermal Instahilities}

The magnetic lield dependence ol the electron thermal conductis is has been show n lo caluse a fieldgenerating thermal instabilit! [117]. The physieal nechanisn for insability in that a perturbation in the plastia temperature $6 \mathrm{~T}$. which varies across the gero-order densily grildient. produces a magnetic field $\dot{b} \mathbf{B} 、$ lil d $\mathrm{Vn}_{1} \times \mathrm{V} \delta \mathrm{T}$ source term. The magnetic field dependence of the electron thermat conduetivitg then changes the heal how in such a wa! as to enhance the original temperalure perturbation $o \mathrm{~T}$, gibing a leedhalck mechanism for instability. This effect requires the instability wavelength to he larger than the collisional mean frec path. $s o$ it is most likely to be important in moderate- $Z$ or high- $Z$ plasmas.

The warelength of the magnetic perturhation giving maximum growth in Tidman and Shannys [11? theor! in roughl! equal to

$$
\lambda_{\text {max }}=+\left(\frac{s}{\omega_{i}, \lambda_{\text {mfp }}}\right)^{1 / 2}\left(L_{n} L_{T}\right)^{1 / 2}
$$

when $Z \gg 1$. Here $\lambda_{\text {mip }}$ is the mein free path given in Eq. (11). Thus near the critical density for a Nd-glass laser, one ohtains typical scale sizes for the magnetic perturhations equal to a fraction of the mean gradient length $\left(L_{n} L_{-}\right)^{1}$ : As a result, thermal-instability matgnetic fields have small spitial scales relative to the lypical gradient length or spot sise. They presumahly maximize at densities slightly belou critical, where the density and temperalure gradients are in the same direction. The nonlinear behavior of this instability has not yet been quantitatively addressed. 


\subsubsection{Magnetic Fields due to Weibel Instabilities}

Electromagnetic instabilities driven by inward heat-flow [86] can also produce small-scale magnetic perturbations in the plasma. Except for the singular limit where $\mathbf{k}$ is exactly perpendicular to the heat flux, these are not strictly speaking dc m.agnetic fields. Rather, they oscillate in time. However such fields cin ippear quasistatic to a fast-moving electron, if the electron`s transit-time across $\delta B$ is shorter than the oscillution timescale.

We can estimate the magnitude of the magnetic perturbations from the nonlinear theory uf Ramani arj Laval [86]. One can deduce the saturation amplitude from the effective collision frequency

$$
\nu_{\text {eff }} \approx \sum_{k}\left(\frac{e \delta B_{k}}{m_{e} c}\right)^{2} \frac{1}{k^{-1} t e}=\frac{v_{t e}}{L_{n}}\left(\frac{L_{n} \omega_{p}}{c}\right)^{1 / 3}
$$

The most unstable mode has wavenumber

$$
k=\frac{\omega_{p}}{c}\left(\frac{c}{L_{n} \omega_{p}}\right)^{1 / 3}
$$

These two equations can be combined to yield

$$
\frac{(\delta \mathrm{B})_{\max }}{10^{6} \text { gauss }}=2\left(\frac{\mathrm{n}_{\mathrm{e}}}{10^{21} \mathrm{~cm}^{-\mathrm{a}}}\right)^{1 / 4}\left(\frac{\mathrm{T}_{\mathrm{e}}}{1 \mathrm{keV}} \frac{1 \mu \mathrm{m}}{\mathrm{L}_{\mathrm{n}}}\right)^{1 / 2} .
$$

Once again we find a mechanism capable of producing megagauss magnetic fields. The spatial suale of these fields is quite small. since the analysis of Ramani and Laval requires instability uavelengths

$$
\lambda_{\text {inst }}<\lambda_{\text {mip }}<L_{n}
$$

where $\lambda_{m i p}$ is the mean frets path.

\subsection{HEAT TRANSPORT IN RE.ALISTIC H-FIELD GEOMETRIES}

Most of the mechanisms for magnetic field generation described ahove are theoretically capathle of producing field magnitudes of it least a few hundred kilogauss. Several mechanisms are predicted to make fields as high as a few megagauss, for typical parameters of a laser fusion target. The overall lield geonnetry (Section 5.2) is predicted to be dominantly toroidal on the large spatial scale, extending over distances ty picill of the laser spot-size. Superposed on this large-stale field, one expects to find small-scale flucluations due to the processes described in Section 5.3. Typical spatial scales for the small-scale fields range from il fraction of the laser wavelength up to a fraction of the density or temperature gradient scale length. Thus the total magnetic lield might resemble that shown [i9] in Fig. 38.

(A parenthetical note of caution is appropriate at this point. The work to date on magnelic field generation has considered only one physical mechanism at a time. A potentially fruitful area for restarch concern; the interaction and interference of several different field-generation mechanisms, if they all accur simultaneously.)

Since laser-produced plasmas typically have very high values of $\beta^{\prime}=8 \pi n k T$; $B^{2}$, the magnetic ficld cannot directly affect the hydrodynamics, particularly since an ion Larmor radius is large compared with the scale length. The principal effect of the magnetic field is un tlie electron thermal conduction. Here we shall obtatn approximate expressions for the cross-field diffusion coeflicient of test electrons in realistic B-field geometries. It is important to realize that this diffusion of test electrons does nut correspond to a 


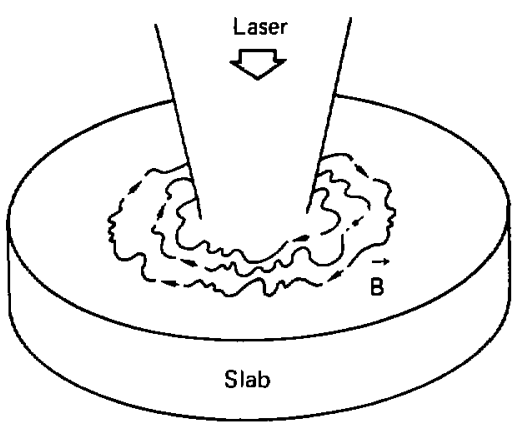

FIC; 38. Schematic representation of total dc magnetic field produced by laser-plasma interaction. in the limit that the field lines are not very stochastic. Jokipii $|119|$ called such a configuration the "Het spaghet ti" model for a turbulent magnetic field.

hydrodynamic motion of electrons. If the electrons begin to drift away from the ions. it is only (wo cits for electric fields to be generated which bring them batk. However. the diffusion of test clectrons docs correspond to a thermal conductivity. The reason is that when electric fields cancel particle fluxes induced by diffusion. they do not cincel energy lluxes. Thus, the test particle diffusion coefficients discussed in this section are a reatsonable approximation to the electron thermal conduction.

Cross-field electron energy transport is well understood in situations whon the field lines ate nicely ordered and nearly straight. Figure 31 illustrates the particle diffusion process when the clectron cyclotron freyuency is large compared to the collision frequency, $\Omega_{\mathrm{ce}} \gg "$ "ei. The step-sice for cross-field dilfusion is the elec-

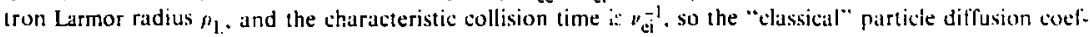
ficient across the field is

$$
D_{\mathrm{cl}}=\rho_{1}^{2} \nu_{\mathrm{u} 1}=v_{\mathrm{te}}^{2} \nu_{\mathrm{ei}} / \Omega_{\mathrm{ce}}^{2}
$$

This is (? "

However, ue have argued above that the field lines in laser-fusion targets are not likely to he particularly well-ordered and straight. In this case one might prefer to describe the total field ats al large-sciale ordered field $B_{v}(x)$, with some smaller-scale fluctuations $\delta B(x)$ superposed:

$$
\mathbf{B}=\mathbf{B}_{\mathbf{o}}(\mathbf{x})+\delta \mathbf{B}(\mathbf{x})
$$

In this case the presence of small-scale fluctuations $\delta$ B can act to enhance the cross-field diffusion over its classical value (94).

This issue of heat transport in a fluctialing de magnetic field has been studied rather extensively in other contexts. Two different regimes present themselves, depending on the degree of disorder of the tutal field. If the fluctuations $\delta \mathbf{B}$ are large enough and if they have appropriate scale-sizes, the tutal tield can be strongly stochastic: two field lines which are close to each other at one point in space can wander awaly from each other randomly, and eventually fill a sizeable fraction of the available volume. In this limit, electrons moving along the stochastic lines can lead to transverse heat flow, due to their motion parallel to the wandering magnetic field. Figure 39 is a crude illustration of such a stochastic situation. 


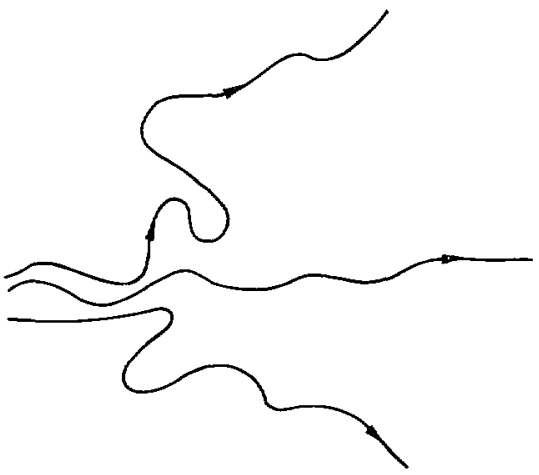

F16. 39. Stochastic magnetic field lines. When the small-scale magnetic perturbations are large enough and of appropriate scale sizes, the overall field line structure can become stochastic: two field lines adjacent to each other at one point in space can wander arbitrarily far apart at other spatial locations. Flectron transport in this type of field structure will be qualitatively different from that in the more regular structure shown in rig. 38.

Several authors lawe investigated electron transport in the stochastic magnetic lields characteristic of lokamak geomelry $[118]$. The application of lokamak-related work to the laser-plasma situation is not im-

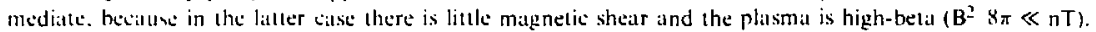
flowerer, it is intuitisely evident that lïeld-line stochasticity must platy at role in laser-produced plasmats ats well as. in 1 ahamatis. if the magnetic field fluctuations around the toroidal mean field are large enough and of appropriate vatial ceales. This in a promising area for further research.

In the upposile limit the mignetic-field luctuations are sufficiently small and well-ordered that the 1wal field retiin a roughly coberent shape, as suggested in Fig. 38. Particle diffusion in such lields has been studied extentsinels in the conlext of cosmic-ray propagation [119].

Applications to laser-produced magnetic fields were discussed in Ref. [69]. The results are shown whemalicatly in l'ig. 40, and miy he summarized ats follows. The general effect of small-scale mognetic field fluetuation, is 16 make cross-field heat flow more rapid than the classical rate for a nontluctuating B field, D.l

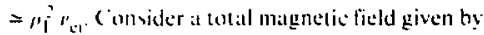

$$
\mathbf{B}=\mathbf{B}_{11}+\sum_{k \neq 0} \delta \mathbf{B}_{k}
$$

and assume for the satke of simplicity that $\Sigma_{k}\left|\delta B_{k}\right| \ll\left|B_{v}\right|$. For very small values of the electron-ion collision

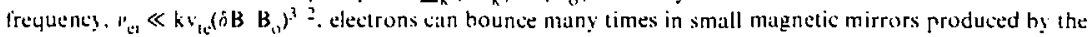
$i B$. Cross-lield drift motion during each bounce then leads to a "neoclassical" dilfusion rate [69]

$$
D_{n c}=D_{i \cdot 1}\left[\sqrt{\frac{\delta B}{B_{0}}} \frac{\pi^{2}}{2} \frac{k^{2}}{k_{n}^{\frac{1}{2}}}\right] \text {. }
$$

where $k_{1}$ and $k$ are the components of $k$ peipendieular and parallel to $\mathbf{B}_{n}$. 


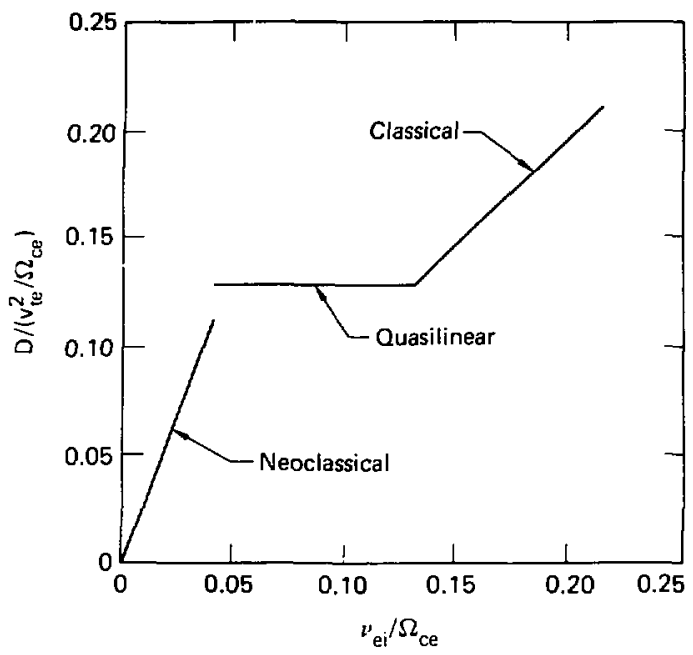

FIG. 41. Cross-field electron diffusion coefficient $[69 \mid$ I) for a turbulent magnetic field such as that of Fig. 38. versus collision frequency $"$ ei. Parameters are $\delta B / B_{0}=0.36$, and in the neoclassical regime $\lambda=\lambda_{1}$, and $\nu_{L} / \lambda_{1}=0.04$.

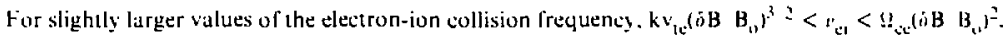
two yuasilinear processes dominate the cross-field heat flow. If the fluctuation scalc-side parallel to $B_{1}$ is cumparable to in electron Larmor radius. $\lambda_{g} \simeq 2 \pi \rho_{\mathrm{L}}$. electrons moving along the field lines are deflected $b$, the $v \times \delta$ B fore once every gyro orbit. This leads to a cross-field diffusion rate due to resonant reatlering $[64\}$

$$
D_{\mathrm{rs}}=\left(\frac{\mathrm{v}_{\mathrm{te}}^{2}}{\Omega_{\mathrm{ce}}} \frac{\sum_{\mathrm{k}} \delta \mathrm{B}_{\mathrm{k}}^{2}}{\mathrm{~B}_{\mathrm{o}}^{2}}\right) .
$$

If $\delta$ Bs are not present with the appropriately resonant parallel wavelengths, diffusion is inste.! deternitfed hs the ransverse "wandering" of the field lines described by Jokipii and Parker [119]:

$$
D_{w}=v_{t_{e}} L_{k}\left(\frac{\sum_{k} \delta B_{k}^{2}}{B_{0}^{2}}\right) \text {. }
$$

Here $L_{i}$ is the correlation length of the fluctuations.

Finally, in the more collisional limit $\Omega_{\mathrm{sec}}\left(\delta \mathrm{B}: \mathrm{B}_{0}\right)^{2}<\nu_{\mathrm{u}}<\Omega_{\mathrm{ce}}$. cross-field trarsport is the chassical value for a magnetized plasma $D_{c]}=\rho_{L}^{2}{ }_{\text {ci }}$. These three regimes of collisionality are depicled in lig. to for plasma parameters listed in the figure caption. (The resonant scaltering expression was used for the "yuasilinear" regime.)

Numerical evaluation of the cross-field diffusion coeflicients given in Ligs. (97)-(99). under plitusible laser-plasma conditions [69], shows that these physical mechanisms produce transporl that is still considerably slower than the classical value for a magnetic field-free plasma $\mathrm{D}_{\mathrm{B}=0}=\mathrm{v}_{\mathrm{ic}}^{\text {? }}$ " $\mathrm{e}$. Thus a nuciuating but non-stochastic laser-produced $B$ field seems capable of explaining some part of the transport inhibition iriferred from experiments, at least at plasma densities less than critical. Stochas:icity would increase the eflective heat flow across the field, but the magnitude of this effect has not yet been studied. 


\section{SCALING OF PHYSICS PROCESSES WITH LASER WAVELENGTH}

The present section addresses uur current understanding of how laser-plasma intractions vary with laser wavelength. This field is just beginning to be explored experimentully. purticularly for lastr wavelengths less than une mieron. Therefore, it seems appropriate to outline the basic physics issues associaled with wavelength staling and to describe our preliminary theoretical predictions. We emphasize laser wavelengths of $1.06 \mu \mathrm{m}$ and shorter, where frequency-multiplication of Nd laser light is espected to provide relerant experimental data.

There has already been a considerable amount of discussion [22.27] comparing $\mathrm{CO}_{2}$ lasers $\left(\lambda_{1}=10.6\right.$ $\mu \mathrm{m})$ with Nd-glass lasers $\left(\lambda_{1}=1.06 \mu \mathrm{m}\right)$. By contrast, the behavior of plasma processes at wavelengths less than a mieron raises neu issues which have nol yet been extensively investigaled, and for th... reason we shall emphasire submicron laser wavelengths.

The plasma phy'sics coupling processes whose wavelength scaling we shall discuss are: 1 ) ahorotion of laser light. 2) hot dectron generation and preheal. 3) stimulated scattering. 4) filamentation, and s; transport inhibilion. We shall show that virtually all of these plasma processes are expected to behale more lavoribly al very short laser wavelengths.

Of sourse the ultimate choice of wavelength for a lision-reactor laser must also take into alciount the wavelength sealing of the basic hydrodynamic processes: ablation pressure, implosion efficiene!. and impl... sion symmetry. W' shall discuss these briefly, showing that ablatio pressure and implosion elficiencs improwe dramatically for short-watelength lasers. By contrast, gocu implosion simmelry is more dillicult to achieve for short than lor long laser wavelengths, and we discuss some of the design trade-offs which or is allow improved symetry for short-wavelength lasers.

In general. the results of this section emphasize the strong potential benefits of lasers with wavelengths considerably less than $\mid \mu \mathrm{m}$.

\subsection{PLASMA PHYSICS AND LASER-PLASMA COLPLING}

\subsection{Absorption of L.aser light}

It is thought that the most important absorption proesses in present experiments are inicerse Bremsitrahlung and resonance absorption. These were diseussed in detail in Section 2. The (wo mechanisms dominate in different regions of parameter space, as shown schenatically in Fig. 41 . For high laser intensities $\mathrm{l}_{\mathrm{I}}$ and long laser wavelengths $\lambda_{1 \text {. }}$ the underdense platsma tends to be collisionless and resonanee ahsorp on is strong. Absorption is roughly $20-30 \%$ independent of $\lambda_{1}$ in this regime.

Inverse Bremsstrahlung (collisional absorption) dominates al stort laser watelengths and lower intensities. The total absorption fraction integraled oser the underdense plasma is given by Fq. (20). For weak absorption, Eqs. (20) and (14) yield a total absorption which scales ats "el (n.) ll. where

$$
\nu_{\mathrm{ei}}\left(\mathrm{n}_{\mathrm{c}}\right) \times 2 \mathrm{n}_{\mathrm{c}} \mathrm{T}_{\mathrm{e}}^{-3 / 2} \times 2 \lambda_{\mathrm{L}}^{-2} \mathrm{~T}_{\mathrm{e}}^{-3 / 2}
$$

A simple argument [120] estimates the scale length as

$$
L=c_{s} \tau_{L} \times\left(Z_{c}\right)^{1 / 2} \tau_{L}
$$

and oblatn, the temperature $T_{e}$ from the absorbed laser intensity:

$$
\alpha_{\text {ats }} I_{\mathrm{l}}=\mathrm{fn}_{\mathrm{e}} \mathrm{m}_{\mathrm{e}}\left(\mathrm{T}_{\mathrm{e}} / \mathrm{m}_{\mathrm{e}}\right)^{\mathrm{i} / 2}
$$




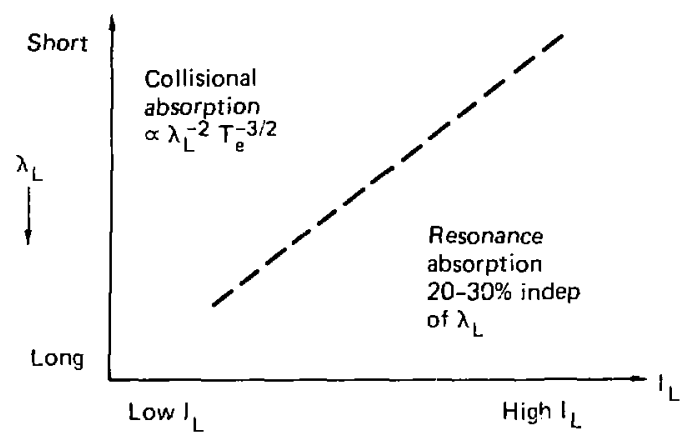

FIG. 41. Regions of (laser intensity, laser wavelength) parameter space where collisional absorption and resinance absorption are dominant. Inverse Bremsstrahlung is strongest at short $\lambda_{1}$ and low $l_{1_{1}}$; resonance absorption at high ralues of $I_{1} \lambda_{1}^{2}$ :

Equations $(100)-(102)$ can be solved for $\mathrm{T}_{e}$ and $\mathrm{t}_{\mathrm{ath}}$. yiclding

$$
\alpha_{\text {abs }} \times \frac{\left(Z^{i / 2} \tau_{L}\right)^{0,1 i}}{1_{l}^{0.4} \lambda_{l}^{j}} .
$$

Thus insersic Bremsstrahlung is predicted to be stronger for high targel $Z$. long laser pulscis ;, low inlemsities $1_{1}$ and especially for short laser wavelengths $\lambda_{1}$. These theoretical trends are confirmed in the datal of fig. t2. $^{2}$ from experimerits at Écoke Polytechnique [121].

\subsubsection{Hot Flectron Generation and Preheat}

Suprathermat electrons are produced when laser light is absorbed by resonance absorption an the critical dersity surface. and by the Raman and two-plismon deciag processes at densities $n_{k}<n_{c}$. thene hot electrons can have long mean free paths, and ean thus cause preheat of in ner target layers or of the fuct regiun. Conseyuences of such preheat include decreased peik fuel densities. or e've higher required liner tenergies to altain a given central density.

Recent research on resonance absorption has shown a somewhat weak dependence of the hol tecttron temperature $T_{h}$ un laser wavelength: Eys. (30) and (31) imply that

$$
\mathrm{T}_{h} \times \lambda_{\mathrm{l}}^{6.6-0.8} .
$$

The range of the hot clectrons is proportional to $T_{\bar{h}}$, and thus

hot electron range $x \lambda_{\mathrm{L}}^{1.2 \cdot 1.6}$.

The range is more sensitive to $\lambda_{L}$, and can be greally reduced by the use of stiort-wavelinglh lasers.

Designs for reactor-sized argets are most vulnerable to protiea from eletrons more energetic than the 10-10 50-keV electrons produced by resonance absorption. This is because the outer shell of the larget tends to be un the urder of $1,2 \mathrm{~mm}$ thick, and thus electrons with $\mathrm{E} \ll, 2 \mathrm{MeV}$ will nol penetrale to the target 


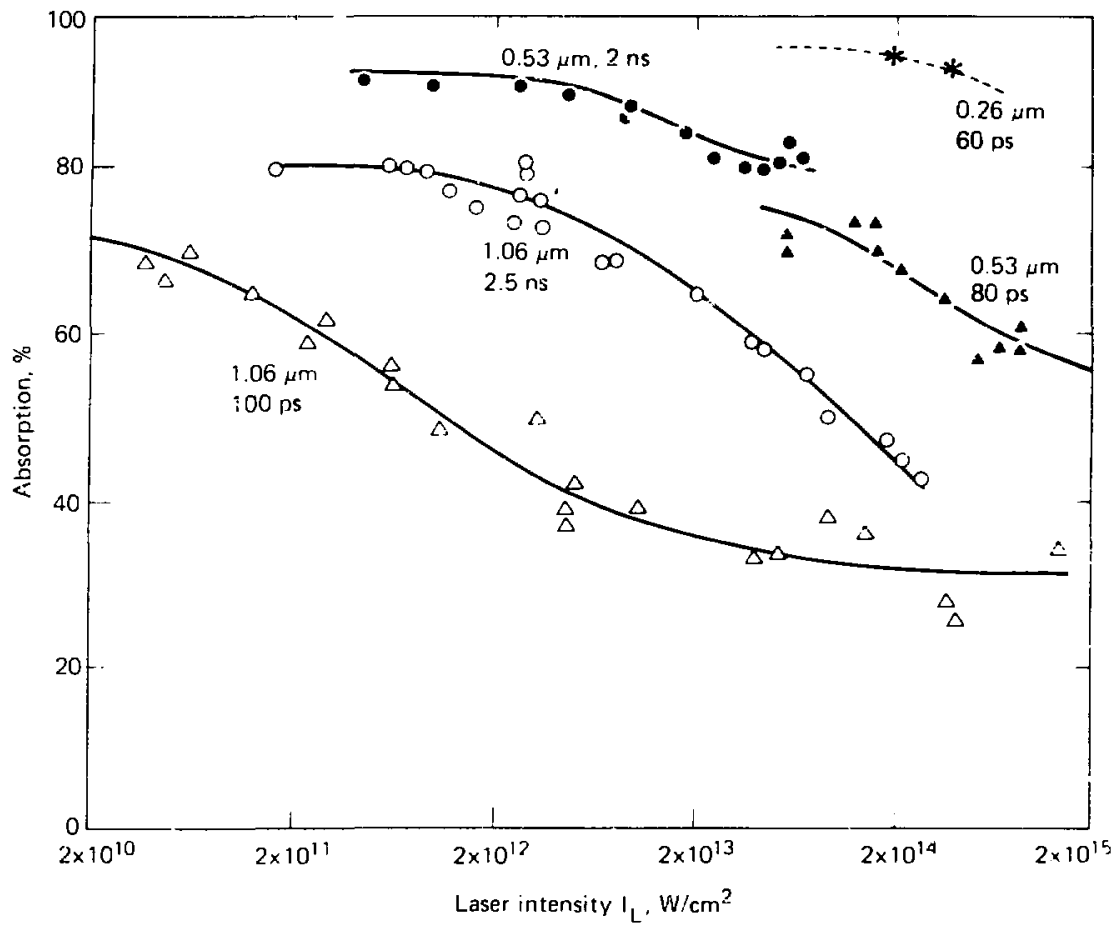

HIG. 42. Fxperimental measurentents of absorption sersus la wer intensits from the Fecule Pelstechnique |1211.

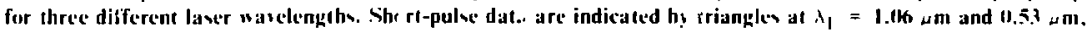
and long-pulse data by circles. The two asterisk in the upper right-hand cormer represent short-pulec aborption

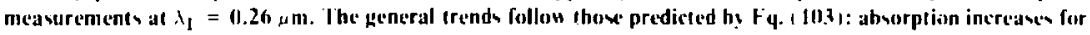
shorter laser wavelengubs. Jower laser intensition. and longer laser pulase lengthe.

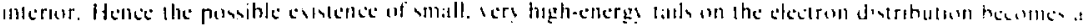
eracial part of an! prohtal prediction.

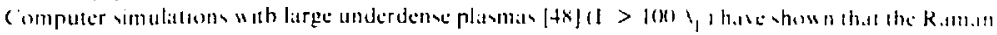

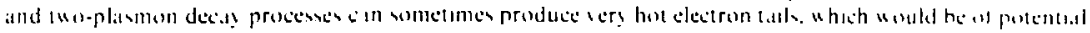

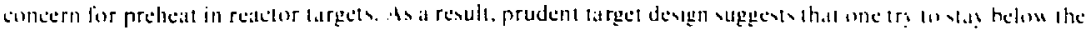

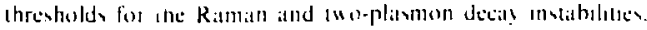




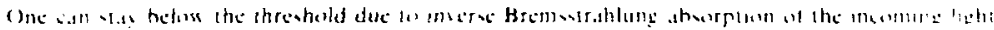
Hal 1 Sietinte: $: 1$.

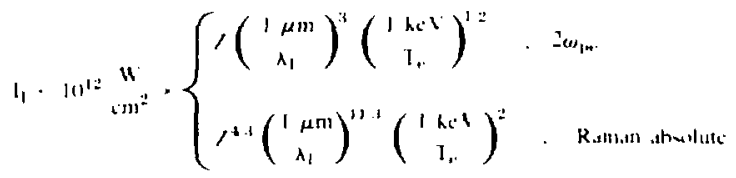
$, 11,0$

ind?.

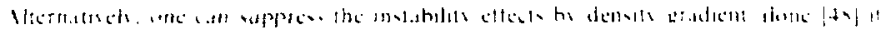

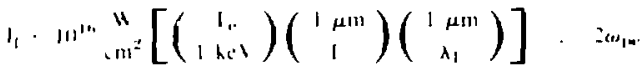

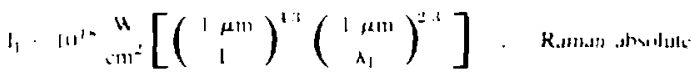

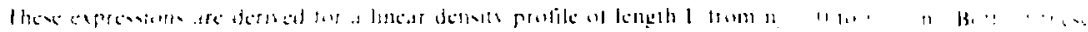

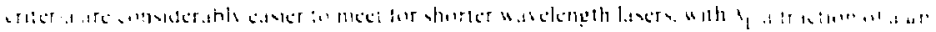

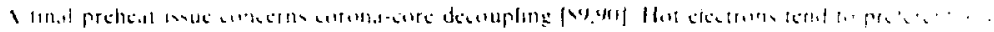

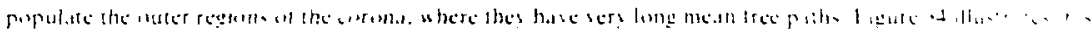

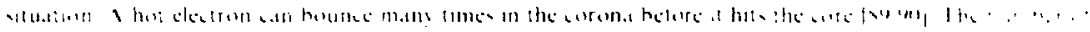

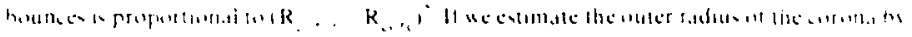

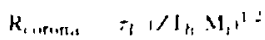

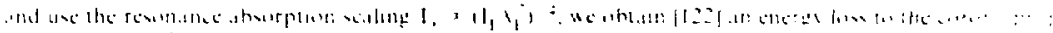

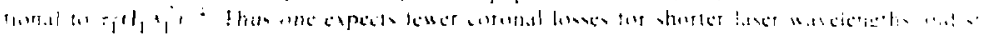
julvis

\section{h. 1. ? Simutaled Scaltering}

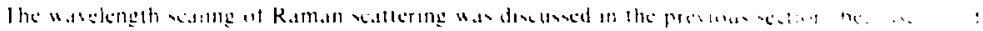

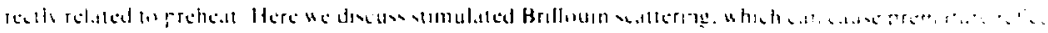

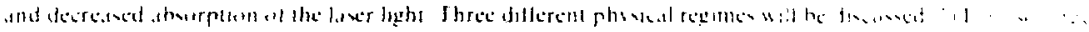

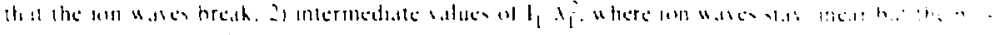

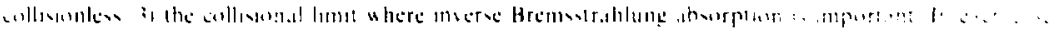

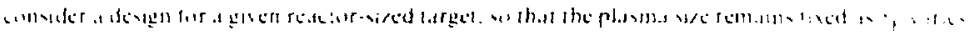

$$
\text { l, I the theh I ahantl i }
$$

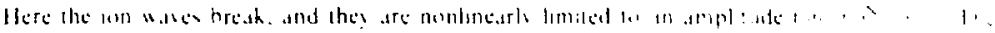

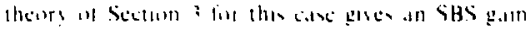

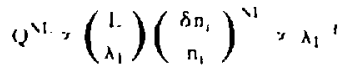

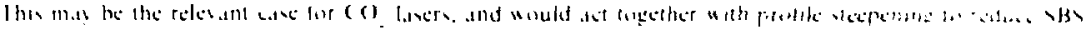

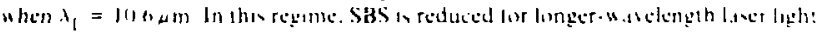


21 mermediate values of $I_{1} \lambda_{i}$.

When the won ualu remain lonear. we shoued in Section 3 I that the total SBS gain citn be paramelrised b!

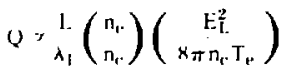

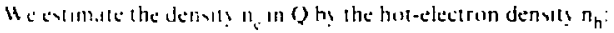

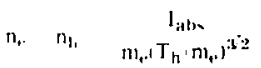

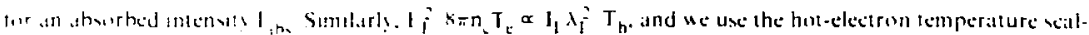

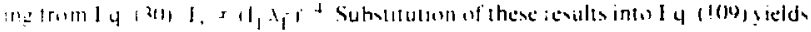

$$
1 \lambda_{i}
$$

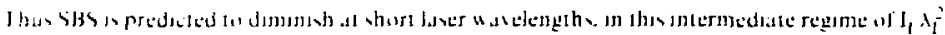

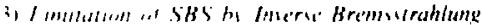

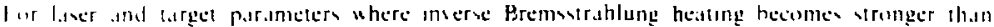

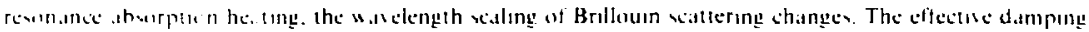

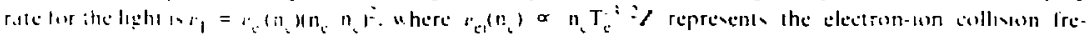

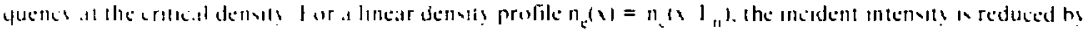

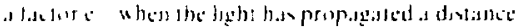

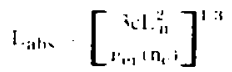

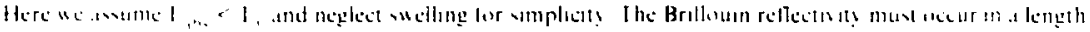

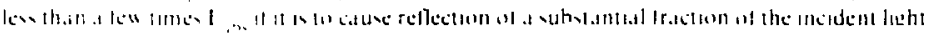

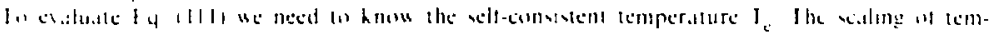

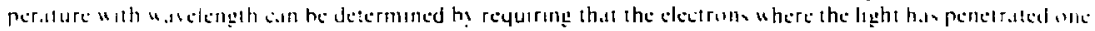

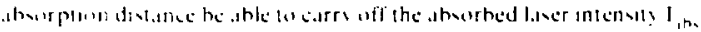

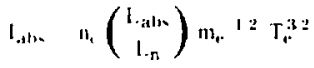

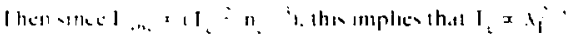

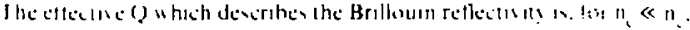

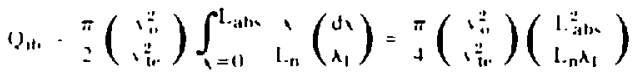

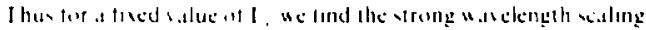

$$
12+\lambda_{i}^{*}
$$


in the regime where inverse Bremsstrahlung is the dominant heating process. In Section 3.1 . f we shou ed that this fav orahle sealing with short laser wavelengths holds for a wide variety of profiles [Eq. (54)]. For a uniform plasmia $[53]$ the above areunents yield the scaling $Q_{16} \propto \lambda_{1}^{11}$ ?

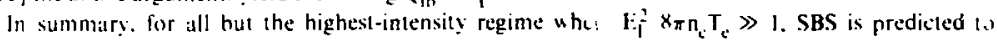
hecome considerably less severe for short-Mavelength lasers. We recall that an alternative waly ton reduce SBS gain is by using a laster with large banduidth. or a laser w ith many appropriately spaced lines [56.:57).

\section{1.4 Filamentation}

l.ike SBS. filamentation hats seteral different scaling regines w hich depend on the baser intensus. At ver high inlensities $1 l_{i}^{2} x_{\pi} n_{c} T_{c} \gg 1 /$ the density profile of the underdenst plasma is very stecp. Computer imulation andwate [4.3] that the underdense plasma has densits of ahout $n_{h}$ 10. Thus. filamentation uould nete il ters longe lenglh of plasmit to grou significantly.

In the intermediale-inlensity regine, the number of spatial gain lengths for filamentation is guca hy

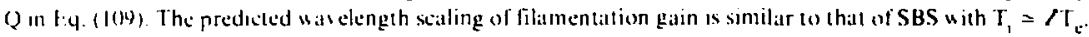
Irom f: 4.11$] 0)$ we then hase $Q \propto \lambda_{1}$ : there should be less filamentation at shorter laser wavelengths. If $T_{\text {, }}$

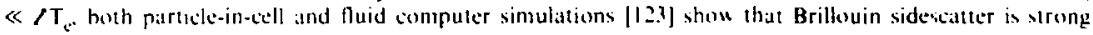
enough w present filament formallion. beciluse the eoherence of the filiaments is dentrosed hy sidescaller. This

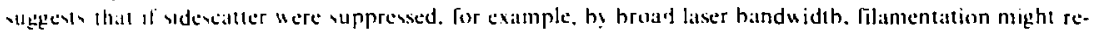
cillerget

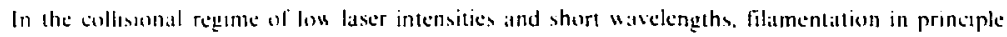
becomes dommated by the foule-heatmg nonlinearity rather than by the ponderomotuse force (Perkins and

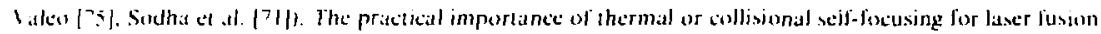
is not vel clear [1:4]

\section{h.1.5 Tranoport Inhibition}

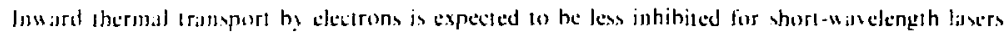
than lor long-watelength liacts.

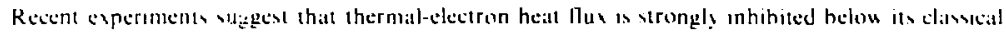

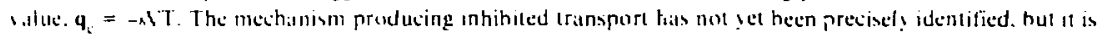

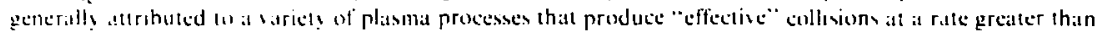

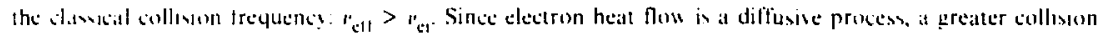

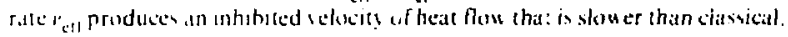

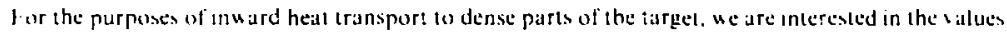

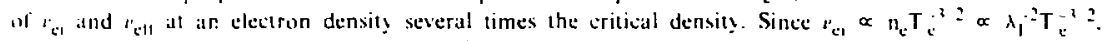
ne sec thall classical collision. increase rapidly with shorter laser wivelengths. As the laser wavelenglh becomes shurter. it then becomes more and more difficult for an "anomalous" plasma physies procesu 11" produce an effectuse collision frequency "eff comparable with "u. Transport inhibition in the over-dence plasmia should thus he less strong for short-wavelength lasers.

Consider magnetic tields as a case in point. Megagauss de magnetic fields are thought is be fenerated by nonparallel dersty and temperature gradients. B! halancing the magnelic field souree with low due to thuid conves:ion.

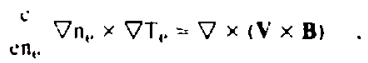

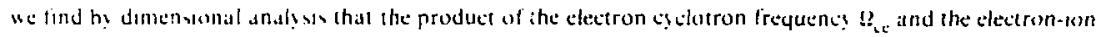
(4)llisis) tums : , 11

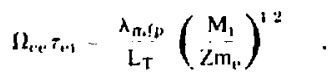

where $\lambda_{m i \Gamma}$ w the sciltering mean free path of an slectron: $L_{T}$ is the temperature gradient scale length: and $M_{i}$. $m_{c}$ are the wh and eicetron messes. 
One expects significant inhibited transport when $! l_{c e}^{\top}{ }_{e l} \gg 1$. The temperature gradient length $L_{T}$ is at least as large as the impressed gradient in the laser-illumination pattern. On the other hand the nean free path $\lambda_{\text {mip }}$ at a fen timen the critical densily seiles as $n_{e}^{-1} T_{e}^{2} \propto \lambda_{l}^{-} T^{2}$. Thus short litser watelenglhs tend to sharply

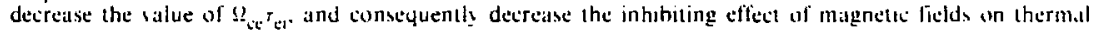
transport into the oser-dense regions.

In a second class of proposed mechanisms for tran port inhihition $[93,95]$. a crucial rule is played hy the collisioniews outward streaning af suprathernsal electrons produced at the critical vurface. Hectrac fields

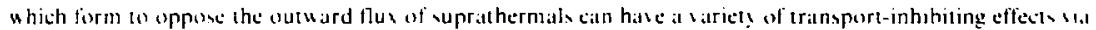

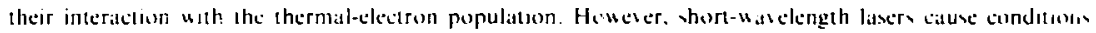

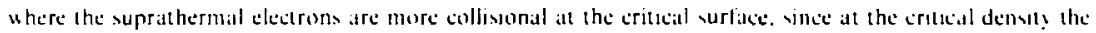
mean liee path säles a

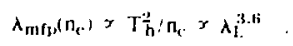

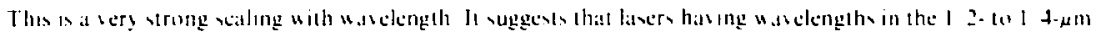

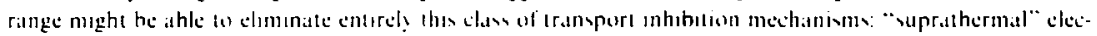

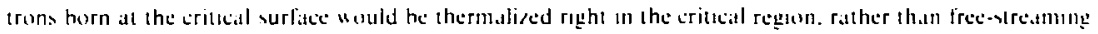
into the underdense plasma and crealung large elestric lictds there

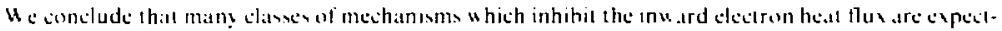
ed to becomc weaker as the laver watelength decreises heles $1 \mu \mathrm{m}$.

\subsection{HYDRODYVAMIS AVIJ IMPLOSION PHYSICS}

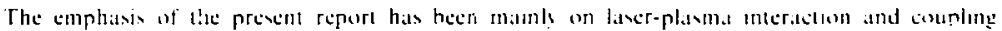

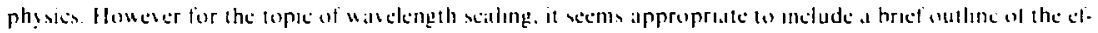

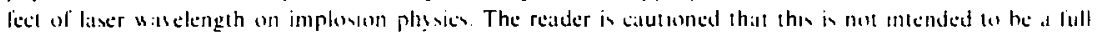
review of the lield.

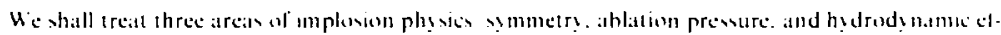
ficiton:

\subsubsection{Implosion Sinmetr!}

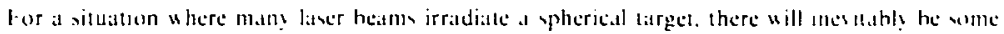

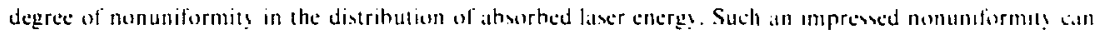
lead to degraded larget perlormance. parlecularis for well targets wh high somsergence ratus

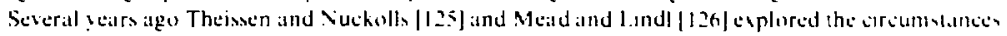

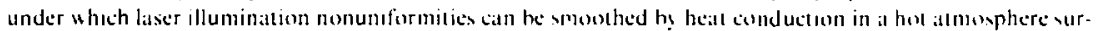

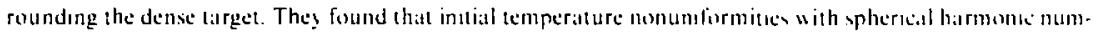

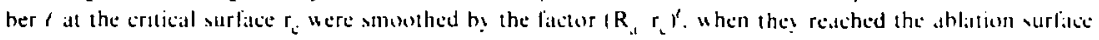

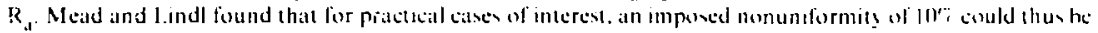

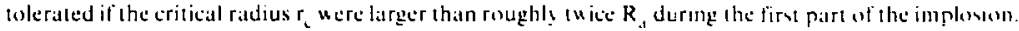

a second requirement for conduction smosthing $|125.126|$ w that the anosphere mus be hat

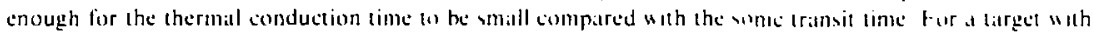
$7=10 . A=20$. thas requirement hecomes

$$
\left.\mathrm{T}_{1} \mathrm{r}_{\mathrm{r}}\right)>\mathrm{T}_{\min }=4.8\left(-\frac{\mathrm{L}}{1 \mathrm{~cm}}\right)^{1 / 2}\left(\begin{array}{c}
1 \mu \mathrm{m} \\
\lambda_{\mathrm{I}}
\end{array}\right) \mathrm{keV}
$$

Here 1 in the we of the atmosphere.

With the ahove two smouthing requirements in mund. we can use the simple spherical stead ablation model of Rel. fif w ask about the waselength-sciling of symmetriatton hy a hot atmosphere. (This mordel 
does not apply w $\mathrm{CO}_{2}$ lasers. where extreme profile steepening and hot electrons dominate corcnal hehavior. nor lo strongly atelerated iargats. Reference [I] predicts the radius and temperature of the critical surface as

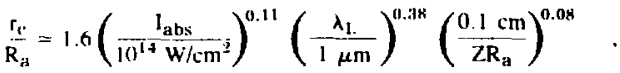

$$
\begin{aligned}
& I_{\mathrm{kcV}}^{T_{0}}=1.7\left(\frac{\mathrm{l}_{\mathrm{als}}}{10^{1+\mathrm{W} / \mathrm{cm}^{2}}}\right)^{0.52}\left(\frac{\lambda_{\mathrm{l}}}{1 \mu \mathrm{m}}\right)^{0 . . \mathrm{k3} 3}\left(\frac{Z R_{\mathrm{a}}}{0.1 \mathrm{~cm}}\right)^{0.11}
\end{aligned}
$$

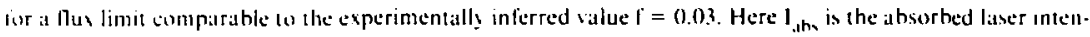
sty cialualed at the surlidee of the dense larget. $R_{,}$

The first crllerion for effective smoolhing is that $r_{6}, R_{A} \geqslant 1.5-2$. Consider for example a target with

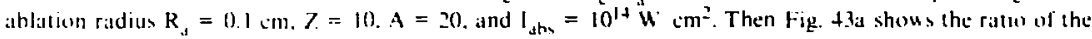
critical to ablation radii $r_{1} R_{1}$. ats a function of laser wavelength $t_{1}$ (Fq. 119 ). It is clear that in this cxample. one needs al laver wivelength $\lambda_{1} \geqslant 2-3 \mu \mathrm{m}$ to be in the desired smoothing regime $r_{\mathrm{c}} \geqslant 1.5-2 \mathbf{R}$.

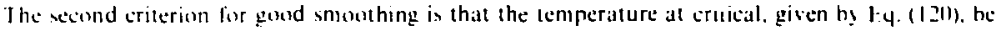

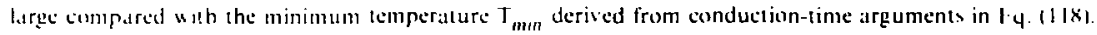

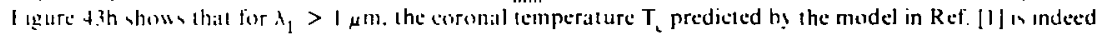
larege compared with $\mathrm{T}_{\text {min. }}$.

Thus the results using the simple ablation model of Ref. 11] are in substantial agrement w th the more detaled numercial analysis of Meid and Lindl: tach of the (wo smoothing triteria are hest mel whth lasers of relattivel! long savelength. $\lambda_{1}>2 \mu \mathrm{m}$, if ane sants to use initial nonuniformties of $\sim 10 \%$ in the ahsorbed liser energy.

In the lirst part of this aatelength-staling section. we shoued that almost all of the lastr-plisnla coupling issues were improved for liser wavetengths considerably smaller that $1 \mu \mathrm{m}$. In the descussion w follow we shall show that ablation pressure and hydrodynamie efliciency are also higher for short-waselength lasery. Thus the symetry issue seents to be the only one where long wavelengths. $\lambda_{I}>2 \mu m$. are more

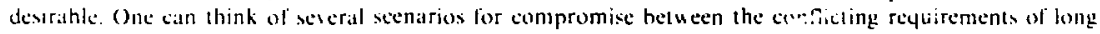
laser "alvelength for symmetry and short wavelength for the remainder of the target physics:

a) References $[125]$ and $[126]$ suggested using a prepulse with $\lambda_{1}=2 \mu \mathrm{m}$ to creale the hort. smosthing atmospitere. Followed hy a main shorter-a avelenglh laser pulse to do the actual inploston. This might allow the best of hoth worlds. since uniformity reguirenents could he relaxed. yet one could still use the optumum short-walelength laser for target compression.

b) One could usc a short-s avelength laser for the entire heating and compression process:

Inder these conditions there would not be a hot, smosthing atmosphere. Conseyuenals, the reyuired st mometry of laser light absorption would be considerably higher. Such a seenario may be feasible by using at larger number of laser beams. and by taking advantage of an appropriate mix of inverse Bremsstrahlung and resonance absorption to optimire the focusing scheme [127].

Both Fahre [128] and Theissen and Nuckolls [125] have noted that these exacting symmetry requirements migh be relaxed if one used snaller-radius targets at the shorter laser wavelengths. For example, one could keep plasma coupling processes well in control by using a constant value of $I_{L} \lambda_{L}^{2}$. and increasing the laser intensity $l_{1}$ as one decreased $\lambda_{1}$. The resulting smaller targets could have lower aspect ratios and perhaps lower convergence ratios. As a result. one might be able to tolerate nonuniformities larger than the $1-2 \%$ level derived h! Mead and Lindl for a high convergence-ratio target. A smaller-radius target might also allow greater flexihilits in choice of a focusing scheme for optimum uniformity of absorption, because the ratio of lastr beam size to larget si<c could be larger. This option of using smaller-radius targets for shorter laser wavelengths needs further quantitative evaluation from the target-design point of view.

c) A third, quite different way to solve the symmetry problem is to convert the incident shortwavelength laser light $10 \mathrm{x}$ rays and then to implode the target using $x$ rays. The latter approach has the potenial of significantly relaxing requirements of illumination aniformity. One is then able to reap the advantages of short-u avelength light for coupling physics, without impairing implosion symmetry. Using this approach, 

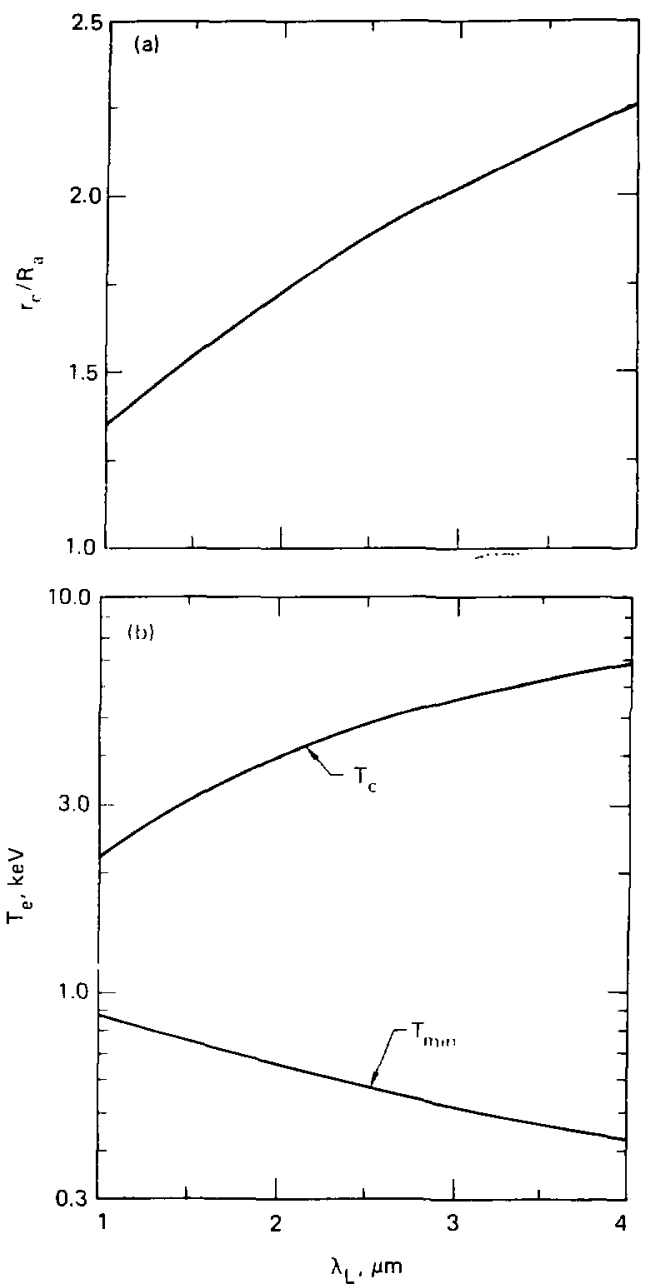

FIG. 43. Wavelength-scaling predictions of a simple spherical ahlation model [ 1]. For this ex ample the ablation radius is $\mathbf{R}=\mathbf{0 . 1} \mathrm{cm}$, the absorbed laser intensity (normalized to $R_{a}$ ) is $I_{a b s}=101+W / \mathrm{cm}^{2}$, and the target material has $A=20, \%=10$ ). a) Variation of criticalsurface radius $r_{c}$ with laser wavelength $\lambda_{I}$. b/ Variation of criticalsurface electron temperature $T_{c}$ and minimum smoothing temperature $\mathrm{T}_{\text {min }}$ Fq. $(118)$, with laser wavelength $\lambda_{\mathrm{I}}$. For $\lambda_{\mathrm{L}}>2 \mu \mathrm{m}$. Mead and L.indl's two symmetry conditions $|126|$ are roughly fulfilled. 
recent experiments at the Laurence Livermore National Laboratory have imploded targets to fuel densition between 100 and 200 tines the densily of liquid D-T $\left(0.2 \mathrm{~g} \mathrm{em}^{3}\right)$, using $1.06-\mu \mathrm{m}$ latser light.

To summarie the results of this symmetry discussion, optimum smoothing by a large, hol altmosphere is oblatinad when a relatively long listr walvelength is usid to create that atnissphere $\left(\lambda_{\mathrm{t}}>2 \mu \mathrm{m}\right)$. Since other larget physits processes uptimire al waselengths eonsiderably shorter than $2 \mu \mathrm{m}$. une might want to use a fong-w alvelength prepulse to ereate the at mosphere, followed bs a short-w atelength main pulise. Alternatively one might be able to achieve adequate symmery with a short-waveleneth laser alont, by using more laser beams and smaller largets. or by converting the laser energy to $x$-ray energy before doing the implosicn. Since the symmery issue is of the essence for high-gain. high convergedice-ratio targets. it is crucial to develop a more quantitative understanding of the advantages and disadvantages of these different alternatives.

\subsubsection{Ablation Pressure}

lmward molion of the dene mpleding target material is drisen by the abiation pressure of the heated cutllowing plasmi. One must therefore understand how ablation pressure scales with laser paranelers such as intensity and $w$ alselength. The main effects mat be illustrated heuristically using the simplified spherical ablattion model of Rel. | l]. (Recill that this model is not valid for a $\mathrm{CO}_{2}$ laser-driven implosion, or for strong inwird acceleration. ?

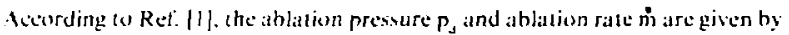

$$
\begin{aligned}
& \mathrm{P}_{\mathrm{a}}=7.2\left[\left(\begin{array}{c}
\mathrm{l}_{\mathrm{abs}} \\
10^{1+} \mathrm{W} / \mathrm{cm}^{2}
\end{array}\right)^{11.57}\left(\begin{array}{c}
1 \mu \mathrm{m} \\
\lambda_{\mathrm{l}}
\end{array}\right)^{11.199}\left(\begin{array}{c}
Z \mathrm{R}_{\mathrm{ab}} \\
0.1 \mathrm{~cm}
\end{array}\right)^{0.07}\right] \text { Mbar } . \\
& \dot{m}=2.3 \times 10^{4}\left[\left(\begin{array}{c}
l_{\mathrm{ahs}} \\
10^{1+} \mathrm{w} / \mathrm{cm}^{\mathrm{I}}
\end{array}\right)^{0.4 \mathrm{M}}\left(\begin{array}{c}
1 \mu \mathrm{m} \\
\lambda_{\mathrm{l}}
\end{array}\right)^{0.42}\left(\begin{array}{c}
\mathrm{R}_{\mathrm{a}} \\
0 . I_{\mathrm{cm}}
\end{array}\right)^{1.49}\right] \mathrm{g} / \mathrm{s} .
\end{aligned}
$$

for a tlus limit $f=9.03$. Thun tor example. the ablation pressure scales roughly ats

$$
p_{\mathrm{il}} \times \mathrm{l}_{\mathrm{i} i \mathrm{in}}^{0,6} / \lambda_{1}
$$

Shorter wasclength, produce hegher ablation pressures. Figure ff illestrates the change in pressure profils with laser wavelength. for $i=0.06$.

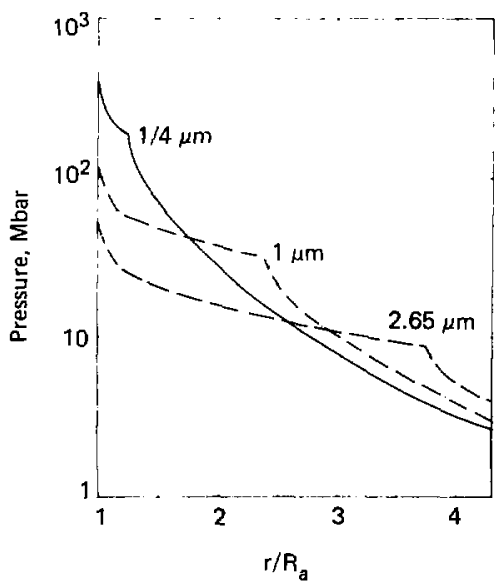

FIG. 44. Pressure profiles predicted by simple ablation model for three different laser wavelengths, with the same absorbed laser power $P_{L}=5 \times 10^{14} \mathrm{~W}$ and target parameters $R_{a}=0.07 \mathrm{~cm}, Z=6, A=12$, and flux limit $f=0.06$. Shorter laser wavelengths produce higher peak pressures at $r=R_{\mathrm{a}}$. Similar behavior was predicted in Refs. [129] and [130] for classical heat flow. 
To assess the impact of this scaling, consider a given target design, optimized to perform at a fixed value of the ablation pressure $p_{a}$. Equation (123) means that if a longer-wavelength laser is used to drive this target, a higher laser intensity will be required to obtain the required fixed ablation pressure $p_{a}$. Equation (123) says that necessary driving intensity scales as

$$
I_{L} \times\left(p_{a} \lambda_{L}\right)^{5 / 3}
$$

Thus an increase of a faclor of 2 in the laser wavelength will require 3.2 times the laser intensity to drive the same target design. As i result $I_{L} \lambda_{L}^{2}$, the parameter which characterizes many laser-plasma coupling processes. will increase by a total factor of 13 for each doubling of $\lambda_{L}$ ! Arguments such as this make short-wavelength lasers look very promising indeed.

Similar trends hold for the mass ablation rate. $\dot{m}$. For spherical targets. Eq. (122) predicts roughly

$$
\dot{\mathrm{m}} \times \mathrm{I}_{\mathrm{abs}}^{1 / 2} / \lambda_{\mathrm{L}}^{0.8}
$$

Although this prediction has not yet been directly tested in spherical geometry. id recent plane-geometry experiment has confirmed that the mass ablation rate increases dramatically at short laser wavelengths. Fabbro et al. [79] measured the amount of ablated material passing outward through the critical surface in a given amount of time. This should be proportional to the ablation rate $\dot{m}$. The experiment used three dilferent techniques to determine the depth of the heated region as a function of wavelength. Figure 45 shows one of these meusures: the foil thickness producing $10 \%$ transmission of the incident laser light. (F: Jiis were made of $\mathrm{CH}$. and the data are normalized to $\mathrm{I}_{\mathrm{l}}=10^{15} \mathrm{~W} / \mathrm{cm}^{2} . \tau_{1}=100 \mathrm{ps}$ for comparison purposes.) lt is obvious from Fig. 45 that much more matter is ablated away for $\lambda_{\mathrm{L}}=1 / 4 \mu \mathrm{m}$ than for $\lambda_{\mathrm{L}}=1 \mu \mathrm{m}$.

\subsubsection{Hydrodynamic E.fficiency}

By implosion or hydrodynamic efficiency we mean the inward kinetic energy of the imploding tilrget. relative to the total absorbed laser energy. With a given amount of inward electron heat Mux. newly heated material at the surface of the cold dense target expands outward. By conservation of momentum. the cold remainder of the target then gets a push inward, due to the rocket elfect. Figure 29 illustrales this process.

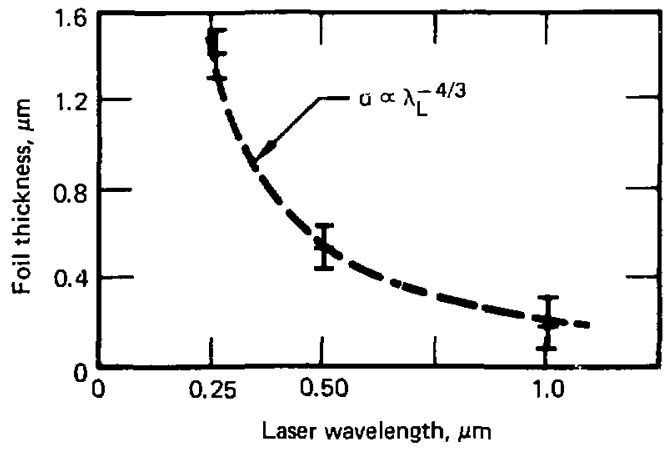

FIG. 45. Experimental measurement by Fabbro et al. [79] of the foil target thickness producing $10 \%$ iransmission of laser light, at three different laser wavelengths. Data are normalized to $I_{L}=1015$ $\mathrm{W} / \mathrm{cm}^{2}, \tau_{1}=100 \mathrm{ps}$ for comparison purposes. Foil material was $\mathrm{CH}$. It is clear that much more matter was heated for $\lambda_{L}=1 / 4 \mu \mathrm{m}$ than for $\lambda_{\mathbf{L}}=1 \mu \mathrm{m}$. 
Transport inhibition influences the implosion mechanism beciuse as inward transport becomes impeded. smaller and smaller fractions of the absorbed laser intensity are put into inward heal mow. Instead. the absorbed intensity goes increasingly into driving the expansion of plasma outside the critical surface. Thus. the inner parts of the target receise less energy tlux and implode less vigorously.

For casts where the ponderomotive fore is ueak, the critical density surfice is farther from the ablation surface for long laser wavelengths than for short ones. This is illustrated in Eq. (1 19). As a conseyuchce, "e shalt show that transport inhibition hals a relatively larger injpite on implosion properties for longer-

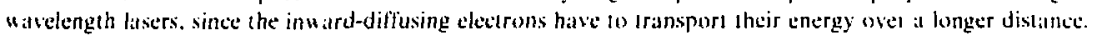

The simple spherieal ablation mudel of Ret. [1] can be exlended to derise the hydrodynamic stficiency of an implosion [55]. One starts by integrating the momentum equation

$$
\rho \frac{d v_{r}}{d t}=-\frac{\partial p}{\partial \tau}
$$

over a spherical wiume whose outer radius is just inside the ablation radius $R_{a 1}$, When the shell moves inmard logether, one obtains

$$
\mathrm{n}(\mathrm{t}) \frac{\partial \overline{\mathrm{v}}}{\partial \mathrm{i}}=-4 \pi \mathrm{R}_{\mathrm{a}}^{\mathrm{a}} \mathrm{P}_{\mathrm{a}} .
$$

where m(t) is the mats remaining in the shell at time t, and $s$ is the mean inward velocity of the shell.

The ablation theory of Ref. II gives expressions for the sealling of the malss athlation rate $\dot{n}$ and the ablation pressure $p_{,}$with the shell radius $R_{a}$ :

$$
\dot{m}=\dot{m}_{0}\left(R_{a} / R_{0}\right)^{a} \cdot p_{a}=p_{o}\left(R_{a} / R_{0}\right)^{-b} .
$$

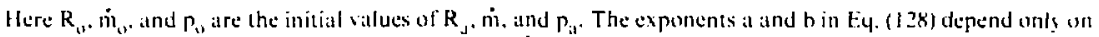
the tlux limit li One can nom divide Eq. (127) by $\dot{m}$. to obtain

$$
m \frac{d \bar{v}}{d m}=\left(\frac{4 \pi R_{11}^{2} P_{01}}{n_{0}}\right)\left(\begin{array}{l}
R_{01} \\
R_{a 1}
\end{array}\right)^{h+4-\underline{z}}
$$

Numericilly, the value of the exponent $b+a-2$ is quite close to gero. For the experimentally observed vilue of the tlux limit $f=0.03$, one has $b+a-2=10^{-2}$, and $b+a-2$ remains less than $10^{-1}$ for all thux limits $\mathrm{f} \leqslant 0.6$. He shall nitke the approximation $\mathrm{h}+\mathrm{a}-2=0$ in $\mathrm{Eq}$. (129), and integrate to oblain the rockel equation

$$
\bar{v}=\left(\frac{4 \pi R_{0}^{2} \Gamma_{0}}{\tilde{h}_{0}}\right) \& n\left[\frac{m(t)}{m_{0}}\right] .
$$

Thus in spherical geometry. including the effects of the lull temperature, densily, and velocity protiles, one ohtains a rocket equation exately analogous to the usual planar "cold rockel" result

$$
\left.\bar{v}(t)=v_{\mathrm{ex}} / \mathrm{n}\left[\frac{\mathrm{m}(t)}{\mathrm{m}_{\mathrm{o}}}\right]\right] .
$$

In the spherical ease the elfective exhaust velocity is

$$
V_{\mathrm{vx}}=\frac{4 \pi \mathbf{R}_{\mathrm{u}}^{2} \mathrm{P}_{0}}{\mathrm{~h}_{\mathrm{v}}}
$$


with the initial ablation pressure $p_{0}$ and mass ablation rate $\dot{m}_{0}$ evaluated using expressions (121) and (122) (or their analogues for different values of the Mux limit $f=0.03$ ).

Equation (130) for the mean inward velocity of the shell can now be used to find the hydrodynamic efficiensy $t$ :

$$
\epsilon \equiv \frac{(I / 2) m(t) \bar{v}^{2}}{P_{a b s} \tau_{L}}=\left[\frac{2 \pi R_{0}^{2} p_{0}^{2}}{l_{a b s} \dot{m}_{0}}\right]\left(\frac{x \ell n^{2} x}{1-x}\right),
$$

where $\mathbf{P}_{\text {atss }}$ and $\mathrm{I}_{\mathrm{abs}}$ are the absorbed laser power and intensity, $r_{L}$ is the luser pulse leng:h, and $x \equiv m(t) \cdot m_{0}$ is the fraction of mass remaining in the shell after a time $t$.

The factor in parentheses in Eq. (133) optimizes for $x=0.2$, when $80^{\circ}$ of the initial shell mass has been ablated away. We can obtain the wavelength scaling of the hydrodynamic efficiency by examining the factor in square brackets in (133). Using the results of Ref. [1] for $p_{a 1}$ and ris as a function of tlux limit $f$ and laser wavelength $\lambda_{I}$. it is straight forward to show that

$$
\epsilon \times \lambda_{L}^{-\mu}
$$

where the exponent p varies from 1.2 to 0.5 , as the flux linit fonges from 0.03 to 0.4 . Figure 46 show s the exponent $p$ as a function of $l$;

Within the validity limils of the simple ablation model (few hot electrons, weak ponderomutive force, gentle aceleration), it is sear from Eq. (134) and Fig. 46 that implosion etficiency increalses dramatically for short-wavelength lasers. The increase is strongest for very inhibited transport. as cxplained at the beginning of this section. But even for nearly classical values of the flux limit. the inplosion efficienc! scales as $1 ; \sqrt{\lambda_{L}}$. For the case when transport is completely classical, Refs. [129] and [130] found .imilar results: the implosion efficency is highest at the shortest laser watelengths.

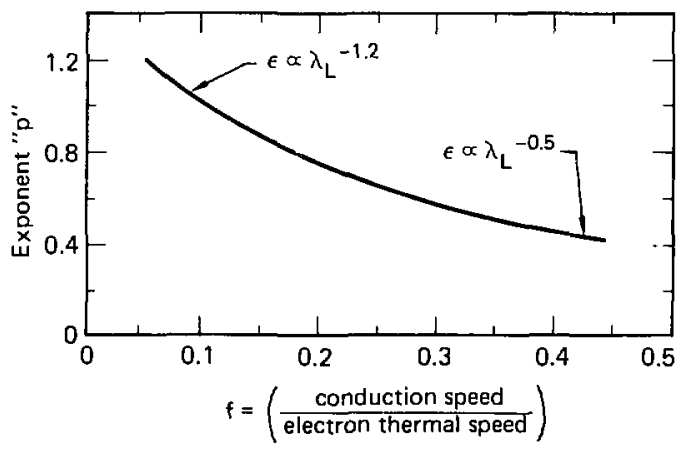

FIG. 46. The simple spherical ablation model of Ref. [1] predicts that hydrodynamic implosion efficiency $\&$ is proportional [55] to $\lambda_{1}^{-p}$, where $\lambda_{L}$ is the laser wavelength. This figure plots the exponent "p" as a function of the flux limit $f$, which measures the degree of transport inhibition. In all cases the efficiency is best for short laser wavelengths. 
The results of our wavelength-scaling discussion may be summari/ed as follows. If ue consider laser wavelengths between a few microns and a fraction of a micron, we hase shown that laser-plasma soup! ing. ublation pressure, and implosion efficiency are all more favorable for the shorlest litser wavelengths. B! col,trast. implosion symmetry seems easier to achieve for longer-wavelength lasers. We discussed several wilys in which symmetry might be improved for short-wavelength lasers. If these methods for better symutri/ation prove effective. the results of this section point strongly to the putential benelits of submicron laser wavelengths. 


\section{REFERENCES}

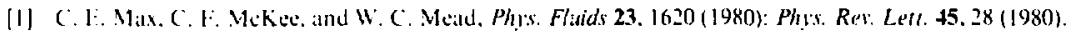

[2] R. L.. Morse and C. W. Neilson. Phis. Fluids 16. 909 (1973).

[3] W. M. Manheimer and H. H. Klein. Phys. Flaids 18. 1299 (1975).

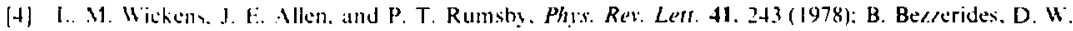
Forslund. and r. J.judman. Phis. Flaws 21. 2179 (1978).

15] 1. V. Guresich et al.. Sor: Phin - JETP 22. 449 (1966): ibid. 27. t/6 (1968).

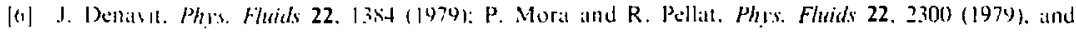
refierilsw therwin.

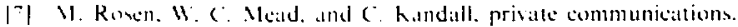

[s] S. Gilomer. R. Vhrse. and B. Vewherger. Phis. Fluds 20. 23411977): L. Montierth and R. L. Morse.

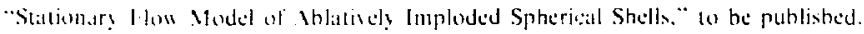

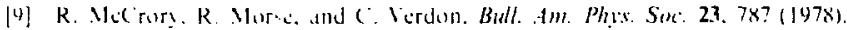

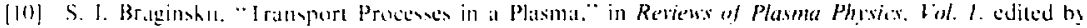
11. 1. I contorict KComultant, Burcitu, X.Y. 1965).

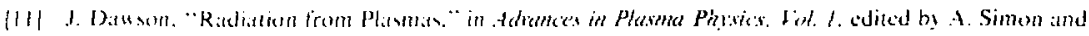
II. Thempenon (Inlersiente. X.Y. 1968).

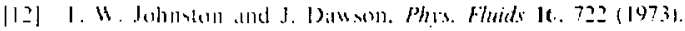

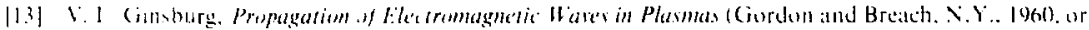

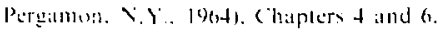

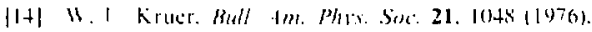

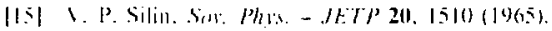

[16] 11. Brish. I Phu, 18. 126011975).

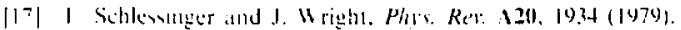

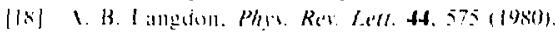

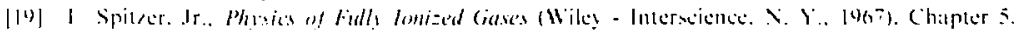

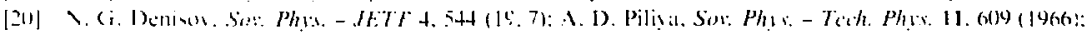

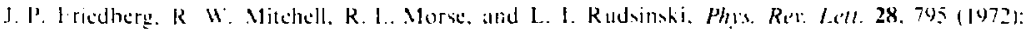

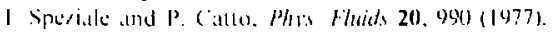

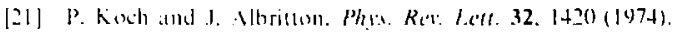

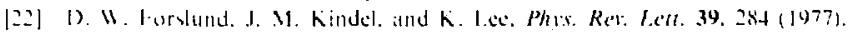

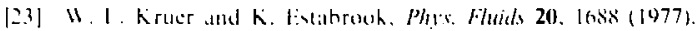

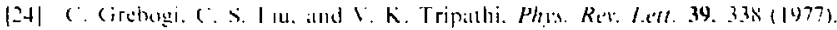

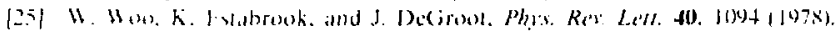

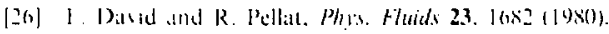

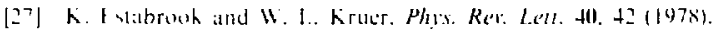

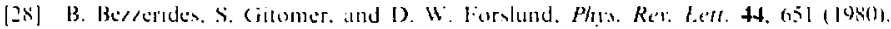

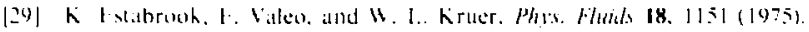

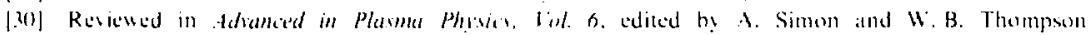

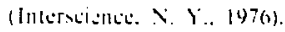

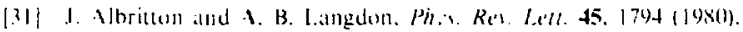

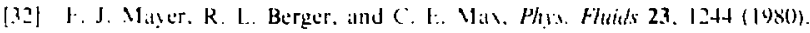

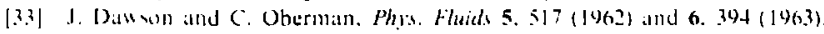

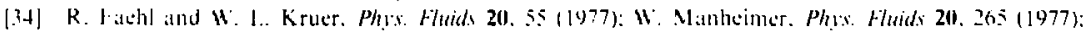

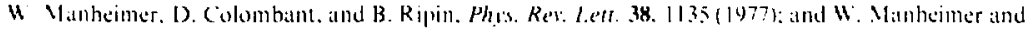

D) (alombant. Phis. Fluids 21. 1818 (1978).

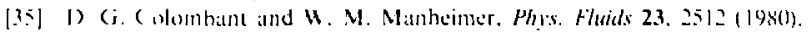

[36] 1). 4 lorslund ed al.. Bull. Am. Phis. Soc. 20. 1377 (1975).

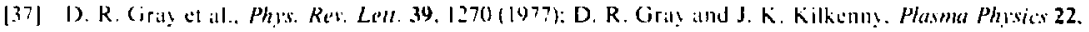

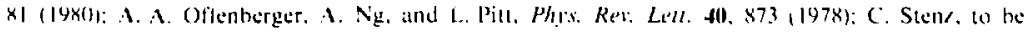
publishad. 


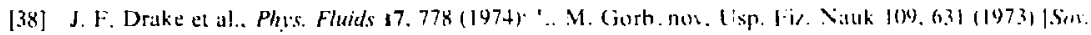

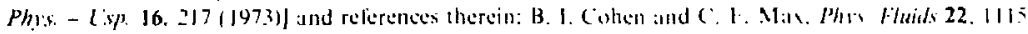
(1979).

[39] M. D. Posen ano J H. Nuckolls. Phrs. Fluids 22. 1.393 (1979): 1. K. Storm. J. T. L.arún. I. I1.

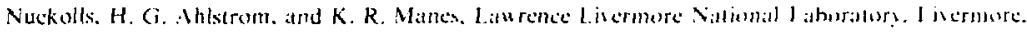

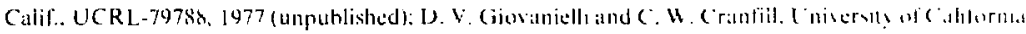

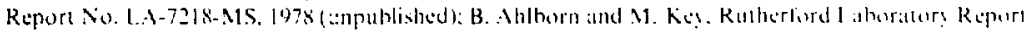
Vo. RI.-79033, 1979 (to he published).

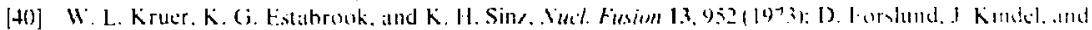
F. Lindman. P/ris. Flaids 18. 1002 and 1017 (1075).

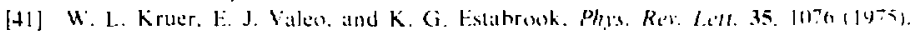

[42] W. C. Mead el al.. Phis. Res. Letr. 37. 4k91197(6).

[43] D. W. Forslund. private communiciltion.

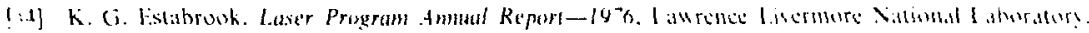

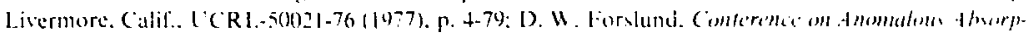

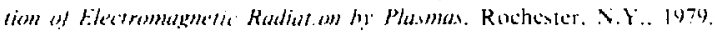

[45] H. l.. Kruer. Phy the thids 23. $1273(19 \mathrm{~s})$ ).

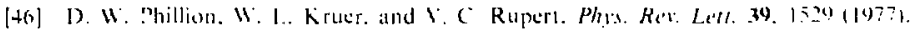

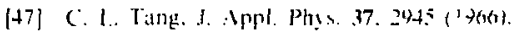

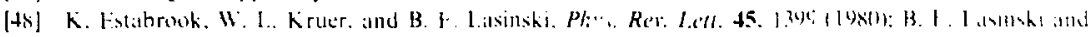

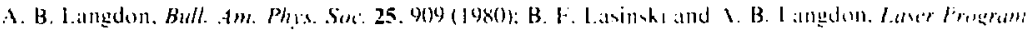

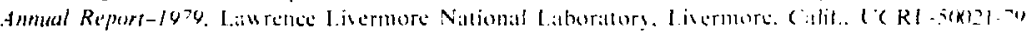
1960). P. 3-23.

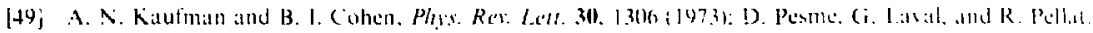
Phys Rex Lett. 31. 203 (1973).

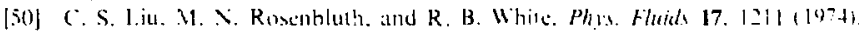

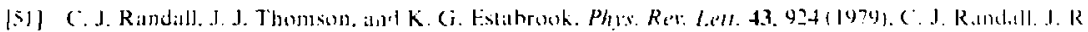
Alhrittom. and J. J. Thomson. Phis. Fluids 24. $147+(198 \mathrm{I})$.

[52] (․ J. Randiall. privale communications.

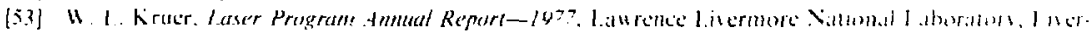

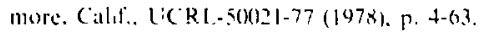

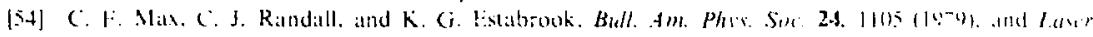

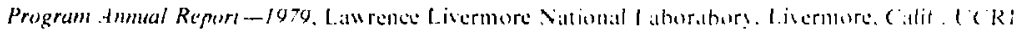
$5(1) 21-7911980)$. p. 3.35.

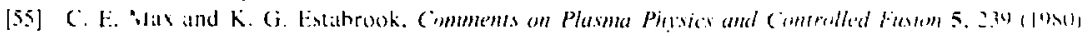

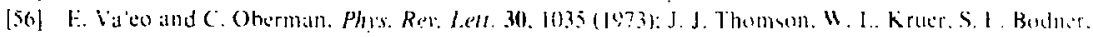

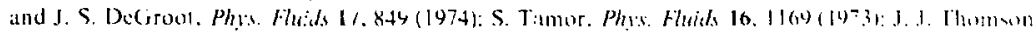

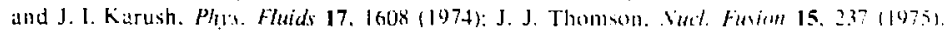

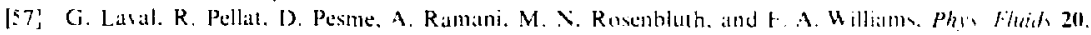
$2049(1977)$.

[58] C. F. Mat. Phis. Fluids 16, 1480 (1973). Table II.

[59] W'. M. Manheimer and H. Klein. Phis. Flude 17. 1889 (1974).

[60] 1:. A. Jackison. Phis. Rev. 153. $235(1967)$.

[61] J. H. Drake and Y.C. I.ec. Phys. Ret. Le?. 31. 1197(1973).

[62] A. B. langdon. B. F. Lasinski. and W. I Kruer, Phis. Rov. Lent. 4.3. 1.3.3 (1979).

[63] H. H. Chen and (. S. Liu. Phys Rei: Lei. 34. 88: 11977).

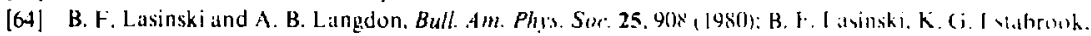

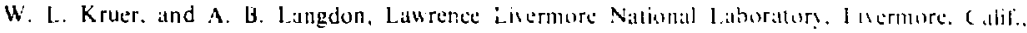
UCRL-84827 (1981).

[65] K. G. Filabrouk. W. L. Kruer. and B. F. Lasinskt. Phis. Re's. Lethers 45. 1360) (1980): W. 1. Krutr. K. (i. Ratabrouk, B. F. Jasiniki, and A. B. Langdon. Phas. Flaicin 23. 1.326 (1980). 
[66] M. Mostrom. Ph.D. Thess. Phy ides Department. Laurence Berkelez Laburatory. Berkete!. (Calit $\left(197^{\top}\right)$.

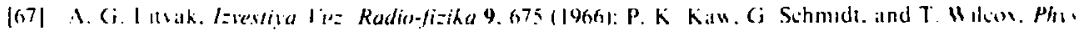
Fluids 16. 1522 (1973): J. W. Shearer and J. 1.. H.ddlentan. Phis. Fladh 16. 1753 (1973.

[68] J. J. Thomson. W. I. Krutr, A. B. I.angdon. C. L. Max. and 4 I Mead. Laser Program Ammat

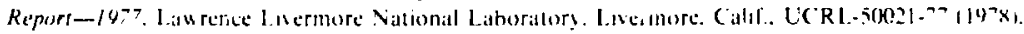
p. +40 .

|(6) ( .1 Max. II. M. Manheimer. and J. J. Thomson. Phis. Flaids 21. I28 (1978).

[70] T. P. Donildson and J. J. Spalding. Phis. Rev. Let/er. 36. 467 (1976): O. Willı and P. Rumb!. Ithh

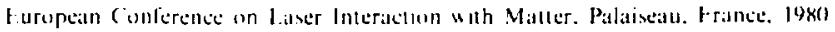

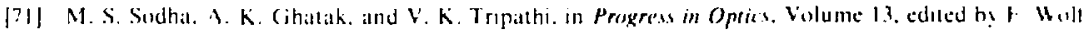

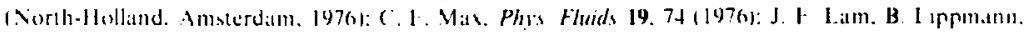
and 1. Tappert. Phas. Fhads 20. 1176,1977$)$. D. Anderson and M. Bonnedal. Phas Hhid. 22. 105

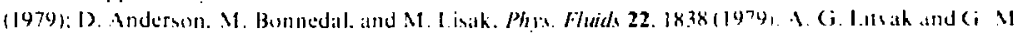

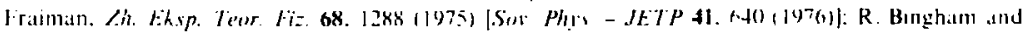
(. N. Iashmore-[) as ics. Plasma Phavics 21. 43.311979$)$.

1721 1. Vialew. Phis Fhids 17.1391 (1974).

[7.3] A. B. 1.angdon and B. F. I.asinski. Phy. Rev. Ledt. 34. 934 (1975).

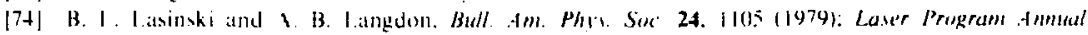

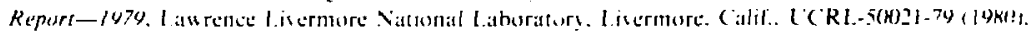

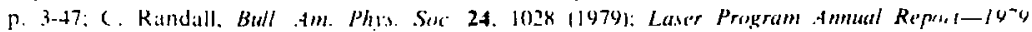

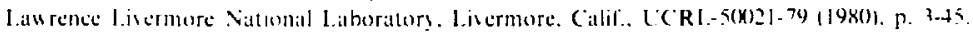

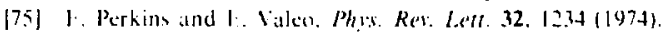

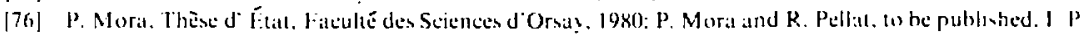

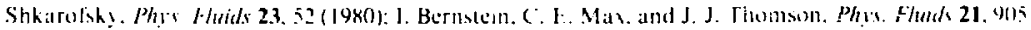
(1978).

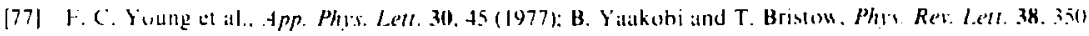
(1977): W. 1. Kruer. Comments on Plasma Phys and Comtrolled Fusiom 5. 69 (1979): 1). L. Banuer and W. C. Mead. Laxer Program Ammad Report-1979. L.awrence Livermore Nalional Laboratory, lincrmors. Calif.. LC RI.-500)21-79 (1980), P. 6-12.

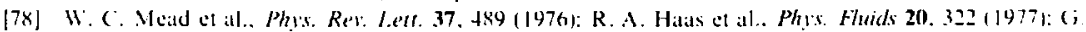
Meclellan. P.H.Y. I.ete and (i. Caporaso, Phys. Re't: Lent A4. 658 11980).

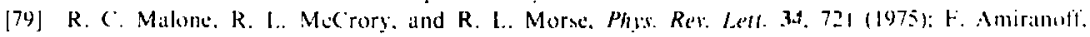
R. Fibhre. Fe Fibre. C. Giarbaln, J. Virmont, and M. Weinleld, Phis. Re, Lett. 43. 522 (1979): I.

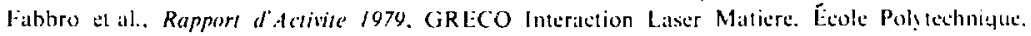
Palitiseau, France. Pр. 113-129.

[K0] M. D. Kosen et al.. Phys. Flaids 22, 2020 (1979).

[8I] K. Mitchell and R. Corduin. App. Phys. Lett. 49. 3851 (1977); J. D. Hares. J. D. Kilkenny. M. H. Key. and J. G. Lunnes, Phys. Rev. Letr. 42. 1216(1979): A. Zigler, H. Zmora. and J. L. Scrwab. Phis. Lett. 6.3.1. $275(1977)$.

[82] D. W. Forslund, J. Geophyx. Res. 75, 17 (1970); R. J. Bickerton. Nucl. Fusiom 1.3, 457 (1973): ik. Munheimer, Phys. Fluids 20. 265 (1977i: D. R. Gra) and J. D. Kilkenny. Plasma Plivics 22, 81 (1980) and references therein.

[8.3] L. Spitzer and R. Harm, Plys. Rev. 89. 977 (1953).

[8-1] F. I.. I.indman, Joumal de Physique, Colloque C6. supp. 12. tome 38, pp. C6-9 (1977).

[85] W. C. Mead. Lawrence Livermore National Laboratory, Livermore, Calif., UCRL-85246 (1980).

[86] E. J. Valeo, Laser Program Ammal Report-1976. Lilwrence Livermore National Laboralory, Livermere, Calif., UCRL-50021-76 (1977), p. 4-101: A. Ramani and G. Laval, Phỵs. Fluids 21. 980 (1978): T. Okada. T. Yabe and K. Niu. J. Phys. Soc. Japan 43. 1042 (1977): H. Takabe at al., 14th European Conference on Laser Interaction with Matter, Palaisealu. 1980. 


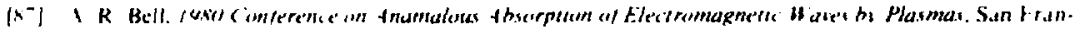

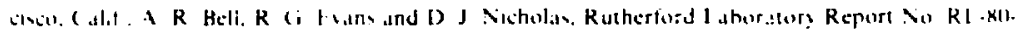

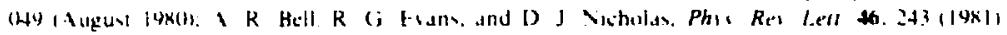

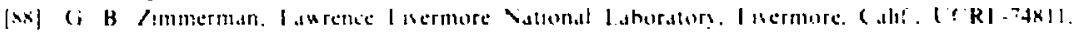
1) $y^{-} 3$ i) (unpuhlished)

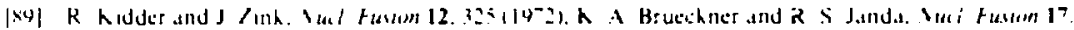
Ins: $\left(14^{-4} 1\right.$

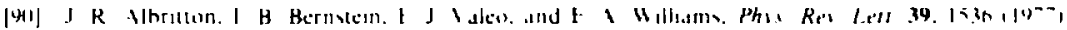

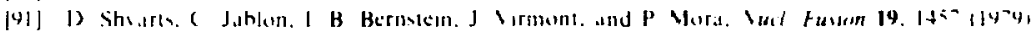

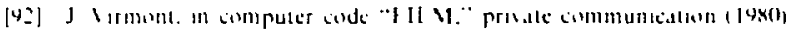

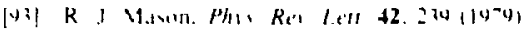

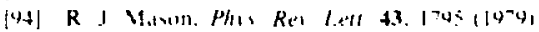

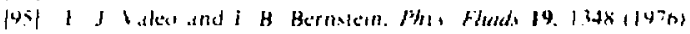

[w] It I hri .. proble communtiallun

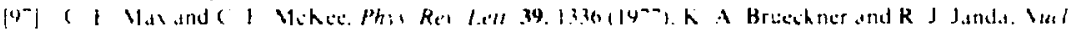

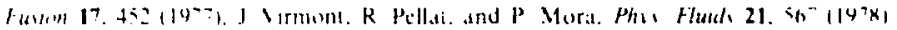

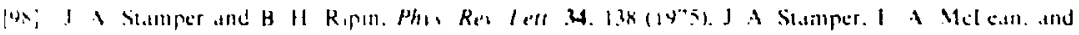

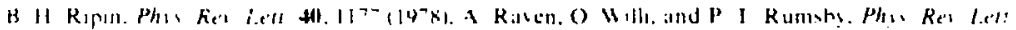

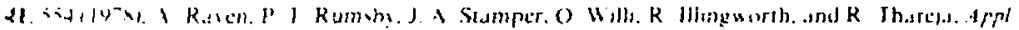

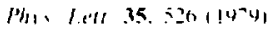

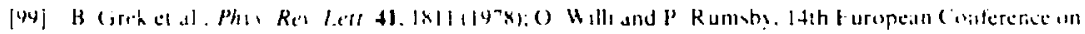

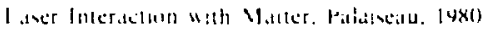

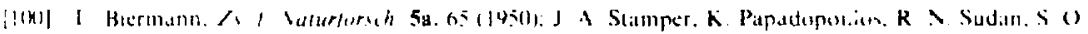

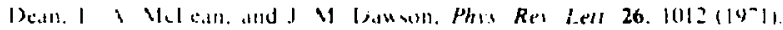

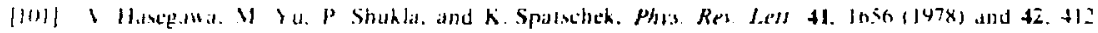
$\left.(\mid)^{-}\right) \mid$

[102] I B ( hince. I 11 I eblans. and I R W Ison. Phis. Fluids I6. 1142 (1973).

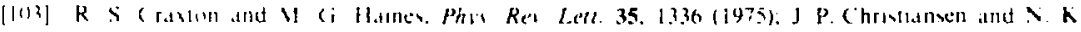
Binur. Comr Pho (comm 17. 397 (1479): Rutherford Laboratury Annual Report lo the 1 ascr

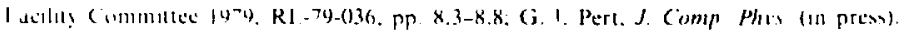

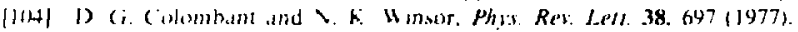

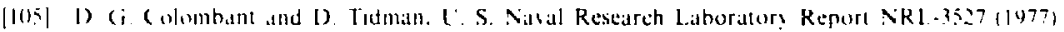

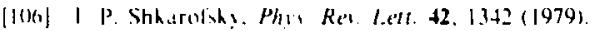

[107] R A. Haas. W. (. Mtild, W. 1.. Kruer. D. W. Phillion, H. N. Kornblum, J. D. I.nnd. D. MadQuigg. V. ( . Rupert. and K. (i. Tirsell. Phys. Fluids 20. 322 (1977).

[|c|x| J. Daw won and F. Villeo, proate communication (1972).

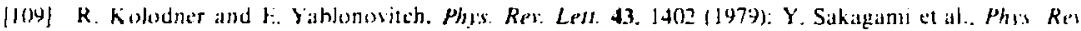
l.ell. 12.839 (1979)

11101 M. (i. Drouet ind R. Bollon. Phys. Rev. Letr. 36, 591 (1976): M. (j. Drouel, in Laser Inleraction and Relared Plasma Phemomena. Vol 4 B, edited by H. Schwars and H. Hora (Plenum, N. Y., 1977), p. 737.

1111 D. A. Tidman. Phys. Rei. Letr. 32. 1179 (1974): D. A. Tidman. Phy. Fluidr 18, 1454 (1975).

[112] J. A. Stamper and D. A. Tidman, Phis. Fluids 16, 2004 (1973).

[113] J. A. Stamper, Phys. Fluids 18, 735 (1975): Phy:s. Fluids 19. 758 (1976).

[114] J. J. Thomson. C. E. Max, and K. G. Estabrook, Phys. Rev. Lett. 35, 663 (1975).

[1]5] B. Bezcerides, D. F. DuBois. D. W. Forsiund, and E. L. Lindman, Phys. Rev. Lett. 38, 405 (1977): B. Bcezerides. D. F. DuBois, and D. W. Forslund, Phys. Rev. Al6, 1678 (1977): K. Nishihara, Y. Ohsaua, K. Mima, and T. Tange. Phys. Fluids 19, 1833 (1976); A. Abdullaev, Yu. Aliev. V. Bychenkov, and V. Stefan, Phys. Lett. 71A, 63 (1979).

[116] A. B. Langdon. Phys. Fluids 21, 705 (1978). 


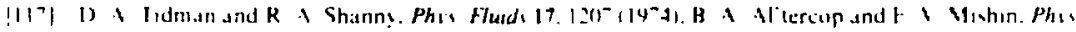

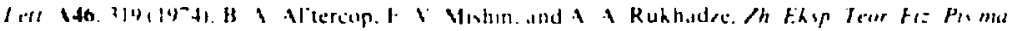

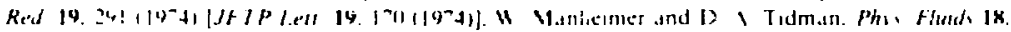

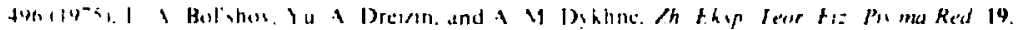

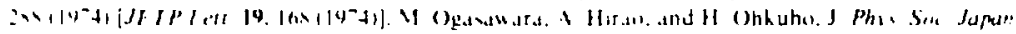

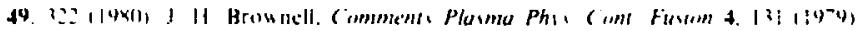

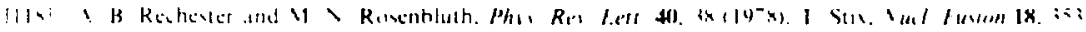

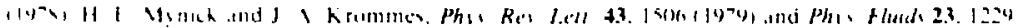

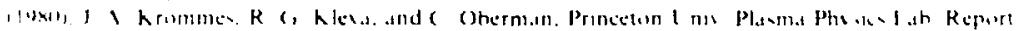

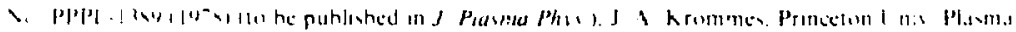

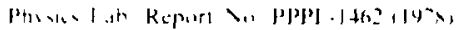

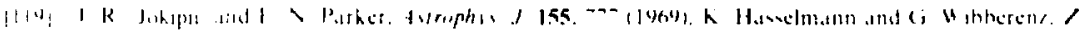

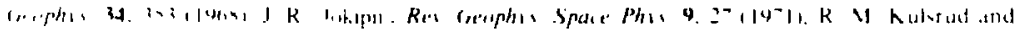

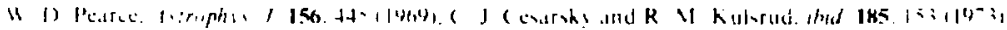

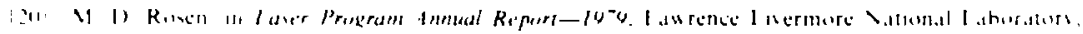

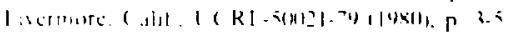

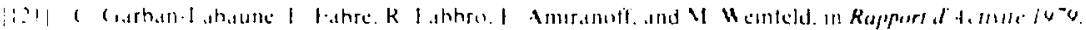

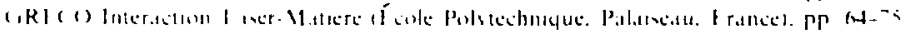

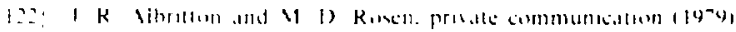

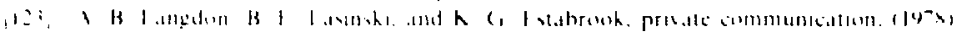

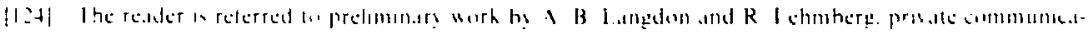

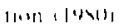

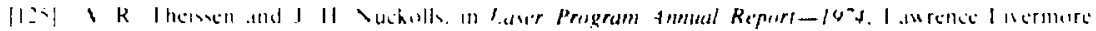

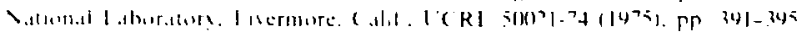

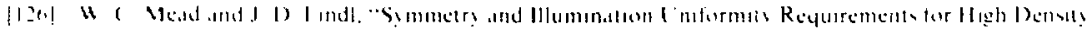

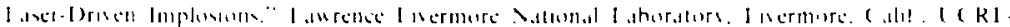

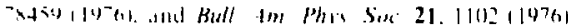

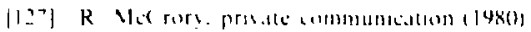

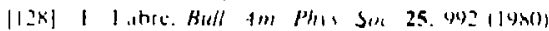

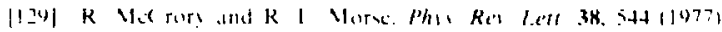

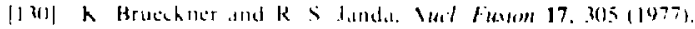

